\title{
Evaluating Private Equity performance using Stochastic Discount Factors*
}

\author{
OLEG GREDIL ${ }^{\dagger}$ \\ WILLIAM WALLER ${ }^{\S}$
}

March 15, 2019

\begin{abstract}
We examine the performance of 2,750 private equity (PE) funds incepted during 19792008 using Stochastic Discount Factors (SDFs) implied by the two leading consumptionbased asset pricing models (CBAPMs): Habit Formation and Long-run Risks. Our approach is motivated by the observation that investment mandates and cash flow patterns of university endowments and public pension funds are strongly consistent with the preferences of a representative investor per these models. Under CBAPM SDFs, venture capital funds did not destroy value in post-2000 vintages and has outperformed buyouts and generalists in the full sample, in contrast to the CAPM-based evidence. Also, we find that 2007-08 venture vintages are on track to provide a relatively good hedge for consumption shocks during and post crisis in comparison to buyout funds. Moreover, there is virtually no spike in PE excess returns in late 90s according to CBAPMs. Our contribution is also methodical: (i) we develop a finite sample bias correction method for the NPV-based inference which is highly relevant in PE-context whereby fund cash flows span a decade and yet the panel of funds is relatively short; (ii) we propose a more efficient estimation of SDF parameters that adopts the realized risk premia matching insight per Korteweg and Nagel (2016) while supporting a more general class of SDFs. Broadly, our methodology enables a construction and calibration of portfolio-specific discount factors for PE performance evaluation that may reflect nontradeable assets and liabilities which risks are not spanned by standard benchmarks.
\end{abstract}

Keywords: Private Equity, Venture Capital, Institutional Investors, Consumptionbased Asset Pricing, University endowments, Pension plans.

JEL-Classification: C11, G12, G14, G23, G24, G32, G34

*We are grateful to the Private Equity Research Consortium and the Institute for Private Capital for support and data access. We thank Arthur Korteweg, Lars Lochstoer, Ric Colacito, Seth Pruitt, 4th Southern California Private Equity Conference, 2018 IPC Spring Research Symposium, 2019 MFA Annual Meeting and Tulane Brownbag seminar participants for useful comments. All errors are our own.

${ }^{\dagger}$ Tulane University Freeman School of Business, ogredil@tulane.edu

${ }^{\ddagger}$ Copenhagen Business School, Columbia Business School, CEPR, and SIFR, mso.fi@cbs.dk

§Tulane University Freeman School of Business, ww@wrwaller.com 
Historically, pension funds and endowments have been the cornerstone investors in private equity (PE) funds, yet the common performance metrics used to evaluate these funds abstract away from the objectives of these investors. Beginning with Ljungqvist and Richardson (2003) and Cochrane (2005), a growing literature studies the risk and return characteristics of private capital investments within the context of the CAPM or similar public market-based factor models. 11 While these models are natural benchmarks, few, if any, endowment or pension funds specify maximizing the excess return over a public market benchmark as their policy objective. Rather, their stated mandates focus on hedging consumption (and/or production) risks for various beneficiaries. Furthermore, these beneficiaries effectively represent non-tradeable assets and liabilities which imply portfolio-specific discount factors that are not necessarily spanned by publicly traded assets (Gârleanu and Panageas, 2017), and Cejnek, Franz, and Stoughton (2015) argue that recursive preferences, such as those in Epstein and Zin (1989), are appropriate for modeling endowment funds where smooth expenditure policies are paramount due to high operating leverage and volatile donations. While these authors solve a portfolio choice problem, we apply similar time-inseparable preferences, and modern consumption-based asset pricing models (CBAPMs) more broadly, to evaluate the performance of a large sample of PE funds relatively to such non-tradeable discount factors.

Specifically, we follow Colacito and Croce (2011) and Ghosh, Julliard, and Taylor (2016) to estimate the time series of the stochastic discount factors (SDFs) implied by the Long-run Risk (LRR) model of Bansal and Yaron (2004) and by the External Habit (Habit) model of Campbell and Cochrane (1999) from a panel of macroeconomic and financial variables. We use these SDFs to evaluate the cash flows of PE funds incepted between 1979 and 2008 and compare the resulting NPVs with those obtained from the CAPM. The sample cash flows are net of all fees, extend through September 2016, and include 1,242 (1,142) [366] venture (buyout) [generalist] funds from the Burgiss database. The natural interpretation for an SDF is a ratio of marginal utilities of consumption across different scenarios (e.g., see Cochrane, 2009). As such, the SDF in CAPM is inversely proportional to the market return realization, whereas in a CBAPM, it is be decreasing in consumption growth.

Our key findings are depicted in Figure 1, which reports the NPV estimates per dollar invested by several vintage groups and fund types. Across the full sample, the abnormal performance is insignificantly different from zero cents on the dollar for venture funds, and negative 10 to 20 cents for other PE funds, according to the CBAPMs. This finding is in contrast to the negative abnormal returns for venture funds and large positive abnormal returns for other funds based on the unrestricted $C A P M$, which calibrates SDF to the risk

\footnotetext{
${ }^{1}$ See Kaplan and Sensoy (2015) for a survey, Sorensen and Jagannathan (2015) and Korteweg and Nagel (2016) or a CRRA-investor perspective.
} 
premia realized in public markets.

Overall, there is little "appreciation" to PE returns under CBAPM discount factors in the early to mid 90s because the stream of positive consumption shocks in late the 90 s means that the abundant distributions (by the 1992-96 venture funds, for example) occur in relatively low marginal utility states. In other words, even though these distributions exceeded the preceding contributions by a factor of 4 to 5 , they occurred when non-investment income stream was relatively high (much more so than an SDF implied by CAPM). CBAPMs suggest that the average buyout and generalist fund (i) delivered a 1-3 cent NPV through vintage year 2000 (instead of a positive $\$ 0.3-0.5$ relative to the CAPM discount factor), (ii) saw its best results in the 2001-05 vintages with gains similar to those implied by the CAPM, and (iii) had its worst result in the 2007-08 vintages incurring significantly larger losses than those suggested by the CAPM.

Unlike CAPM-adjusted returns, CBAPM-adjusted returns suggest that venture funds incepted after 2000, including the 2001-2005 vintages, on average did not destroy value for investors after accounting for the performance of public equities (i.e., the NPV in excess of that from investing in public market is, on average, positive). Moreover, 2007-08 venture vintages (unlike with other types of $\mathrm{PE}$ funds) have provided a relatively good hedge to the stream of negative consumption shocks that arrived in the aftermath of the recent financial crisis and are on track to achieve a NPV on the order of $\$ 0.20-0.90$ per dollar committed. However, it is 3-5 years early to reliably project the performance of 2007-08 funds against CBAPMs reliably as an average fund has over 80 cents per dollar of committed capital still invested as of the end of 2016. Should the CBAPM SDFs continue to drift lower as the macro conditions improve and venture funds distribute their NAVs shortly after, the performance evaluation may fall significantly. Figure 2 conveys this intuition by plotting aggregate cash flows and residual NAVs of venture funds against those of buyout for 2005-2006 vintages, which appear to be one of the worst according to CBAPMs, against those of 2007-08. It follows that the currently superior performance of 2007-2008 venture funds is largely due to the yet to be realized investments. The figure also demonstrates how significantly CBAPM SDFs can depart from that of CAPM. Finally, we find that all types of funds appear to underperform their size and style public benchmarks, according to CBAPMs. However, lower risk aversion may result in inference of positive NPV from venture fund investing in excess of similarly timed investments in small growth stocks.

While different inference on PE fund returs does not in and of itself validate our contribution, we do point to the rich literature, beginning with Mehra and Prescott (1985), of CBAPMs being used to price public assets. Moreover, we argue that CBAPMs may better convey the variation in the marginal utility (for investment returns) of pension plans and 
university endowments. To highlight this link between representative agents of consumptionbased model and pension funds or university endowments, we compare the temporal variation of the model-implied SDF series to the real growth in gifts to the endowments of US universities, as well as to the average contributions growth across public pension plans. In each of these cases, cash inflows correspond to $3-10 \%$ of the total assets. Thus, they strongly and directly relate to the marginal utility of returns obtained through investing. Figure 3 Panel B plots these series over the sample periods in which these data are available. We document a strong negative correlation between our proxy of investors' marginal utility, as measured by CBAPMs, and the growth rates in the external cash inflows to these portfolios. That is, in the case of university endowments, the SDF realizations tend to be low when universities receive relatively large gifts (that are either invested as a part of the total endowment or substitute for distributions from it), and vice-verse. For example, the correlation coefficients with the LRR-SDF is between -0.33 and, more recently, -0.57 for the endowment gifts and -0.41 for public pension funds. This finding has intuitive explanations since alumni and employee incomes plausibly depend on the aggregate state of the economy. In comparison, the correlation coefficients with the inverse of public equity market returns (and, hence, CAPM SDFs) are at most -0.1, suggesting only a weak hedge of non-investment inflows to those core PE investor portfolios..$^{2}$

We also examine the stated investment policies and performance reports of these institutions to assess whether the preferences of endowments and pension plans map closely to these of investors with risk-sensitive preferences and near infinite investment horizons in the LRR and Habit models. We find evidence of a close mapping. For example, Harvard University strives "to ensure that it has the financial resources to confidently maintain and expand its preeminence in teaching, learning and research for future generations." Stanford University manages its endowment with the primary objective "to provide a permanent source of financial support for the university." CalPERS Investment Beliefs state "ensuring the ability to pay promised benefits by maintaining an adequate funding status... consider[ing] the impact of its actions on future generations of members and taxpayers... [taking] advantage of factors that materialize slowly such as demographic trends." Yale university calculates constraints for its mean-variance analysis from a Monte Carlo simulation of the risks to the purchasing power of the endowment for up to 50 year horizon (Lerner and Leamon, 2011). In addition to supporting the preference for early resolution of uncertainty regarding the amount of funding available in the future, most documents explicitly acknowledge the limitations in forecasting

${ }^{2}$ This is lower in magnitude than the average 0.18 across endowments as documented in Gilbert and Hrdlicka (2015) because we do not normalize the gifts by the operating budget (since those may mechanically depend on the endowment valuation through the fixed distribution rules) and do not adjust timing to match the academic and calendar years ends. 
current economic and market trends. Meanwhile, Bidder and Dew-Becker (2016) show that in settings where investors are unsure about the dynamics of the economy, assets are priced as though long-run risks are present.

Broadly, our analysis contributes to the literature by shedding light on the performance of a comprehensive sample of PE funds through the lens of modern macro-finance models. Previous studies have considered the (conditional) CAPM for risk-adjusting PE returns (see, e.g., Korteweg and Sorensen, 2010; Franzoni, Nowak, and Phalippou, 2012; Robinson and Sensoy, 2013, Ang, Chen, Goetzmann, and Phalippou, 2017; Korteweg and Nagel, 2016) while prior empirical evidence on Habit and LRR models has been confined to publicly traded assets (see, e.g., Constantinides and Ghosh, 2011; Breeden, Litzenberger, and Jia, 2015). Our results also contribute to the discussion on what, why, and how institutional investors (should) invest in PE (see, e.g., Lerner, Schoar, and Wongsunwai, 2007; Lucas and Zeldes, 2009, Bernstein, Lerner, and Schoar, 2013; Ang, Papanikolaou, and Westerfield, 2014; Gilbert and Hrdlicka, 2015, Robinson and Sensoy, 2016).

Our contribution is also methodological. We show that cash flow NPV-based measures of performance for multi-period funds (i.e., PME and GPME) are biased relative to a perperiod abnormal return estimate because of the idiosyncratic return compounding. Therefore, adjusting for this bias is necessary for correct inference on PE fund performance and interpretation in context of the asset pricing model under consideration. Our simulations suggest that this bias (i) can be quite large - two to 25 percent, (ii) is largely of a finite sample nature (hence, especially strong when the funds under consideration span only a few vintages), but (iii) present even asymptotically under certain realistic conditions $\mathrm{3}^{3}$ Among these conditions are measurement errors and/or temporal dependencies which are endemic to the type of SDFs considered in this study. We develop two complementary bootstrap-based methods to correct for the compounding error bias and propose a more efficient GMM procedure to estimate the SDF parameters. Specifically, we use standard time series overidentified GMM on periodic quarterly returns of publicly traded benchmarks and account for differences in PE activity levels across time periods using the instrumented portfolio approach (e.g., see Cochrane, 2009). This adopts the realized risk premia matching insight of Korteweg and Nagel (2016) while avoiding some of its drawbacks which hinder the application of the GPME method in short samples or when the SDF is not a tradeable portfolio.

The paper proceeds as follows. Sections II and II present our data and methodology, respectively. Section III reports our main empirical results. Section IV concludes.

${ }^{3}$ While acknowledging that these conditions are consistent with the model misspecifications (see, e.g., Chernov, Lochstoer, and Lundeby, 2018), we emphasize that models' evaluation is outside the scope of our study while some non-tradeable assets can imply SDFs that violate these standard conditions. 


\section{Data}

\section{A. Private equity funds}

Our PE fund sample is from Burgiss and is comprised of cash flow information for 1,242 venture, 1,142 buyout, and 366 generalist funds incepted between 1979 and 2008. This sample is similar to the sample of Harris, Jenkinson, and Kaplan $(2014)$ and is representative of the universe of private capital funds available for institutional investors (see Brown, Harris, Jenkinson, Kaplan, and Robinson (2015) for a detailed comparison of the Burgiss sample with other commercially available private equity fund data) 4

The fund cash flows span from the third quarter of 1979 to the third quarter of 2016 and represent complete transaction histories between each fund and its investors. The contributions to the funds include management fees paid, while distributions to investors are net of performance and other applicable fees. Following the literature, we use the latest net asset value reported as the last distribution for funds yet unresolved. Although the transaction history is daily, we aggregate intra-quarter cash flows (by growing the them at risk-free rate) to match the frequency of the consumption-based SDF series. When real cash flows are needed, we deflate nominal fund cash flows using the U.S. CPI index.

Panel A of Table I reports the fund count and the summary statistics for the moneymultiple by vintage year. Money-multiple is computed as the sum of cash distributions paid to investors plus final net asset value (if non-zero) divided by the sum of contributions received from investors over the life of each fund. The table depicts the previously welldocumented heterogeneity in venture and buyout returns, both over time and across funds. The peaks in performance (unadjusted for risk) correspond to the mid 1990s vintages for venture funds and the late 1980s and early 2000s for buyout funds.

Figure 5 depicts the relative size of the private equity industry over the last 36 years per the Burgiss dataset. We plot the value of capital calls (scaled by fund size) invested in valueweighted CRSP index net of hypothetical distributions determined by the time since fund inception and the frequency of fund distributions as in Korteweg and Nagel (2016). This "pseudo-NAV" is computed for each fund-month. We then report averages across funds, buyout and venture, weighted by inflation-adjusted fund size. If normalized by the time series average, these pseudo-NAVs can be viewed as "importance weights" for private equity

\footnotetext{
${ }^{4}$ Following the classification scheme of the 2016 Burgiss Manager Universe dataset, we exclude funds that invest primarily in debt securities, 'Real Assets' (including Real Estate), as well as funds that are 'Not elsewhere classified' and 'Unknown' according to asset_class1-field. In addition to the funds classified as 'Generalist' as per asset_class1-field, we reclassify as generalists those funds that have the following asset_class1- and asset_class2-field values: 'Equity'-'Expansion Capital', 'Equity'-'Unknown', and 'Equity'-'Generalist'.
} 
activity. The solid line plots the underlying $\$$ values deflated by the CPI index, whereas the dashed line plots same series deflated by the market capitalization of the CRSP index.

\section{B. Other data}

Panel B of Table I reports descriptive statistics and pairwise correlations for other variables used in this study. Data on U.S. consumption of nondurables and services, gross domestic product, and population are from the National Income and Product Accounts of the Bureau of Economic Analysis. Consumption growth is real per capita personal consumption expenditures in non-durable goods. Where applicable, the data are adjusted for seasonality. Value- weighted market returns, yields on 3-month Treasury bills, dividends, and dividend yields for the United States are from the Center for Research in Security Prices. Consumer price index (CPI) inflation and the spread between BAA and AAA corporate bonds (our measure of the default premium) were obtained from the website of the Federal Reserve Bank of St. Louis. Section II.C.2 describes the construction of SDF series $(m)$.

$\triangle . U E d w$ is the real growth rate of gifts to US institutional endowment funds obtained from the Council for Financial Aid to Education. $\triangle . S P P$ is the growth rate of contributions to state pension plans, equally weighted by assets, obtained from the Center for Retirement Research at Boston College. We argue that periods of low $\triangle . U E d w(\triangle . S P P)$ proxies for times when utility for investment payouts are higher for the university endowments (pension plans) and vice verse. Panel $\mathrm{C}$ of Table $\mathrm{I}$ highlights recent trends in correlations between these proxy for marginal utility of core PE sponsors and the SDFs implied by CAPM and selected CBAPMs. Figure 3 provides are graphical representation thereof.

\section{Methodology}

We use a statistical GMM methodology to evaluate PE fund performance using SDFs. Our approach nests the the Generalized Public Market Equivalent methodology, introduced by Korteweg and Nagel (2016), by permitting non-tradeable SDFs, such as those implied by the Long-run Risk (LRR) model of Bansal and Yaron (2004) and the habit formation model of Campbell and Cochrane (1999), among others. We also argue that our method allows for greater efficiency in both the SDF parameters identification and the inference about PE abnormal returns regardless of the SDF type.

An asset pricing models can be expressed as an Euler restriction with respect to the asset returns whereby the model imply an SDF which conveys the variation in the agent's marginal utility per that model (e.g., see Cochrane, 2009). Hence, evaluation of an investment strategy 
returning $R_{t}$ involves two steps. In the first step, one estimates the SDF that in expectation prices a set of relevant benchmark assets $B$ as per the Euler equation:

$$
\mathbb{E}\left[z_{t}\left(R_{t+1}^{B} \cdot M_{t+1}\left(\theta_{B}\right)-1\right)\right]=0
$$

where $R_{t}^{B}$ is a vector of gross returns on the benchmark assets for period $t, M_{t}\left(\theta_{B}\right)$ is the series of SDF parametrized with $\theta=\theta_{B}$ that make equation (1) hold, while $z_{t}$ are the instruments implementing the investment strategy (Hansen and Richard, 1987; Cochrane, 2009). If the case under evaluation involves a constant allocation to the strategy (e.g., PE portfolio), then $z_{t}=1$ for all $t$. Either way, $z_{t}$ must be independent from the SDF pricing error:

$$
e_{t}^{B}(\theta):=R_{t}^{B} \cdot M_{t}(\theta)-1
$$

if parameters $\theta_{B}$ are estimated via GMM from the sample counterpart of equation (1). Therefore, $z_{t}$ need to be lagged relatively to the strategy return and the SDF realization to emphasize that the instrument construction does not involve information beyond period $t$ (i.e., when the pricing error $e_{t+1}^{B}(\theta)$ is realized).

\section{A. NPV-based inference bias}

Ideally, in the second step, we would like to perform the following test on the pricing errors implied by the strategy periodic returns:

$$
\begin{gathered}
e_{t}\left(\theta_{B}\right)=R_{t} M_{t}\left(\theta_{B}\right)-1 \\
\mathrm{H}_{0}: \mathbb{E}\left[z_{t-1} e_{t}\left(\theta_{B}\right)\right]=0 \quad \mathrm{H}_{\mathrm{A}}: \mathbb{E}\left[z_{t-1} e_{t}\left(\theta_{B}\right)\right] \neq 0
\end{gathered}
$$

However, since the per period returns for PE funds cannot be observed reliably, it is natural to replace test (3) with a similar test based on the Net Present Value of PE fund cash flows:

$$
\begin{gathered}
N P V_{i}\left(\theta_{B}\right)=\sum_{t=s(i)}^{T(i)} C_{i t} \cdot \prod_{\tau=s(i)}^{t} M_{\tau}\left(\theta_{B}\right), \\
\mathrm{H}_{0}: \mathbb{E}\left[N P V_{i}\left(\theta^{B}\right)\right]=0 \quad \mathrm{H}_{\mathrm{A}}: \mathbb{E}\left[N P V_{i}\left(\theta^{B}\right)\right] \neq 0,
\end{gathered}
$$

where $C_{i t}$, is period $t$ cash flow realized by fund $i \in I$, the sample, during the time it was operating-between periods $s(i)$ and $T(i)$. If in period $t$ the fund made more [less] capital calls than distributions, then $C_{i t}<[>] 0$. Similarly if the fund made no capital calls or distributions, then $C_{i t}=0$.

The premise for equivalence between the two tests is the existence of a mapping between 
the sequence of fund per-period returns and its cash flows. Denote this mapping with $\delta_{i t} \in\left[-\underline{C}_{i t}, 1\right]$, such that:

$$
C_{i t}=-C_{i 0} \cdot \delta_{i t} \cdot \prod_{\tau=s(i)}^{T(i)-1} R_{i \tau} \cdot\left(1-\delta_{i \tau}\right)
$$

where $\underline{C}_{i t}$ is fund $i$ 's uncalled capital as of period $t$ while the first cash flow for every fund is a capital call (i.e., $\left.C_{i 0}<0\right)$.

While the two tests may indeed be equivalent in expectation, for any feasible finite sample of PE fund alike cash flows test (4) will be biased relative to (3) - see PROPOSITION 1 in Appendix.A.1 ${ }^{5}$

$$
\overline{N P V_{i}}\left(\theta_{B}\right) \approx \overline{e_{t}}\left(\theta_{B}\right) \cdot \text { FundDuration }+ \text { CompoundingError }
$$

Besides the fund duration effect, which is linear in test's (3) statistic and, therefore, inconsequential, the inference based on NPV estimate is confounded by compounding error that is very slow to converge even if in expectation the compounding error is zero and $e_{t}$ 's are iid. Our simulations suggest that for 44-quarter funds making uniform distributions from their 20th quarter, the compounding error bias remains meaningful even with a few hundred fund-vintages, regardless of how many funds are there in each vintage (i.e., compounding error reduces in $T$ but not $I$ ).

While compounding of returns matters for portfolio choice (e.g., see Hakansson, 1971), we argue that a direct interpretation of asset pricing models warrants purging the compounding error effects - i.e. 3 being the first-best test. One can think about the compounding error as a source of bias in the feasible test statistic, per (4). In simulations reported in Appendix.A.1. the magnitude of this bias (i) varies from 3 to $25 \%$ depending on the SDF type and PE fund data generating process and (ii) increases rapidly as the span of vintage years in the fund sample contracts. Importantly, both the sign and the magnitude of the compounding error depend on the true level of abnormal returns.

\footnotetext{
${ }^{5}$ Note that by definition, $e_{t}$ is driven by (i) shocks in the SDF and (ii) the asset idiosyncratic return component (i.e. unspanned by SDF). From 1 it also follows that if either (i) or (ii) exhibit autocorrelation, the expectation of the compounding effects is non-zero. This appears a highly relevant consideration, given that Ang, Chen, Goetzmann, and Phalippou (2017) find autocorrelation in PE return residuals with respect to standard factor models, while most SDFs implied by macro-economic models exhibit autocorrelation (e.g., both LRR and Habit models). While autocorrelation in pricing errors can be regarded as evidence of SDF misspecification, as discussed in Chernov, Lochstoer, and Lundeby (2018) since Euler restriction has to hold at any horizon by the Law of Iterative Expectations, the evaluation of the performance of asset pricing models per se is outside the scope of our study.
} 


\section{B. Compounding error bias correction}

There are several ways to correct the compounding error bias. One way is to estimate $M(\theta)_{t}$ at the frequency corresponding to the duration of the sample PE funds. Korteweg and Nagel (2016) implement this approach by constructing hypothetical cash flows for each fund $i$ (pseudo funds) obtained as though the fund invested in a benchmark asset, rather than in private equity, and returned capital in the same periods as the actual funds. Per Korteweg and Nagel (2016), the first step is (implicitly):

$$
\mathbb{E}\left[N P V_{i}^{B}\left(\theta_{C B}\right)\right]=0
$$

where $N P V\left(\theta_{C B}\right)_{i}^{B}$ is the vector of fund $i$ NPVs derived from investing in benchmark assets, $b=1, \ldots, B$ :

$$
N P V_{i}^{b}\left(\theta_{C B}\right)=\sum_{t=s(i)}^{T(i)} C_{i t}^{b} \prod_{\tau=s(i)}^{t} M_{\tau}\left(\theta_{C B}\right)
$$

and $C_{i t}^{b}$ are obtained from utilizing equation (5) and assuming a particular mapping function $\tilde{\delta}_{i t}$ in place of the unobserved $\delta_{i t}$.

Intuitively, one can think of Korteweg and Nagel (2016) as jointly estimating the SDF parameters, $\theta$, and correcting for the compounding error in the NPV estimate. The NPV bias correction is embedded in $\theta_{C B}$ making the interpretation of these parameters difficult. ${ }^{6}$ Put differently, $\theta_{C B}$ attempts to fit the compounding error of the pseudo fund NPVs. Importantly, the GPME methodology requires that there exists such a $\theta_{C B}$ for which the benchmark NPVs are zero for the just-identified case. This might not be feasible for some SDFs while also resulting in a tendency to produce implausible parameters from the GMM estimation.7

\section{B.1. Excess NPV}

Because the compounding error in the NPV estimate is present in pseudo funds as well, $N P V^{b}\left(\theta^{B}\right)$ is informative about the relative size of the compounding error in $N P V\left(\theta^{B}\right)$ if the benchmark asset is a reasonable proxy for the private equity returns. The presence of the compounding error implies that the finite sample estimate of $\mathbb{E}\left[N P V_{i}\left(\theta^{B}\right)\right]$ is shifted away from the true values just as the estimates of $\mathbb{E}\left[N P V_{i}^{b}\left(\theta^{B}\right)\right]$ so long as their pricing errors

\footnotetext{
${ }^{6}$ For instance, $\theta_{C B}$ does not generally satisfy the Euler equation with high-frequency periodic returns given by equation 1 despite these high frequency returns being the basis for constructing the pseudo funds. Nor will it price to zero pseudo funds constructed with a slightly different mapping function $\delta_{i t}$.

7 For example, large and positive compounding error bias in the pseudo portfolio requires large and negative drift in the SDF to satisfy equation 7 which pushes the present values of all cash flows to near zero leaving little power to reject $\mathrm{H}_{\mathrm{A}}$.
} 
for a given SDF exibit strong positive correlation. Therefore, another way to mitigate the compounding error bias in PE NPV estimates is to subtract the estimates of $\mathbb{E}\left[N P V_{i}^{b}\left(\theta^{B}\right)\right]$ from those of $\mathbb{E}\left[N P V_{i}\left(\theta^{B}\right)\right]$ since both have the same direction of the bias arising due to the SDF history and common component in the returns $R_{i t}$ and $R_{i t}^{b}$ :

$$
\begin{gathered}
\Delta \cdot N P V_{i}(\theta)=N P V_{i}(\theta)-N P V_{i}^{b}(\theta), \\
\mathrm{H}_{0}: \mathbb{E}\left[\Delta \cdot N P V_{i}(\theta)\right]=0 \quad \mathrm{H}_{\mathrm{A}}: \mathbb{E}\left[\Delta \cdot N P V_{i}(\theta)\right] \neq 0 .
\end{gathered}
$$

Comparing this approach to the GPME of Korteweg and Nagel (2016), excess NPV does not require the existence of $\theta^{C B}$ that satisfies equation (7) while allowing for more efficient estimates of SDF parameters using standard time series GMM - see PROPOSITION 2 in Appendix.A.1. It also does not require that the set of benchmarks used to identify SDF parameters be the same as those used to determine the bias correction with the regards to the PE returns path. In fact, we argue that the set of benchmarks used to identify $\theta$ and the set of benchmarks used to correct for compounding error should be different (see Proposition (3) in Appendix.A.1). This leads to the excess NPV being more efficient estimate of PE funds NPV than GPME.

\section{B.2. Bootstrap}

Given that compounding error arises from a particular sequence of pricing errors, resampling the pricing errors offers a natural solution to gauge the effect of drawing a particular sequence of per-period pricing errors (defined by equation 2). Intuitively, randomizing the sequence of pricing errors allows us a baseline from which to construct a sample estimate of the compounding error. This estimate provides not only a correction for finite sample bias but also addresses the potential for an asymptotic bias arising from the auto-correlation in the pricing errors (see PROPOSITION 1).

In fact given that both tests (3) and (4), can be viewed as J-statistics for the overidentifying GMM restriction, a bootstrap is particularly attractive since it is known to improve the finite sample performance of those type of tests (e.g., see Hall and Horowitz, 1996). Unfortunately, we cannot observe the per period pricing error for PE funds, $e_{t}(\theta)$. This issue prevents us from implementing the first-best test 3 and makes a bootstrap sampling these per period pricing errors infeasible. Prior literature finds that PE fund reports of periodic returns are subject to appraisal bias (e.g., see Ewens, Jones, and Rhodes-Kropf, 2013; Goetzmann, Gourier, and Phalippou, 2018, among others). Nevertheless, we argue and provide simulation-based evidence that bootstrapping feasible estimates of PE fund $e_{t}(\theta)$ corrects the compounding error bias present in our problem. 
Specifically, given a subset of sample funds for which the NPV inference is conducted, we construct a high-frequency proxy, $\tilde{r}_{t}$, of the unobserved PE fund returns, where $\tilde{r}_{t}$ is the residual from an $\operatorname{ARMA}(p, q)$ model of average quarterly returns of PE funds based on reported NAVs. Utilizing expression (5), we construct pseudo PE funds from $\tilde{r}_{t}$, as Korteweg and Nagel (2016) to construct pseudo funds investing in benchmark assets. Denote the sample average NPV estimate across these pseudo PE funds for an estimate of $\theta$ as $N \hat{P} V^{*}(\theta)$. Our bootstrap procedure re-samples $\hat{e}_{t}=\tilde{r}_{t}-r_{b, t}$, the per period pricing errors of PE fund returns relative to a priced benchmark, to construct a bootstrap sample, $\left\{\tilde{r}_{t}^{k}\right\} .8$ Given $\left\{\tilde{r}_{t}^{k}\right\}$, we form a new estimate of the sample average of the pseudo funds $\operatorname{NPV}, N \hat{P} V^{k}(\theta)$. Our sample estimate of the compounding error is then $N \hat{P} V^{*}(\theta)-N \bar{P} V^{k}(\theta)$ where $N \bar{P} V^{k}(\theta)=$ $\frac{1}{K} \sum_{k=1}^{K} N \hat{P} V^{k}(\theta)$. Therefore, our bias-corrected estimate of PE fund NPV is given by:

$$
N P V_{B C}(\theta)=N P V(\theta)-\left(N \hat{P} V^{*}(\theta)-N \bar{P} V^{k}(\theta)\right) \cdot \frac{D u r}{D u r^{*}},
$$

where the last term adjusts for any duration mismatch between the actual PE funds and the pseudo PE funds constructed using $\tilde{r}_{t}$.

\section{Implementation}

Given the discussion below, we utilize the sample equivalent of the Euler equation (1) for the set of benchmark assets $b=1, \ldots, P \in B$ for which we observe non-overlaping quarterly returns $R_{t}^{1}, \ldots, R_{t}^{P}$ :

$$
g^{R}\left(\theta ; z_{t}\right)=\left[\begin{array}{c}
\sum_{t=1}^{T} z_{t-1}^{1} \cdot\left(R_{t}^{1} M_{t}(\theta)-1\right) \\
\vdots \\
\sum_{t=1}^{T} z_{t-1}^{P} \cdot\left(R_{t}^{P} M_{t}(\theta)-1\right)
\end{array}\right],
$$

We obtain $\theta$ estimates using the standard GMM estimator:

$$
\theta^{*}=\underset{\theta}{\arg \min } g^{R}\left(\theta ; z_{t}\right)^{\prime} W g^{R}\left(\theta ; z_{t}\right)
$$

where $W$ is a suitable weighting matrix, and $z:=\left(z^{1}, \ldots, z^{P}\right)$ is the set of instruments implementing the PE strategy. The system is just identified when the number of moments, $P$, equals the length of parameters vector $\theta$. When $P$ exceeds it, the system is overidentified, allowing for greater estimation efficiency and for testing whether $M(\theta)$ is an appropriate pricing kernel- given the instruments, $z$, and the returns of the benchmark portfolios, $R^{B}$.

Our instruments, $z_{t}$ are pseudo fund NAVs aggregated across the full sample of PE funds

\footnotetext{
${ }^{8} r_{b, t}$ can be either return on SDF itself or a benchmark asset which returns are observed at high frequency.
} 
scaled by the public market capitalization as discussed in section I.A and plotted in Figure 5. This implements the intuition embedded in Korteweg and Nagel (2016) GPME estimation that the size of PE portfolios is a natural way to asses the importance weight for each period. Moreover, these instruments condition on the past benchmark returns, in spirit of Chernov, Lochstoer, and Lundeby (2018), enabling a more robust parameter identification.

The mapping function between pseudo fund returns and cash flows, $\tilde{\delta}_{i t}$ is defined as follows:

$$
\delta_{i t}= \begin{cases}C_{i, t} & \text { if } C_{i, t}<0 \\ \min \left(\frac{t-p_{i}}{T_{i}^{\prime}-p_{i}}, 1\right) & \text { if } C_{i, t}>0 \\ 1 & \text { if } t=T \\ 0 & \text { otherwise }\end{cases}
$$

which is a simplified version of the mapping used in Korteweg and Nagel (2016) as discussed in Appendix.A.2.

Next, given $\theta^{*}$, we evaluate NPV for PE funds and the pseudo funds of interest using equations (4) - (8) to derive excess NPV metric as described in section II.B.1 and apply bootstrap procedure to PE NPV values as described in section II.B.2. We choose to report results using both bias correction methods because our simulations suggest that in some cases excess NPV performs better than the feasible bootstrap.

\section{C.1. Tradeable SDFs}

Standard factor models have been used to risk-adjust the returns of private equity funds (e.g. see Korteweg and Sorensen, 2010, Franzoni, Nowak, and Phalippou, 2012; Ang, Chen, Goetzmann, and Phalippou, 2017, among others). These models imply an SDF that is a portfolio of publicly traded assets with returns that are perfectly observable (i.e. without any measurement error) and at any frequency, e.g.:

$$
M_{t}(\theta)=\exp \left\{\left(1 \quad r_{t}^{\tilde{B}}\right) \theta\right\}
$$

where $r_{t}^{\tilde{B}}$ is a vector log returns of selected benchmarks, typically a subset of $B$.

To obtain the GPME estimator of Korteweg and Nagel (2016), the estimator given by $11-12$ is just-identified-i.e., set of benchmarks $B$ is the same as $\tilde{B}$ augmented with risk free rate-and uses instrument which are the products of (i) pseudo fund NAVs investing in the respective benchmark, (ii) the history of SDF lagged by one period, and (iii) the return-to-'cash flow' mapping, $\tilde{\delta_{i t}}$, aggregated across funds active in period $t$ - see PROPOSITION 2. In this CAPM implementation, $M_{t}=\exp \left\{a-\gamma r_{t}^{m}\right\}$ and $R_{t}^{B}=\exp \left\{\left(r f_{t} r_{t}^{m}\right)\right\}$ 
where $r f_{t}$ and $r_{t}^{m}$ are the log returns on risk free asset and the market portfolio respectively.

This SDF generalizes the log-utility CAPM of Rubinstein (1976) that Kaplan and Schoar (2005) PME implements as shown in Sorensen and Jagannathan (2015). In PME, the SDF is the inverse of gross market returns. Thus, the moment condition- $g^{R}(\theta)=\sum_{t=1}^{T} z_{t-1}$. $\left(\exp \left\{r_{t}^{m}\right\} \cdot \exp \left\{-\gamma \cdot r_{t}^{m}\right\}-1\right)$-yields zero pricing error for every $t$ for $\gamma=1$, so the choice of instrument, $z_{t}$, is irrelevant.$^{9}$ Nonetheless, it is important to note that PME is also subject to the compounding error bias [i.e., NPV is not simply equal to the fund duration-scaled CAPM $\alpha$ ] as discussed in the beginning of this section and shown in PROPOSITION 1 . The magnitude of this bias increases in the level of idiosyncratic volatility in fund returns, tends to exceed several percentage points for a sample spanning over 20 vintages and can be on the order of 5 to $10 \%$ by individual vintage year.

\section{C.2. Non-tradeable SDFs}

For a large class of asset pricing models, the SDF is not a traded portfolio of assets but reflects variation in macro variables that are almost surely measured with error. In this study, we consider several well established CBAPMs. However in principle, our method can be used to construct customized SDFs reflecting the subjective utility of certain types of investors. ${ }^{10}$ Naturally due to the higher variance and intertemporal dependencies in the pricing errors with these SDFs, the compounding bias tends to be an order of magnitude larger than in the case of tradeable SDFs.

\section{C.2.1 The Long-run Risk model}

The long-run risk model of Bansal and Yaron (2004) couples a small, but persistent, shock in the conditional expectation of consumption growth with the non-time separable utility in the form of Epstein-Zin preferences to form an SDF more volatile than the observed consumption growth. Specifically, consumption growth is modeled as

$$
\begin{aligned}
\Delta c_{t+1} & =\mu+x_{t}+\sigma \eta_{t+1} \\
x_{t+1} & =\rho x_{t}+\psi_{e} \sigma e_{t+1},
\end{aligned}
$$

where $e_{t+1}, \eta_{t+1}$ are independent mean-zero shocks with unit unit variance, $\Delta c_{t}$ is real $\log$ growth in consumption, and $x_{t}$ is the persistent long-run risk factor. In this model, the $\log$

\footnotetext{
${ }^{9}$ As shown in Korteweg and Nagel (2016), the advantage of having an analytical solution for SDF comes at a cost of restricting risk premia to equal to the variance of the market return. Insofar this assumption does not hold empirically, PME credits excess risk premia realized on the market towards PE fund performance.

${ }^{10}$ For example, the manager of a university endowment could replace the aggregate consumption shocks series with those reflecting the innovation in alumni gifts and capital project liabilities.
} 
$\mathrm{SDF}$ is equal to

$$
\begin{aligned}
m_{t+1} & =\bar{m}-\frac{1}{\psi} x_{t}-\gamma \sigma \eta_{t+1}-\frac{\gamma-\frac{1}{\psi}}{1-\rho \kappa_{c}} \kappa_{c} \psi \psi_{e} \sigma e_{t+1} \\
& =\mathbb{E}_{t}\left[m_{t+1}\right]-\gamma \sigma \eta_{t+1}-\frac{\gamma-\frac{1}{\psi}}{1-\rho \kappa_{c}} \kappa_{c} \psi \sigma \sigma e_{t+1},
\end{aligned}
$$

where $\bar{m}$ is the unconditional mean of the $\log \mathrm{SDF}, \psi$ is the intertemporal elasticity of substitution, $\gamma$ is the coefficient of relative risk aversion, $\kappa_{c}$ is the coefficient in the Campbell and Shiller (1988) approximation given by Equation 2 of Bansal and Yaron (2004).

We follow Colacito and Croce (2011) to obtain the estimates of the latent Long-run Risk process $x_{t}$, the $\psi_{e} \sigma e_{t+1}$-innovations to it $\left(\equiv \epsilon_{x, t}^{L}\right.$, as well the to consumption growth innovations, $\sigma \eta_{t+1} \equiv \epsilon_{c, t}^{L}$. Correspondingly, $\hat{x}_{t}$ is the projection of quarterly growth in consumption (i.e., $c_{t}$ ) on the one past growth in consumption, the consumption to output ratio, pricedividend ratio, risk free rate, and default spread during 1951-2016.11 Whereas $\epsilon_{x, t}^{L}$ is the residual of an AR1-model estimated on $\hat{x}_{t}$-series and $\epsilon_{c, t}^{L}$ is obtained as $c_{t}-\hat{x}_{t-1}$.

We then use Equation (16) above and the model parameters from the calibration of Bansal and Yaron (2004) $\left(\gamma=10, \psi=1.5, \rho=0.979^{3}\right)$ to construct the "off-the-shelf" LRR SDF series used in Table I and Figure 3. This SDF series also allows us to obtain the NPV estimates for selected benchmark assets in Table AIV. For the main analysis, we proxy $\mathbb{E}_{t}\left[m_{t+1}\right] \equiv \bar{m}-\frac{1}{\psi} x_{t}$, the conditional mean of the SDF, with $a+r f_{t}$, where $r f_{t}$ is the ex-ante risk-free rate as in Beeler, Campbell, et al. (2012). We then estimate $(a, \gamma)$ as described in the previous subsections.

\section{C.2.2 External Habit model}

The external habit model of Campbell and Cochrane (1999) relies on the multiplicative effect of a surplus consumption ratio, $S_{t}$, to lever consumption volatility. Specifically, let

$$
\begin{aligned}
\Delta c_{t+1} & =g+u_{t+1} \\
s_{t+1} & =(1-\phi) \bar{s}+\phi s_{t}+\lambda\left(s_{t}\right) u_{t+1}
\end{aligned}
$$

where $\Delta c_{t}$ is real log growth in consumption, subject to temporarily independent socks $u_{t} ; s_{t}$ is the $\log$ surplus consumption ratio; $\lambda\left(s_{t}\right)=\frac{1}{\bar{S}} \sqrt{1-2\left(s_{t}-\bar{s}\right)}-1$ when $s \leq s_{\max }$, 0 elsewhere, $\bar{S}=\sigma \sqrt{\frac{\gamma}{1-\phi-b / \gamma}}$ is the steady-state surplus-consumption ratio, and $s_{\max }=\bar{s}+\frac{1-\bar{S}^{2}}{2}$ is the

\footnotetext{
${ }^{11}$ All variables are in logs and adjusted for inflation, all explanatory variables are lagged by one quarter, also see section I.B
} 
upper bound of the log surplus-consumption ratio. In this model, the log SDF is equal to

$$
\begin{aligned}
m_{t+1} & =\bar{m}-\gamma(\phi-1) s_{t}-\gamma\left(1+\lambda\left(s_{t}\right)\right) u_{t+1} \\
& =\mathbb{E}_{t}\left[m_{t+1}\right]-\gamma\left(1+\lambda\left(s_{t}\right)\right) u_{t+1},
\end{aligned}
$$

where $\bar{m}$ is the unconditional mean of the $\log \mathrm{SDF}$ and $\gamma$ is the coefficient of relative risk aversion. Following Ghosh, Julliard, and Taylor (2016), we define $u_{t+1}$ as the deviation in $\log$ consumption growth from its sample mean and $\sigma$ as the sample standard deviation of $\log$ consumption growth. For notational convenience, we define $\epsilon_{c, t}^{H} \equiv u_{t}$ and $\epsilon_{s, t}^{H}=u_{t} \lambda\left(s_{t}\right)$.

Again, we take the "canonical" parameter values from the literature (Wachter (2005): $b=0.011, \phi=\sqrt[4]{0.894}, \gamma=2$ ) to construct the "off-the-shelf" SDF series for Tables I, AIV and Figure 3 which motivate our analysis. As with Long-run Risk case above, we replace the conditional expectation of SDF, $\mathbb{E}_{t}\left[m_{t+1}\right] \equiv \bar{m}-\gamma \phi$, with $a+r f_{t}$ and estimate $(a, \gamma)$ as described in the previous subsections.

\section{C.3. Inference}

For our estimate of $\theta$, the asymptotic covariance matrix is

$$
\operatorname{var}\left(\theta^{*}\right)=\frac{1}{T}\left(G^{\prime} W G\right)^{-1} G^{\prime} W S^{\prime} W G\left(G W G^{\prime}\right)^{-1}
$$

where $G=\partial g^{R} / \partial \theta$ is the gradient of the moment conditions and $S$ is an estimate of the covariance matrix of the moment conditions. For the moment conditions, the sandwich estimator of the covariance matrix is

$$
\operatorname{var}\left(g\left(\theta^{*}\right)\right)=\frac{1}{T}\left(I-G\left(G^{\prime} W G\right)^{-1} G^{\prime} W\right) S\left(I-G\left(G^{\prime} W G\right)^{-1} G^{\prime} W\right)^{\prime} .
$$

We can measure the performance of our choice of SDF in pricing public market returns using a $J$ statistic when the dimension of $g^{R}$ exceeds the dimension of $\theta$ and we use a $W$ such that $\theta$ is identified solely by $g^{R}$. In this case, the $J$ statistic is

$$
J=g^{R}\left(\theta^{*}\right)^{\prime} \operatorname{var}\left(g^{R}\left(\theta^{*}\right)\right)^{-1} g^{R}\left(\theta^{*}\right)
$$

To perform inference PE fund NPVs (and the bias-corrected versions of PE fund NPVs), we rely on a semiparametric bootstrap procedure that takes advantage of the fact that PE cash flows, and hence, NPV estimates do not affect estimates of the SDF parameters. Specifically, for each bootstrap sample, we draw $\theta^{k}$ from the asymptotic distribution of $\theta^{*}$. We can then obtain a bootstrap estimate of the PE fund NPVs, $N P V^{*}\left(\theta^{k}\right)$. Correspondingly, 
the bootstrap estimate of the standard error is the standard deviation of the $K$ bootstrap replications $N P V^{*}\left(\theta^{k}\right)$. Our simulations suggest that, as a nonlinear function of $\theta$, the NPV estimate tends to have leptokurtotic sampling distribution, and as such, we use the percentile method to identify the critical values for the hypothesis test. Specifically, we find the upper $\alpha / 2$ and lower $\alpha / 2$ quantiles of the bootstrap estimates and reject $H_{0}$ if the bootstrap-adjusted NPV estimate falls outside this region.

\section{Results}

In this section, we implement the NPV analysis of PE fund cash flows using the SDFs implied by the Long-run Risk and Habit models. We argue that the latter are plausible approximations of preferences of core PE investors, such as pension plans and university endowments. We examine the time-series variation in those NPVs across different vintage years and compare with the inference based on CAPM. We begin with estimating SDF parameters as described in section II.C to minimize the pricing errors on the relevant publicly traded benchmarks during the times PE portfolios were relatively large (Figure 5).

\section{A. SDF Parameters}

Our estimand $(\theta)$ comprises of two parameters, the drift $(a)$ and the coefficient of risk aversion $(\gamma)$. We estimate them for three exponentially affine SDFs: (i) implied by CAPM as in Korteweg and Nagel (2016), (ii) - by the Long-run Risk model of Bansal and Yaron (2004), and (iii) - by the Habit formation model of Campbell and Cochrane (1999):12

$$
\log \left(M(\hat{\theta})_{t}\right)= \begin{cases}\hat{a}-\hat{\gamma} \cdot r_{m, t} & \text { (i) }- \text { CAMP } \\ \hat{a}-r_{f, t}-\hat{\gamma} \cdot \epsilon_{c, t}^{L}-\left(\hat{\gamma}-\frac{1}{\psi}\right) \frac{\kappa}{1-\kappa \rho} \cdot \epsilon_{x, t}^{L} & \text { (ii) }- \text { LRR } \\ \hat{a}-r_{f, t}-\hat{\gamma} \cdot\left(\epsilon_{c, t}^{H}+\epsilon_{s, t}^{H}\right) & \text { (iii) }- \text { Habit }\end{cases}
$$

via time series GMM with the identity weighting matrix and the pricing errors, as discussed in section II.C. Consistent with the previously introduced notation, $r_{m, t}$ - is the market $\log$ return adjusted for inflation; $r_{f, t}$ - the ex ante real risk free rate; $\left(\epsilon_{c, t}^{L}, \epsilon_{x, t}^{L}\right)$ - the consumption and the long-run risk innovations; and $\left(\epsilon_{c, t}^{H}, \epsilon_{x, t}^{H}\right)$ - the consumption- and habit innovations (see section II.C.2). Table II reports the parameter estimates, the J-statistic with associated p-value, and (last eight lines) the average pricing errors for each of eight assets (henceforth, test assets): risk free rate, broad market, and six Fama-French size and style portfolios.

\footnotetext{
${ }^{12}$ In unreported results, we also consider augmenting CAPM SDF with risk free rate: $\hat{a}-r_{f, t}-\hat{\gamma} \cdot r_{r m, t}$. The results are similar to (i) and available upon request.
} 
Unlike in Table AIV, all return series are adjusted for inflation.

Specifications (1), (4), and (7) report the just-identified estimations as in Korteweg and Nagel (2016) where $R_{t}^{B}$ include just the realized risk free rate and the market return for the quarter. Thus, the respective pricing errors for the risk free rate and the market returns are zero. However, we can see that for other assets the pricing errors are quite notable. In particular, for small growth and small value portfolios which can be viewed a proxy of venture and buyout funds (Ang, Chen, Goetzmann, and Phalippou, 2017), the average quarterly pricing errors (weighted by $w_{t-1}^{B}$ ) with CAPM's SDF are minus 24 and 58 basis points respectively. Thus, assuming the holding period of five years, a VC fund that returned exactly small growth (after all fees) would be viewed to have delivered a negative NPV of approximately $5\left(=24.22 / 10,000^{*} 20\right)$ cents one the dollar of capital committed. Whereas a buyout fund delivering exactly the returns of small value portfolio would appear to have a positive NPV of approximately 12 cents $\left(=58.46 / 10,000^{*} 20\right)$ under the same assumptions. If one relied on the LRR SDF from specification (7) instead, the small growth (value) stocks would appear more (less) unattractive than with the CAPM SDF, yet the corresponding fund life-time NPV estimates would remain positive of about 3 to 4 cents on the dollar.

In specifications (2), (5), and (8), we over-identify the GMM estimation by adding returns of the small growth and the small value portfolios to $R_{t}^{B}$. Thus, we now can conduct Hansen's J-test from which it follows that none of the SDFs can be rejected as a plausible pricing kernel for $R_{t}^{B}$ (conditional on the period weights). The J-test statistics are notably lower for the two consumption-based asset pricing models we consider which resonates with their empirical success documented in the literature.13 Now part of the objective function, the pricing errors for small growth and value tend to get meaningfully closer to zero although at a cost of not perfectly-priced risk free rate and market portfolios. Specifically, for the LRR model (specification 5), the pricing errors for the small growth portfolio decrease from 13.6 to 2.3 basis points per quarter and from over 20 to under 7 basis points for the small value portfolio. However, for the market portfolio, the average pricing error is now negative 11 basis points per quarter.

We include six Fama-French portfolios in specifications (3), (6), and (9) so that $R^{B}$ contains all eight test assets. While some of the largest average pricing errors do decrease relatively to the four-asset $R^{B}$, p-values on J-statistics fall for all three SDFs indicating a deterioration in the model overall performance. For instance, the CAPM SDF (specification 3) can now be rejected at $5 \%$ confidence level.

We note that our parameter estimates are close to these in the literature Colacito and Croce, 2011; Wachter, 2005) and, by construction, minimize the aggregate mispricing (which

\footnotetext{
${ }^{13}$ For example, see Breeden, Litzenberger, and Jia (2015).
} 
is at least partially due to the sampling errors) of the relevant benchmark assets during the period of PE performance evaluation (weighted by the relative size of PE investments). Based on results in Table $\mathrm{II}$ and the simulatation-based evidence reported in Appendix.A.2, for the reminder of the paper we focus on the SDFs parameter calibrations with four tests assets (i.e. specifications 2, 4, and 6).

\section{B. PE fund NPVs}

Tables III, IV, and Vreport results separately for venture funds, buyout funds, and funds that Burgiss classifies as 'generalist' and/or 'expansion capital' since these funds pursue investments that exhibit characteristics of both venture and buyout transactions. The number of funds in the group denoted by the row's title (a vintage year or a cohort thereof) is reported in column (1). In each table, panel A reports analysis assuming equally weighted cash flow (normalized by fund size) of all funds in the respective group so that the values from columns (2) through (12) can be interpreted as the expected NPV cents per dollar from investing in an average fund from that group. Whereas panel B restricts the sample to substantially resolved funds as of the sample end (September 2016) which we define as those with cumulative inflation-adjusted distributions of at least three times the latest residual NAV reported.

The estimates in columns (2) through (12) significant at 5\%(10\%) confidence level are superscripted with $a(b)$. We use asymptotic standard errors of Korteweg and Nagel (2016) in columns (2) and (3) and p-values based on empirical distributions of the bootstrap samples as discussed in Appendix.

Columns (2) reports GPMEs of Korteweg and Nagel (2016) for the log-utility CAPM case which corresponds to the assumption in Kaplan-Schoar PME: the discount factor is $\exp \left\{a-b \cdot r_{m, t}\right\}$ with $(a, b)$ set to $(0,1){ }^{14}$ Column (3) reports GPMEs for the general case (referred to as ' $\mathrm{KN}$ ') considered in Korteweg and Nagel (2016) with $(a, b)$ estimated to set the NPVs of public benchmarks' (hypothetical) cash flows to zero. However, for most vintage groups the corresponding parameters cannot be identified due to too short a span and excess overlap in the fund cash flow schedules. Therefore, for the purpose of estimating $(a, b)$, we pool funds (of the respective type) into pre-1999 vintage cohort and 1999-onwards. Hence, the NPV of benchmark cash flows is not guaranteed to be zero except for row 'All'.

Conceptually closest to KN-GPME reported in column (3) is NPV.CAPM in column (4). The difference amounts to the time-period weights implied in the estimation of $(a, b)$

\footnotetext{
${ }^{14}$ In this case, the difference from the traditional Kaplan-Schoar PME formulation in this amounts to GPME being a difference of present values of cumulative distributions and cumulative contributions (rather than a ratio thereof).
} 
and the set of public benchmarks used to calibrate the discount factor. As discussed in sections II.C, the estimates in column (4) reflect the size of the sample funds invested capital relatively to public equities capitalization as depicted in Figure 5 and the GMM estimation per specification (2) of Table II 15

It is important to note that the fund cash flow NPV estimates in column (4) do not imply that similarly timed investments in public markets yield zero NPV. The question about the PE fund performance relatively to a particular public benchmark is best answered by computing the excess $N P V$ of fund cash flow (over the similarly timed hypothetical cash flow from investing in the benchmarks of interest). The results of the excess NPV analysis with the SDF implied by CAMP are reported in column (7) - relatively to CRSP valueweighted index, and column (10) - relatively to the matching style portfolio ('small growth' for venture, 'small value' for buyouts).

Furthermore, the excess $N P V$ analysis has additional advantage of being more robust when SDF measured with error as it is almost the case with macro-finance SDFs that we focus on in this study. Correspondingly, columns (8) and (11) report $\delta . N P V$ estimates with the SDF implied by the Long-run Risk model relatively to (cash flows from investing in) CRSP value-weighted index and the style-matched portfolio, respectively. Whereas columns (9) and (12) return those estimates for the Habit model SDF. It is important to highlight that, unlike with Kaplan-Schoar PME that can be used to measure the performance against a particular public benchmark in the CAPM-framework, here we do not impose additional restrictions on investors utility function (or risk premium).

Finally, columns (5) and (6) of each table report NPV estimates of investing in the respective private equity funds cohort to a representative investor in the Long-run Risk and Habit model without regards to performance of public equities over a particular subperiod. In other words, columns (5) and (6) answer the question of how good a hedge to the investors' marginal utility the commitments to those private funds would have provided without regards to the opportunity costs of investing elsewhere. Nonetheless, both SDF series are "calibrated" (see Table II) to have minimal pricing errors to most relevant benchmarks on average over the period from 1979 to 2016 with weights proportional to the relatively size of PE investments.

\section{B.1. Venture funds}

Next we turn to the discussion of estimation results for the sample of 1,242 venture funds as reported in Table III. We first focus on the CAPM-based inference with equally-weighted cash flows (i.e., columns 2 through 4, 7 and 10 of panel A).

\footnotetext{
15 Also, the NPVs in columns (4) through (12) are adjusted for inflation. However, this has very small impact on difference in GPME.KN and NPV.CAPM estimates (untabulated).
} 
We note that for the full sample (row 'All'), when compared to Korteweg and Nagel (2016)'s Table I Panel A, the point estimates are larger for GPME.KS case (0.29 cents on the dollar versus 0.048$)$ and are close for the GPME.KN case $(-0.15$ versus -0.103 , although insignificant statistically in our case). This could be explained by differences in the sample as we seem to have more better performing funds and their temporal cash flow pattern resulting in greater risk aversion coefficient and drift estimates.16 However, the overall picture is very consistent with Korteweg and Nagel (2016)'s findings: (i) assessment of venture fund performance notably deteriorates as we relax the log-utility assumption, (ii) the performance against the unrestricted CAPM turns significantly negative in post-2000 vintages.

As follows from column (4) of Table III. CAPM-based NPV estimates obtained with our calibration of SDF (section III.A) reveal a pattern generally similar to that from GPME.KN. ${ }^{17}$ We do find some differences at the vintage granularity though. For example: vintages 1999 switch from being positive to negative (both insignificant), deeper (shallower) losses in early (late) 2000 vintages.

As discussed above, neither CAPM.NPV nor GPME.KN guarantees that replicating the specific vintage's cash flows by investing in public benchmarks yields a zero NPV estimate (CAPM.NPV does not do so for group 'All' either). This apparent disadvantage of relaxing the assumption underlying Kaplan-Schoar PME can be easily mitigated by computing excess $N P V$ (for detail and more intuition, see the beginning of this section and section II.C). Here we consider two such benchmarks: (i) the broad market index itself, and (ii) the small growth stocks which arguably better resemble exposure to risk factors that venture investors effectively undertake.

Column (7) of Table III shows that through the lens of an unrestricted CAPM-SDF venture funds have performed largely in-line with similarly timed investments in CRSP valueweighted index. The average gain (as of average fund's starting time) amounts to 2 cents on the dollar as opposed to a gain of 29 cents one would infer with GPME.KS which implies the log-utility CAPM. However, if the investors were funding their commitments to venture funds by reducing their exposure to publicly traded small growth stocks (in proportion to the PE AUM size) the loss per CAPM would be significant 9 cents on the dollar for the full sample.

Nonetheless, the average performance post-2000 vintage appears significantly worse, economically and statistically, then for funds incepted before 2001.

\footnotetext{
${ }^{16}$ Our mean/median TVPI is $1.95 / 1.34$ as per Table I versus 1.57/1.16 amongst 545 Preqin funds; our $(a, b)$ estimates are $(0.168,3.622)$ versus $(0.088,2.650)$.

${ }^{17}$ We estimate the risk aversion coefficient of 2.464 as per specification (2) of Table II which is lower than 3.62 via GPME.KN for our sample while the drift estimate is not outright comparable as we utilize returns and cash flows adjusted for inflation for comparability with macro-finance SDFs.
} 


\section{B.1.1 NPV against consumption-based SDFs}

We now turn to the inference about NPV from investing in venture funds through the lens of the Long-run Risk and the Habit formation models as plausible proxies for preferences of the cornerstone PE investors.

Columns (5) and (6) of Table III indicate the abnormal returns are per both models, at 20 and 73 cents on the dollar respectively, albeit insignificant statistically. As for byvintage performance, the losses from funds incepted in 1980 through 1992 are as consistent and of a similar magnitude as per GPME.KN in column (3). However, the biggest positive contributions here come from the vintages of 2004-08 as opposed to the "famed" mid-to-late 90s. Meanwhile the vintage of 2007, which the unrestricted CAPMs regards as the worst (GPME.KN and NPV.CAPM of -1.54 and -0.41 respectively), appears as best ever according to the consumption-based models with the per dollar-invested NPV of $\$ 2.56$ against the LRR-SDF and $\$ 5.0$ against the Habit-SDF.

The explanation for these results is that the stream of positive consumption shocks in late 90s makes the abundant distributions by the 1992-96 venture funds to be of a relatively low utility. Even though these distributions exceeded the preceding contributions by a factor of 4 to 5 (as per panel A of Table I), they were occurring when non-investment income stream was high as Figure 3 depicts. Whereas a significant fraction of distributions by the post2002 vintages took place during the times of adverse shocks to consumption and, thus, high utility for the money. In other words, the post-2002 vintages have hedged the consumption shocks well as opposed to the average fund incepted in the 90s. In particular, the NPV of 1996-00 funds is \$-0.33 against the LRR-SDF and \$-0.14 against the Habit-SDF. Whereas the respective estimates for the cohort of 2001-05 funds are both positive at $\$ 0.42$ and $\$ 0.89$, significant at $10 \%$ level.

Next, we turn to the excess $N P V$ analysis with the consumption-based SDFs. Holding hypothetical cash flows from investing in CRSP value-weighted index as the benchmark, columns (8) and (9) show that both LRR- and Habit-SDFs evaluate the incremental distributions from venture funds far less favorably (than on a stand-alone basis). For the full sample (row 'All'), the NPV is virtually zero at, respectively, 2 and -1 cents on the dollar. It is interesting to note that, unlike with CAPM-based inference, the aggregate results for underperforming 2001-05 funds are very close to those of 1996-00, particularly with Habit SDF, where the difference is just 3 cents.

If the incremental distributions from venture funds are assessed against small growth stocks, the excess NPVs turn significantly negative for the post-2000 subsamples driven by 2003-07. Specifically, the full sample and post-2000 funds estimates with LRR-SDF are both significant statistically at $-\$ 0.13$ and $-\$ 0.32$, respectively. For Habit-SDF, the corresponding 
estimates suggest even steeper losses of $\$ 0.25$ and $\$ 0.59$, respectively.

Overall, as highlighted in Figure 6, we note significantly lower volatility of the vintage level excess NPVs according to the consumption-based models (even though the SDFs are actually more volatile than per CAPM). $\triangle$ NPV.LRR and $\triangle$ NPV.Habit are closer to zero in 80-90\% of vintage groups than are $\triangle$ NPV.CAPM and GPME.KS.

\section{B.1.2 Nearly resolved funds}

Figure 2 shows that many funds incepted as early as 2005 carry significant NAVs (which are treated as the terminal cash flow in our estimates). As a fraction of capital committed, the residual NAVs average over 40\% (80\%) for 2005-06 (2007-08) funds as of September 2016 - our cash flow sample end - nearly twice as large as respective buyout funds. Therefore, the final readings of NPVs and $\triangle . N P V s$ may substantially deviate from the current "to-date" values reported in Panel A of Table III.

As a simple way to gauge the magnitude of potential change from current to final we limit our sample to funds that have distributed at least three times the residual NAVs. We report these results in Panel B of Table III. It follows that the potential change to the final means is quite substantial. First, it is striking that even for pre-2000 venture funds nearly $17 \%$ do not meet this rather a low threshold for realized performance status. However, this seems to make no difference for our CBAPM-based inference about those funds, unlike with only 64\%-resolved (=162/251) '2001-05'-cohort where $\Delta . \mathrm{NPVs}$ dip by $10-20$ cents from Panel A to become significantly negative $\$ 0.10$-to- $\$ 0.18$ in Panel B.

Meanwhile, 2007 vintage, the best ever according to CBAPMs' $\Delta$.NPVs in Panel A, has the smallest fraction of nearly resolved funds of $24 \%$. For these funds only, $\Delta . N P V s$ suggest statistically significant loss of $\$ 0.20$ (\$0.54) against CRSP for LRR (Habit) SDF. It is therefor 3-5 years too early to conclude whether venture funds indeed provided for a good hedge to investors' utility through the crises.

\section{B.2. Buyout funds}

Table IV] is identical to Table III but reports the performance of buyout funds and, in columns (10) through (12), uses hypothetical cash flows from small value stocks investing to compute excess $N P V$. As before, we first focus on full sample of funds. These results are reported in panel $\mathrm{A}$.

Starting with the CAPM-based inference, we note that the full sample performance of buyout funds appears abnormally good: GPME.KS at $\$ 0.25$, GPME.KN at $\$ 0.45$, NPV.CAPM at $\$ 0.21$ are all positive and significant statistically, so as $\triangle$ NPV.CAPM against the broad 
market portfolio - \$0.29. While NPV.CAPM uses the value of 2.46 as per specification (2) of Table II, the procedure of Korteweg and Nagel (2016) results in the following coefficients for the full/pre-00/post-99 samples: 3.67/2.40/3.85 (untabulated). However, the excess NPV estimate is negative 10 cents on the dollar against the small value stocks (although insignificant statistically).

There is generally high concordance in the split-sample estimates across CAPM models except for the small value $\triangle \mathrm{NPVs}$, which point that 2001-05 was the best period for buyout performance with an average NPV of statistically significant $\$ 0.22$ as opposed to steep losses in 1996-00. All CAPM-based estimates "agree" that 2007-08 vintages have not performed well. Nonetheless, the magnitudes of loss estimates vary markedly: from 3 cents on the dollar according to GPME.KS to more than a amount invested (-\$1.3) according to GPME.KN ${ }^{18}$

\section{B.2.1 NPV against consumption-based SDFs}

Turning to the SDFs from the consumption-based models, we find several differences from the pattern we observed for venture funds. While the full-sample NPV.LRR and NPV.Habit at $\$ 0.55$ and $\$ 1.34$ are even larger than in the venture sample, the excess NPVs over benchmark's cash flows are all significantly negative. This contrast is especially stark in the > 2000 group where the "stand-alone" NPVs are $\$ 1.07$ and $\$ 2.35$ for LRR- and HabitSDF respectively (columns (5) and (6)) while the excess NPVs against the CRSP index investments are \$-0.25 and \$-0.42 (columns 8 and 9, i.e., 27-67 cents worse than those of venture). The results appear even weaker across all subsamples when cash flows in excess of those from public small value investments are considered. Nonetheless, the excess NPVs are far more concordant with the CBAPM SDFs regardless of the benchmark asset than under CAPM.

Once again, the excess NPV estimates indicate incremental change in utility if a representative agent from the respective model invested in the particular group of funds. With the consumption-based models, there is no implicit comparison with the performance of any publicly traded asset over that specific period. In fact, the NPV of public investing on a given period may significantly deviate from zero due to a sampling error and/or mismeasurement of the SDF series. Therefore, the evaluation based on $\Delta$.NPV is more reliable (and/or relevant) when investing in the aforementioned public asset is indeed a viable alternative to committing capital to buyout funds.

\footnotetext{
${ }^{18}$ This result may strike as counter intuitive given the limited liability of PE partnerships. However, it reflects the "utility-adjusted" present value which is not bounded and may rationalize the steep discounts that some LPs were willing to trade their commitments at during the 2008 crisis (e.g., see "Harvard, Other Big Endowments Selling Private Equity Stakes at Big Losses", by Yves Smith, Naked Capitalism).
} 
Figure 7 and columns (11)-(12) of Table IV show that for the lens of both, the LRR and Habit models, (following moderately weak results in late 80s) buyout funds yielded zero NPV, statistically and economically, throughout the 90s. Thus, unlike CAPM, the consumptionbased SDFs do not detect any "surge" in performance during the late 90s (as opposed to the venture sample). Furthermore, the "all CAPM versions" record-setting vintage of 2000 is not even in top-5 according to $\triangle$ NPV.LRR (Habit) with statistically insignificant gains of $\$ 0.12$ (\$0.08), which less than half of the 2004-vintage's results of $\$ 0.36(0.49)$.

Another large difference in the assessment of buyouts' performance between the consumptionbased SDFs and CAPM is the excess NPV delivered by the '1996-00'-cohort in comparison to that of the funds incepted in 2001-05. While regular CAPM (column 7) states that the former at $\$ 0.76$ was about two times as good as in 2001-2005 funds, LRR and Habit (columns 8 and 9) suggest that "mere" $2-4$ cents on the dollar from the '1996-00'-cohort are dwarfed by \$0.24-0.34 from the '2001-05'-cohort. The track record of the 2000-2004 buyouts (through the lens of LRR and Habit investors) might rationalize the surge in commitments to 2007-08 buyout funds. However, unlike venture funds, those vintages of buyout funds (on average) failed to deliver attractive incremental cash flows (over investing in comparable public equities) during 2008-2016. $\Delta$ NPV.LRR (Habit) indicates large and statistically significant losses against CRSP investments: $\$-1.01$ (\$-1.52) for the 2007 vintage, and $\$-0.63(\$-1.29)$ for the 2008 vintage.

\section{B.2.2 Nearly resolved funds}

As with venture funds sample, it turns out that over half (396) of 704 post-2000 funds being far from resolution as of September 2016, with the ratio of funds with latest NAVs being over a third of inflation-adjusted cumulative distributions approaching $80 \%$ in 2008 vintage. However, the drop in CBAPM $\triangle$ NPVs for 2006-08 vintages in Panel B of Table IV relatively to Panel A appears somewhat smaller at $\$ .50$-to-1.02 than for comparable venture funds. Interestingly, in contrast to the venture sample, the $\triangle$ NPVs for 2001-2004 funds from Panel B are higher than these readings in Panel A for both CBAPMs and CAPMs.

The average performance across All vintages in Panel B is also higher than in Panel A according to almost all performance metrics, suggesting that buyout funds that take longer to resolve tend to underperform. The all-vintage CBAPMs' $\triangle$ NPVs against CRSP improve to being 10 cents above those of venture in Panel B of Table III but still below those in Panel A. However, CBAPMs' $\triangle$ NPVs against Size\&Style benchmark remained below than those of venture even in Panel B. 


\section{B.3. Generalist funds}

Table $\mathrm{V}$ is similar to table [V] but reports the performance of funds that Burgiss classifies as 'generalist' and/or 'expansion capital'. These funds pursue investments that exhibit characteristics of both venture and buyout transactions. Henceforth, we will refer to them as generalist funds. As with buyouts, we use small value stocks in columns (10) to (12) as an alternative to value-weighted CRSP index to compute excess NPV. Because we observe significantly fewer funds of this type (especially, before 2005), we combine vintages in larger cohorts. Overall, the results appear similar to the buyout sample. In fact, the NPV estimates for the pre-2001 cohort (untabulated) across all models are within one standard deviation from those of Table IV]. For brevity, we highlight only key patterns.

Focusing on panel A that reports NPV estimates for equally weighted cash flows across funds regardless of the resolution status, we see that CAPM-based results (columns 2, 3, 4, 7 and 10) for generalist funds incepted during 2001-08 tend to be weaker than the corresponding estimates for buyout funds: GPME.KS is halved at $\$ 0.16$, DeltaNPV versus CRSP is only a third at 4 cents. As with buyouts, performance of generalists funds seems to strongest in 2001-05 vintages while still being about 10 cents short of that by comparable buyouts.

As for the inference based on consumption-based SDFs, the post-2000 stand-alone NPVs (columns 5 and 6) are somewhat higher than those of venture and buyouts. However, on the excess $N P V$ basis, the readings are the lowest amongst the three funds types with 40-60 cent certainty equivalent loss even against the CRSP investments, driven by steep losses in 2007-08 vintages. Whereas for 2001-05 vintages, $\Delta$.NPVs are virtually indistinguishable from those of 2001-05 buyouts at statistically significant 20-30 (4-7) cents on the dollar against CRSP (small value).

Also, as with buyouts, the performance for relatively resolved funds does not seem be weaker for funds incepted before 2006. In fact, for 2001-03 cohort, $\Delta . \mathrm{NPVs}$ improve as the funds with NAVs comprising more than third of cumulative distributions are dropped, particularly against the small value benchmark. However, the readings for 2007-08 vintages drop stronger in Panel B from Panel A than they do in case of buyouts in Table IV.

\section{Additional Analysis}

Significance and magnitude of negative excess NPVs against the style\&size benchmarks reported in Tables III IV is quite stunning and hard to reconcile with the PE fundraising records observed recently. In this section, we question whether lower risk aversion can rationale the seemingly growing interest from CBAPM investors to PE. For brevity, we focus on Long-run Risk model only and re-estimate excess NPVs against both benchmarks 
assuming a less volatile SDF by setting the coefficient of relative risk aversion to 7 from 10.5 estimate per Table II and reducing persistence of shocks to 0.9383 from 0.95 as an alternative calibration considered in the literature (Ghosh, Julliard, and Taylor, 2016).

Figure 8 reports the results of this experiment. It follows that less risk-averse Long-run Risk investors may prefer venture funds to small growth stocks as the full sample $\Delta$.NPV turns positive as well as the one for 2007-08 funds cohorts, but only if yet to be substantially resolved funds are considered. However, $\Delta$.NPVs against small value on buyout and venture funds remain significantly negative yet do also improve markedly.

Figures AV AVI provide additional details by plotting $\Delta$.NPVs across vintage years against both CSRP and Size\&Style benchmarks. For buyout funds, the series of $\Delta$.NPVs across different calibrations of SDF appear very close up to 2005 vintage. The sign on the difference is not consistent however, with lower risk aversion resulting in lower estimates of $\Delta . \mathrm{NPVs}$ for some vintages particularity during late 90 s and against the small value. In contrast, the effect of reducing risk aversion seems to be much more pronounced and uniformly positive for venture funds.

\section{Conclusion}

This paper documents novel facts about PE fund performance. We compare inference about NPV of investing in various cohorts of venture, buyout and generalist funds derived from CAPM and the leading consumption-based asset pricing models. We show that latter may explain the continued interest to venture capital investments by university endowments and pension funds. However, the methodology that we develop applies beyond these specific SDFs, enabling a construction and calibration of portfolio-specific discount factors reflecting non-tradeable assets and liabilities, unspanned by publicly-traded assets.

There are limitations to our analysis. While our methodology emphasizes robustness, other studies may find different results using conceptually same methods since this approach involves not explicitly observable discount factors. Furthermore, many funds in our sample are far from being resolved, especially those incepted after 2005. Thus, some key results may change as post-2016 cash flows are added and SDF realizations are obtained. 


\section{References}

Ang, Andrew, Bingxu Chen, William N Goetzmann, and Ludovic Phalippou, 2017, Estimating private equity returns from limited partner cash flows, Journal of Finance, Forthcoming.

Ang, Andrew, Dimitris Papanikolaou, and Mark M Westerfield, 2014, Portfolio choice with illiquid assets, Management Science 60, 2737-2761.

Bansal, Ravi, and A Yaron, 2004, Risks for the long run: A potential resolution of asset pricing puzzles, The Journal of Finance 59, 1481-1509.

Beeler, Jason, John Y Campbell, et al., 2012, The long-run risks model and aggregate asset prices: An empirical assessment, Critical Finance Review 1, 141-182.

Bernstein, Shai, Josh Lerner, and Antoinette Schoar, 2013, The investment strategies of sovereign wealth funds, The Journal of Economic Perspectives 27, 219-238.

Bidder, Rhys, and Ian Dew-Becker, 2016, Long-run risk is the worst-case scenario, American Economic Review 106, 2494-2527.

Breeden, Douglas T, Robert H Litzenberger, and Tingyan Jia, 2015, Consumption-based asset pricing, part 2: Habit formation, conditional risks, long-run risks, and rare disasters, Annual Review of Financial Economics 7, 85-131.

Brown, Gregory W, Robert S Harris, Tim Jenkinson, Steven N Kaplan, and David Robinson, 2015, What do different commercial data sets tell us about private equity performance?, Working Paper.

Campbell, John Y, and John H Cochrane, 1999, By force of habit: A consumption-based explanation of aggregate stock market behavior, Journal of Political Economy 107, 205-251.

Campbell, John Y, and Robert J Shiller, 1988, The dividend-price ratio and expectations of future dividends and discount factors, Review of Financial Studies 1, 195-227.

Cejnek, Georg, Richard Franz, and Neal M Stoughton, 2015, An Integrated Model of University Endowments, Working Paper pp. 1-54.

Chernov, Mikhail, Lars A Lochstoer, and Stig RH Lundeby, 2018, Conditional dynamics and the multi-horizon risk-return trade-off, National Bureau of Economic Research Working Paper.

Cochrane, John H, 2005, The risk and return of venture capital, Journal of Financial Economics $75,3-52$.

— , 2009, Asset Pricing (Revised Edition) (Princeton university press). 
Colacito, R, and M M Croce, 2011, Risks for the Long Run and the Real Exchange Rate, The Journal of Political Economy 119, 153-181.

Constantinides, George M, and Anisha Ghosh, 2011, Asset pricing tests with long-run risks in consumption growth, Review of Asset Pricing Studies 1, 96-136.

Epstein, Larry G, and Stanley E Zin, 1989, Substitution, risk aversion, and the temporal behavior of consumption and asset returns: A theoretical framework, Econometrica 99, 937-969.

Ewens, Michael, Charles M Jones, and Matthew Rhodes-Kropf, 2013, The price of diversifiable risk in venture capital and private equity, The Review of Financial Studies 26, 1854-1889.

Franzoni, Francesco, Eric Nowak, and Ludovic Phalippou, 2012, Private equity performance and liquidity risk, The Journal of Finance 67, 2341-2373.

Gârleanu, Nicolae, and Stavros Panageas, 2017, Finance in a time of disruptive growth, Berkeley University Working Paper.

Ghosh, Anisha, Christian Julliard, and Alex P Taylor, 2016, What is the consumption-capm missing? an information-theoretic framework for the analysis of asset pricing models, Review of Financial Studies.

Gilbert, Thomas, and Christopher Hrdlicka, 2015, Why are university endowments large and risky?, The Review of Financial Studies 28, 2643-2686.

Goetzmann, William N., Elise Gourier, and Ludovic Phalippou, 2018, How Alternative Are Alternative Investments? The Case of Private Equity Funds, Yale University Working Paper.

Hakansson, Nils H, 1971, Multi-period mean-variance analysis: toward a general theory of portfolio choice, The Journal of Finance 26, 857-884.

Hall, Peter, and Joel L Horowitz, 1996, Bootstrap critical values for tests based on generalizedmethod-of-moments estimators, Econometrica: Journal of the Econometric Society pp. 891-916.

Hansen, Lars Peter, and Scott F Richard, 1987, The role of conditioning information in deducing testable restrictions implied by dynamic asset pricing models, Econometrica: Journal of the Econometric Society pp. 587-613.

Harris, Robert S, Tim Jenkinson, and Steven N Kaplan, 2014, Private equity performance: What do we know?, The Journal of Finance 69, 1851-1882.

Kaplan, Steven N, and Antoinette Schoar, 2005, Private Equity Performance: Returns, Persistence, and Capital Flows, The Journal of Finance 60, 1791-1823. 
Kaplan, Steven N, and Berk A Sensoy, 2015, Private equity performance: A survey, Annual Review of Financial Economics 7, 597-614.

Korteweg, Arthur, and Stefan Nagel, 2016, Risk-Adjusting the Returns to Venture Capital, The Journal of Finance 71, 1437-1470.

Korteweg, Arthur, and Morten Sorensen, 2010, Risk and return characteristics of venture capitalbacked entrepreneurial companies, The Review of Financial Studies 23, 3738-3772.

Lerner, Josh, and Ann Leamon, 2011, Yale university investments office: February 2011, Harvard Business School Entrepreneurial Management Case.

Lerner, Josh, Antoinette Schoar, and Wan Wongsunwai, 2007, Smart institutions, foolish choices: The limited partner performance puzzle, The Journal of Finance 62, 731-764.

Ljungqvist, Alexander, and Matthew Richardson, 2003, The cash flow, return and risk characteristics of private equity, National Bureau of Economic Research.

Lucas, Deborah J, and Stephen P Zeldes, 2009, How should public pension plans invest?, The American Economic Review 99, 527-532.

Mehra, R, and Edward C Prescott, 1985, The equity premium: A puzzle, Journal of Monetary Economics 15, 145-161.

Robinson, David T, and Berk A Sensoy, 2013, Do private equity fund managers earn their fees? compensation, ownership, and cash flow performance, The Review of Financial Studies 26, 27602797.

— , 2016, Cyclicality, performance measurement, and cash flow liquidity in private equity, Journal of Financial Economics 122, 521-543.

Rubinstein, Mark, 1976, The valuation of uncertain income streams and the pricing of options, The Bell Journal of Economics pp. 407-425.

Sorensen, Morten, and Ravi Jagannathan, 2015, The public market equivalent and private equity performance, Financial Analysts Journal 71, 43-50.

Wachter, Jessica A, 2005, Solving models with external habit, Finance Research Letters 2, 210-226. 


\section{Table I}

\section{Summary statistics}

This table reports summary statistics for data used in this study. Panel A describes the sample of venture, growth equity and buyout funds with cash flow data from Burgiss, for vintages between 1979 and 2008. We exclude funds with committed capital below $\$ 5$ million in 1990 dollars. The means and quartile statistics are for the for total value to paid-in capital ("Money Multiple") of each fund. Consistent with Burgiss policies, values are not reported for groups smaller than 5 funds.

Panel A: PE funds sample

\begin{tabular}{|c|c|c|c|c|c|c|c|c|c|c|}
\hline & \multicolumn{5}{|c|}{ Venture } & \multicolumn{5}{|c|}{ Buyout and Generalists } \\
\hline & count & mean & $\mathrm{p} 25$ & p50 & p75 & count & mean & p25 & p50 & p75 \\
\hline 1979 & 3 & & & & & 0 & r & . & . & . \\
\hline 1980 & 8 & 2.84 & 1.74 & 2.30 & 3.32 & 3 & . & . & . & . \\
\hline 1981 & 10 & 1.73 & 1.05 & 1.73 & 2.51 & 0 & . & $\cdot$ & . & . \\
\hline 1982 & 13 & 1.46 & 1.18 & 1.59 & 1.70 & 2 & . & . & . & . \\
\hline 1983 & 22 & 1.78 & 1.39 & 1.72 & 2.16 & 3 & . & . & . & . \\
\hline 1984 & 26 & 1.66 & 1.11 & 1.59 & 2.09 & 4 & & . & & . \\
\hline 1985 & 27 & 2.04 & 1.22 & 1.79 & 2.86 & 6 & 5.17 & 2.41 & 2.72 & 2.79 \\
\hline 1986 & 27 & 2.06 & 1.45 & 1.74 & 2.10 & 8 & 2.70 & 1.26 & 1.48 & 2.47 \\
\hline 1987 & 31 & 2.11 & 1.10 & 1.95 & 2.62 & 14 & 2.71 & 1.49 & 2.18 & 4.17 \\
\hline 1988 & 32 & 2.08 & 1.32 & 1.89 & 2.76 & 14 & 1.96 & 1.57 & 1.75 & 2.18 \\
\hline 1989 & 29 & 2.34 & 1.09 & 1.73 & 3.02 & 19 & 2.24 & 1.44 & 2.07 & 3.29 \\
\hline 1990 & 18 & 2.74 & 1.38 & 2.22 & 3.64 & 14 & 2.10 & 1.45 & 1.91 & 2.59 \\
\hline 1991 & 7 & 2.77 & 1.66 & 2.37 & 3.64 & 13 & 2.54 & 1.89 & 2.60 & 2.77 \\
\hline 1992 & 20 & 3.09 & 1.22 & 1.79 & 3.08 & 15 & 2.09 & 1.25 & 1.86 & 3.10 \\
\hline 1993 & 21 & 4.90 & 1.67 & 2.79 & 4.42 & 20 & 2.27 & 1.42 & 1.89 & 2.85 \\
\hline 1994 & 22 & 4.93 & 1.26 & 2.51 & 5.82 & 39 & 1.98 & 1.20 & 1.88 & 2.38 \\
\hline 1995 & 29 & 5.44 & 1.57 & 2.74 & 5.64 & 42 & 1.87 & 1.05 & 1.67 & 2.26 \\
\hline 1996 & 22 & 5.75 & 1.23 & 2.21 & 6.72 & 39 & 1.57 & 0.96 & 1.50 & 2.14 \\
\hline 1997 & 49 & 3.42 & 1.04 & 1.87 & 4.00 & 66 & 1.43 & 0.88 & 1.33 & 1.74 \\
\hline 1998 & 57 & 1.86 & 0.71 & 1.07 & 1.64 & 89 & 1.55 & 1.03 & 1.47 & 1.98 \\
\hline 1999 & 101 & 0.87 & 0.38 & 0.76 & 1.09 & 80 & 1.50 & 0.99 & 1.51 & 2.00 \\
\hline 2000 & 125 & 0.90 & 0.54 & 0.76 & 1.20 & 107 & 1.83 & 1.33 & 1.76 & 2.24 \\
\hline 2001 & 69 & 1.28 & 0.62 & 1.12 & 1.44 & 58 & 1.89 & 1.45 & 1.94 & 2.24 \\
\hline 2002 & 30 & 1.17 & 0.86 & 1.18 & 1.49 & 47 & 2.11 & 1.57 & 1.93 & 2.54 \\
\hline 2003 & 25 & 1.27 & 0.52 & 1.08 & 1.44 & 43 & 1.96 & 1.35 & 1.83 & 2.68 \\
\hline 2004 & 52 & 1.38 & 0.70 & 0.95 & 1.52 & 92 & 1.76 & 1.36 & 1.71 & 2.05 \\
\hline 2005 & 75 & 1.55 & 0.84 & 1.18 & 1.73 & 125 & 1.61 & 1.12 & 1.50 & 1.93 \\
\hline 2006 & 104 & 1.48 & 0.80 & 1.36 & 1.89 & 177 & 1.50 & 1.02 & 1.44 & 1.74 \\
\hline 2007 & 100 & 1.92 & 1.16 & 1.65 & 2.26 & 198 & 1.44 & 1.15 & 1.44 & 1.69 \\
\hline 2008 & 88 & 1.96 & 1.02 & 1.37 & 2.21 & 171 & 1.46 & 1.16 & 1.43 & 1.72 \\
\hline Total & 1,242 & 1.95 & 0.84 & 1.34 & 2.02 & 1,508 & 1.70 & 1.19 & 1.55 & 2.03 \\
\hline
\end{tabular}




\section{Table I}

\section{Summary statistics (Continued)}

Panel B reports the summary statistics at annual frequency for the log changes in the discount factors $(m)$ considered in this study (log-utility CAPM, Long-run Risk model, and the Habit formation model); the underlying data used to construct them (U.S. Price-dividend ratio, 3-month Treasury Bill rate, Moody's BBB to AAA credit spread, U.S. Consumption growth, U.S. Consumption to Output ratio); and the proxies for the marginal utility of core PE sponsors, University Endowments and State Pension Plans (real growth rates of gifts and contributions respectively). The sample period is from 1951 through 2016 or earliest availability. Panel C reports the pairwise correlation for selected variables during years 1998-2016.

Panel B: Other data

\begin{tabular}{|c|c|c|c|c|c|c|}
\hline & \multicolumn{3}{|c|}{ Univariate Statistics: } & \multicolumn{3}{|c|}{ Correlations with: } \\
\hline & Mean & StDev & Skew & $m^{l u C A P M}$ & $m^{L R R}$ & $m^{\text {Habit }}$ \\
\hline & (1) & (2) & (3) & (4) & $(5)$ & (6) \\
\hline$m^{l u C A P M}$ & -0.069 & 0.173 & 0.891 & 1.000 & -0.094 & 0.417 \\
\hline$m^{L R R}$ & -0.061 & 0.942 & 0.045 & -0.094 & 1.000 & -0.203 \\
\hline$m^{\text {Habit }}$ & -0.063 & 0.625 & -0.060 & 0.417 & -0.203 & 1.000 \\
\hline Price-to-Dividend & 0.01 & 0.39 & 0.263 & -0.054 & -0.000 & -0.069 \\
\hline Risk Free Rate & -0.000 & 0.022 & -0.110 & -0.263 & -0.173 & -0.118 \\
\hline BBB-AAA (pct pts) & -0.019 & 0.328 & 1.274 & 0.074 & 0.127 & -0.003 \\
\hline$\Delta$. Cons. (in logs) & -0.000 & 0.004 & -0.442 & -0.403 & -0.110 & -0.533 \\
\hline Cons.-to-Output & -0.000 & 0.019 & -0.645 & -0.132 & 0.089 & -0.182 \\
\hline$\Delta . \mathrm{SPP}$ (Contributions) & 0.057 & 0.030 & -0.049 & -0.067 & -0.410 & -0.239 \\
\hline$\Delta . \mathrm{UEd}$ (Gifts) & 0.038 & 0.054 & -0.525 & -0.067 & -0.335 & -0.192 \\
\hline
\end{tabular}

Panel C: Correlations post-1998

\begin{tabular}{lcccccc}
\hline & $m^{C A P M}$ & $m^{\text {LRR }}$ & $m^{\text {Habit }}$ & $\Delta$.Cons & $\Delta$. SPP & $\Delta$. UEd \\
\cline { 2 - 6 }$m^{C A P M}$ & 1.000 & & & & & \\
$m^{\text {LRR }}$ & 0.077 & 1.000 & & & & \\
$m^{\text {Habit }}$ & 0.283 & 0.131 & 1.000 & & & \\
$\Delta$.Cons & -0.077 & -0.642 & -0.386 & 1.000 & & \\
$\Delta$.SPP & -0.067 & -0.410 & -0.239 & 0.503 & 1.000 & \\
$\Delta$. UEd & -0.040 & -0.573 & -0.252 & 0.685 & 0.467 & 1.000 \\
\hline
\end{tabular}




\section{Table II \\ GMM estimation of SDF parameters}

This table reports stochastic discount factor $M$ parameter $(a, \gamma)$ estimates via quarterly time series GMM that utilizes the Euler restriction $E_{w}\left[M(\hat{a}, \hat{\gamma})_{t} \cdot R_{t}^{B}\right]-1=0$ for three asset pricing models (CAPM, Long-run Risk model of Bansal and Yaron (2004), and the Habit formation model of Campbell and Cochrane (1999)), where $w$ denotes the weights of each quarter during 1979-2016 reflecting the relative size of the PE portfolio (see Figure 5); and $R_{t}^{B}$ - a vector of test assets. The test assets include returns on risk free rate ( $\mathrm{rfr}$ ), CRSP value-weighted index (mkt), and six size and style portfolios: small capitalization growth, medium book-to-market, and value stocks (smlo, smme, and smhi); and the corresponding large capitalization portfolios (bilo, bime, bihi). Last eight rows report mean pricing error by each test asset in basis points per quarter. Italicized are test assets excluded from the respective estimation. First two rows report the model J-statistic and the associated p-value for over-identified models. The remaining rows report the point estimates and robust for heteroskedasticity and autocorrelation standard errors (in parentheses) for the SDF drift $(a)$, and the relative coefficient of risk aversion $(\gamma)$. See section III.A for details.

\begin{tabular}{|c|c|c|c|c|c|c|c|c|c|}
\hline & \multicolumn{3}{|c|}{ CAPM } & \multicolumn{3}{|c|}{ LRR } & \multicolumn{3}{|c|}{ Habit } \\
\hline & (1) & (2) & (3) & (4) & $(5)$ & (6) & $(7)$ & (8) & (9) \\
\hline \multirow{2}{*}{$\begin{array}{l}\text { J-statistic } \\
\text { p-value }\end{array}$} & - & 4.224 & 13.72 & - & 0.776 & 10.93 & - & 1.749 & 9.771 \\
\hline & - & 0.121 & 0.033 & - & 0.679 & 0.090 & - & 0.417 & 0.135 \\
\hline \multirow[t]{2}{*}{$a$} & 0.014 & 013 & 0.013 & $\begin{array}{l}-0.142 \\
0.043\end{array}$ & -0.158 & -0.156 & -0.200 & $\begin{array}{l}-0.218 \\
(0.054\end{array}$ & -0.218 \\
\hline & $\begin{array}{l}(0.000) \\
2.466\end{array}$ & $\begin{array}{l}(0.000) \\
2.464\end{array}$ & $\begin{array}{l}(0.000) \\
2471\end{array}$ & 96 & U) & $\begin{array}{c}(0.041) \\
1035\end{array}$ & 5 & $\begin{array}{l}(0.054) \\
2.555\end{array}$ & $\begin{array}{l}\text { (U.056) } \\
2.552\end{array}$ \\
\hline$\gamma$ & $(0.61)$ & $(0.62)$ & $(0.62)$ & (3.04) & $(2.90)$ & $(2.97)$ & $(0.76)$ & $(0.69)$ & $(0.71)$ \\
\hline rf & 0.00 & -8.82 & -10.69 & 0.00 & 1.87 & -1.73 & 0.00 & -0.91 & -2.96 \\
\hline $\mathrm{mk}$ & 0.00 & -8.68 & -10.95 & 0.00 & -11.23 & -12.47 & 0.00 & -10.96 & -12.87 \\
\hline smlo & -24.22 & -32.84 & -35.19 & 13.65 & 2.77 & 1.46 & 21.44 & 11.40 & 9.47 \\
\hline smme & 52.98 & 44.22 & 41.93 & 41.91 & 29.35 & 28.33 & 38.51 & 26.11 & 24.21 \\
\hline smhi & 58.46 & 49.69 & 47.40 & 21.69 & 6.56 & 6.01 & 15.14 & 0.42 & -1.45 \\
\hline bilo & 21.97 & 13.23 & 11.02 & -6.16 & -17.94 & -19.08 & -13.36 & -25.54 & -27.43 \\
\hline bime & 13.42 & 4.71 & 2.47 & -9.53 & -22.13 & -23.12 & -8.79 & -20.87 & -22.77 \\
\hline bihi & -16.84 & -25.48 & -27.80 & -8.37 & -20.99 & -21.97 & -3.74 & -15.18 & -17.08 \\
\hline
\end{tabular}




\section{Table III Venture funds performance: CAPM versus CBAPMs}

This table reports the Net Present Values and excess Net Present Values ( $\triangle N P V)$ of venture fund cash flows for the full sample (row 'All') and by a vintage year group using several discount factors. Columns (2) and (3) report Generalized Public Market Equivalents (GPMEs) following Korteweg and Nagel (2016) who consider discount factors affine in the public equity returns for the general case $(K N)$, and the special case $(K S)$ where market risk premium is restricted to the log-Utility CAPM as per PME of Kaplan and Schoar (2005). Columns (4), (7), and (10) report conceptually same NPV estimates as in column (3) obtained with the discount factor implied by CAPM but using a different procedure to estimate parameters and adjust for the sampling errors. The remaining columns report either $N P V$ or $\triangle N P V$ estimates against consumption-based discount factors implied by the Long-run Risk model of Bansal and Yaron (2004), and the Habit formation model of Campbell and Cochrane (1999). $\triangle N P V$ is the differences between the venture funds' NPV and that of the hypothetical funds (constructed as in Korteweg and Nagel (2016)) invested in CRSP value-weighted index or Fama-French small growth portfolio. The estimates statistically significant at 5\%(10\%) are superscripted with ${ }^{a}\left({ }^{b}\right)$. Fund cash flows are normalized to $\$ 1$ commitment and equally weighted. Panel A reports results for all funds in the respective vintage year group. Panel B reports results for funds with inflation-adjusted distributions being at least three times the latest residual NAV reported by the fund. 


\begin{tabular}{|c|c|c|c|c|c|c|c|c|c|c|c|c|}
\hline \multirow[b]{2}{*}{ Vintage } & \multirow[b]{2}{*}{$\begin{array}{c}\text { Funds \# } \\
(1) \\
\end{array}$} & \multicolumn{2}{|c|}{ GPME } & \multicolumn{3}{|c|}{ NPV } & \multicolumn{3}{|c|}{$\Delta \mathrm{NPV}(\operatorname{crsp})$} & \multicolumn{3}{|c|}{$\Delta \mathrm{NPV}(\mathrm{ff} 6)$} \\
\hline & & $\begin{array}{l}\mathrm{KS} \\
(2)\end{array}$ & $\begin{array}{c}\mathrm{KN} \\
(3)\end{array}$ & $\begin{array}{c}\text { CAPM } \\
(4)\end{array}$ & $\begin{array}{c}\text { LRR } \\
(5)\end{array}$ & $\begin{array}{c}\text { Habit } \\
(6)\end{array}$ & $\begin{array}{c}\text { CAPM } \\
(7)\end{array}$ & $\begin{array}{c}\text { LRR } \\
(8)\end{array}$ & $\begin{array}{l}\text { Habit } \\
(9)\end{array}$ & $\begin{array}{c}\text { CAPM } \\
(10)\end{array}$ & $\begin{array}{c}\text { LRR } \\
(11)\end{array}$ & $\begin{array}{c}\text { Habit } \\
(12)\end{array}$ \\
\hline \multicolumn{13}{|c|}{ Panel A: All venture funds } \\
\hline$\leq 1985$ & 109 & -0.20 & $-0.45^{b}$ & $-0.44^{a}$ & $-0.49^{a}$ & $-0.48^{a}$ & $-0.14^{a}$ & -0.02 & -0.01 & $-0.07^{a}$ & -0.02 & -0.02 \\
\hline$\overline{1986}$ & 27 & $-0.11^{b}$ & $-0.39^{b}$ & $-0.38^{a}$ & $-0.47^{b}$ & $-0.43^{b}$ & $-0.16^{a}$ & -0.02 & -0.01 & -0.10 & -0.01 & -0.01 \\
\hline 1987 & 31 & $-0.09^{b}$ & $-0.44^{b}$ & $-0.42^{a}$ & $-0.55^{a}$ & $-0.52^{a}$ & $-0.16^{a}$ & -0.03 & -0.01 & $-0.12^{b}$ & -0.02 & -0.01 \\
\hline 1988 & 32 & $-0.02^{b}$ & $-0.31^{b}$ & $-0.33^{a}$ & $-0.41^{b}$ & $-0.40^{b}$ & $-0.06^{a}$ & $-0.03^{b}$ & $-0.03^{b}$ & -0.04 & -0.04 & -0.03 \\
\hline 1989 & 29 & $0.07^{b}$ & $-0.31^{b}$ & $-0.33^{a}$ & $-0.48^{a}$ & $-0.44^{b}$ & $-0.03^{b}$ & $-0.04^{b}$ & -0.03 & -0.01 & -0.04 & -0.03 \\
\hline $1990-91$ & 25 & $0.30^{a}$ & -0.18 & $-0.18^{b}$ & $-0.52^{a}$ & $-0.48^{b}$ & 0.11 & -0.02 & -0.01 & 0.15 & -0.02 & -0.02 \\
\hline 1992 & 20 & $0.49^{a}$ & -0.13 & -0.12 & $-0.36^{b}$ & -0.34 & 0.19 & 0.01 & 0.02 & 0.26 & 0.02 & 0.03 \\
\hline 1993 & 21 & $1.25^{a}$ & 0.10 & 0.12 & $-0.29^{a}$ & -0.30 & 0.45 & 0.02 & 0.03 & 0.52 & 0.03 & 0.04 \\
\hline 1994 & 22 & $1.30^{a}$ & 0.16 & 0.18 & $-0.34^{a}$ & $-0.37^{b}$ & 0.42 & 0.02 & 0.01 & 0.48 & 0.03 & 0.03 \\
\hline 1995 & 29 & $1.95^{a}$ & 0.59 & 0.63 & $-0.25^{b}$ & $-0.30^{b}$ & 0.79 & 0.10 & 0.07 & 0.83 & 0.11 & 0.08 \\
\hline 1996 & 22 & $3.04^{a}$ & $1.37^{a}$ & 1.40 & $-0.19^{a}$ & $-0.25^{a}$ & 1.49 & 0.22 & 0.16 & 1.51 & 0.23 & 0.17 \\
\hline 1997 & 49 & $4.28^{a}$ & 2.69 & 2.74 & 0.00 & -0.16 & 2.65 & 0.30 & 0.12 & 2.56 & 0.30 & 0.12 \\
\hline 1998 & 57 & $0.91^{a}$ & $1.33^{a}$ & 1.26 & $-0.31^{a}$ & $-0.33^{a}$ & 0.90 & 0.09 & 0.04 & 0.61 & 0.08 & 0.03 \\
\hline 1999 & 101 & $-0.27^{a}$ & 0.05 & -0.05 & $-0.40^{b}$ & -0.34 & $-0.58^{a}$ & 0.00 & 0.00 & $-0.90^{a}$ & -0.01 & 0.00 \\
\hline 2000 & 125 & $-0.39^{a}$ & -0.43 & $-0.53^{a}$ & $-0.42^{b}$ & $-0.39^{b}$ & $-0.85^{a}$ & $-0.04^{b}$ & -0.01 & $-1.17^{a}$ & -0.07 & -0.04 \\
\hline 2001 & 69 & $-0.15^{a}$ & -0.10 & $-0.24^{a}$ & -0.17 & -0.16 & $-0.29^{a}$ & 0.02 & $0.06^{b}$ & $-0.47^{a}$ & -0.03 & 0.01 \\
\hline 2002 & 30 & $-0.18^{a}$ & -0.19 & $-0.25^{b}$ & -0.19 & -0.16 & $-0.19^{a}$ & $-0.08^{a}$ & -0.07 & $-0.31^{a}$ & $-0.16^{b}$ & -0.14 \\
\hline 2003 & 25 & $-0.11^{a}$ & -0.05 & $-0.15^{a}$ & 0.10 & 0.18 & $-0.11^{a}$ & $-0.11^{a}$ & $-0.09^{a}$ & $-0.20^{a}$ & $-0.20^{a}$ & $-0.18^{a}$ \\
\hline 2004 & 52 & -0.09 & -0.32 & $-0.25^{b}$ & $0.50^{b}$ & $1.00^{b}$ & $-0.18^{a}$ & $-0.07^{a}$ & -0.03 & $-0.30^{a}$ & $-0.24^{a}$ & $-0.27^{a}$ \\
\hline 2005 & 75 & 0.09 & -0.10 & -0.07 & $1.27^{b}$ & $2.43^{a}$ & $0.05^{b}$ & 0.07 & 0.03 & $-0.06^{a}$ & $-0.23^{a}$ & $-0.46^{a}$ \\
\hline 2006 & 104 & $-0.12^{b}$ & $-1.13^{a}$ & $-0.52^{a}$ & $0.85^{b}$ & $2.47^{a}$ & $-0.24^{a}$ & $-0.81^{a}$ & $-1.33^{a}$ & $-0.36^{a}$ & $-1.26^{a}$ & $-2.13^{a}$ \\
\hline 2007 & 100 & $0.20^{b}$ & $-1.54^{b}$ & $-0.41^{a}$ & $2.56^{a}$ & $5.00^{a}$ & 0.08 & $0.72^{b}$ & $0.91^{a}$ & -0.03 & 0.09 & $-0.07^{b}$ \\
\hline 2008 & 88 & $0.15^{b}$ & -0.70 & $-0.29^{a}$ & $0.69^{b}$ & $2.20^{a}$ & 0.08 & 0.23 & $0.24^{b}$ & 0.04 & $-0.08^{a}$ & $-0.37^{a}$ \\
\hline$\leq 2000$ & 699 & 0.51 & 0.16 & 0.13 & $-0.38^{a}$ & $-0.38^{a}$ & $0.10^{a}$ & 0.03 & 0.01 & -0.01 & 0.02 & 0.01 \\
\hline $1996-00$ & 354 & $0.71^{a}$ & 0.53 & 0.47 & $-0.32^{a}$ & $-0.33^{a}$ & $0.14^{b}$ & 0.06 & 0.03 & $-0.12^{a}$ & 0.04 & 0.02 \\
\hline $2001-05$ & 251 & -0.06 & -0.15 & $-0.18^{a}$ & $0.42^{b}$ & $0.89^{b}$ & $-0.13^{a}$ & -0.01 & 0.00 & $-0.26^{a}$ & $-0.16^{a}$ & $-0.22^{b}$ \\
\hline$>2000$ & 543 & 0.01 & $-0.68^{b}$ & $-0.31^{a}$ & $0.94^{b}$ & $2.16^{a}$ & $-0.08^{a}$ & 0.01 & $-0.05^{b}$ & $-0.19^{a}$ & $-0.32^{a}$ & $-0.59^{a}$ \\
\hline All & 1,242 & 0.29 & -0.15 & $-0.06^{a}$ & 0.20 & 0.73 & $0.02^{b}$ & 0.02 & -0.01 & $-0.09^{a}$ & $-0.13^{a}$ & $-0.25^{b}$ \\
\hline \multicolumn{13}{|c|}{ Panel B: Nearly resolved venture funds } \\
\hline$\leq 2000$ & 578 & $0.63^{b}$ & 0.20 & 0.17 & $-0.37^{a}$ & $-0.37^{a}$ & $0.13^{a}$ & 0.03 & 0.02 & $0.02^{a}$ & 0.02 & 0.01 \\
\hline$\overline{2001}$ & 51 & -0.18 & $-0.34^{a}$ & $-0.28^{a}$ & -0.20 & -0.19 & $-0.33^{a}$ & 0.00 & 0.03 & $-0.51^{a}$ & $-0.06^{b}$ & -0.02 \\
\hline 2002 & 22 & $-0.23^{a}$ & $-0.30^{a}$ & $-0.29^{a}$ & -0.26 & -0.23 & $-0.23^{a}$ & $-0.13^{a}$ & $-0.11^{b}$ & $-0.35^{a}$ & $-0.20^{a}$ & $-0.18^{b}$ \\
\hline 2003 & 20 & $-0.12^{a}$ & -0.13 & $-0.16^{a}$ & 0.12 & 0.20 & $-0.12^{a}$ & $-0.09^{a}$ & $-0.07^{a}$ & $-0.20^{a}$ & $-0.18^{a}$ & $-0.15^{a}$ \\
\hline 2004 & 33 & $-0.15^{b}$ & $-0.34^{b}$ & $-0.28^{a}$ & $0.44^{b}$ & $0.91^{b}$ & $-0.18^{a}$ & $-0.12^{a}$ & $-0.09^{a}$ & $-0.30^{a}$ & $-0.29^{a}$ & $-0.33^{a}$ \\
\hline 2005 & 36 & -0.05 & -0.17 & $-0.16^{a}$ & $0.86^{b}$ & $1.43^{b}$ & $0.00^{a}$ & $-0.21^{a}$ & $-0.66^{a}$ & $-0.11^{a}$ & $-0.48^{a}$ & $-1.07^{a}$ \\
\hline 2006 & 49 & $-0.40^{b}$ & $-1.16^{b}$ & $-0.79^{a}$ & $-0.53^{a}$ & -0.18 & $-0.45^{a}$ & $-1.84^{a}$ & $-3.17^{a}$ & $-0.56^{a}$ & $-2.24^{a}$ & $-3.88^{a}$ \\
\hline 2007 & 24 & 0.05 & -1.00 & $-0.40^{a}$ & $0.83^{b}$ & $2.04^{a}$ & 0.16 & $-0.20^{a}$ & $-0.54^{a}$ & 0.07 & $-0.65^{a}$ & $-1.26^{a}$ \\
\hline 2008 & 29 & -0.15 & -0.66 & $-0.44^{a}$ & -0.07 & $0.39^{b}$ & $-0.05^{a}$ & $-0.09^{a}$ & $-0.17^{a}$ & $-0.09^{a}$ & $-0.33^{a}$ & $-0.63^{a}$ \\
\hline $1996-00$ & 302 & $0.81^{a}$ & 0.53 & 0.47 & $-0.32^{a}$ & $-0.32^{a}$ & $0.13^{a}$ & 0.06 & 0.03 & $-0.13^{a}$ & 0.04 & 0.02 \\
\hline $2001-05$ & 162 & $-0.14^{a}$ & $-0.27^{b}$ & $-0.24^{a}$ & 0.20 & $0.44^{b}$ & $-0.19^{a}$ & $-0.10^{a}$ & $-0.18^{a}$ & $-0.32^{a}$ & $-0.23^{a}$ & $-0.36^{a}$ \\
\hline$>2000$ & 264 & $-0.17^{a}$ & $-0.54^{a}$ & $-0.38^{a}$ & 0.09 & $0.46^{b}$ & $-0.19^{a}$ & $-0.43^{a}$ & $-0.77^{a}$ & $-0.30^{a}$ & $-0.66^{a}$ & $-1.12^{a}$ \\
\hline All & 842 & 0.38 & -0.08 & $0.00^{a}$ & $-0.23^{a}$ & -0.11 & $0.03^{a}$ & $-0.11^{a}$ & $-0.23^{a}$ & $-0.08^{a}$ & $-0.19^{a}$ & $-0.34^{a}$ \\
\hline
\end{tabular}




\section{Table IV Buyout fund performance: CAPM versus CBAPMs}

This table reports the Net Present Values and excess Net Present Values $(\triangle N P V)$ of buyout fund cash flows for the full sample (row 'All') and by a vintage year group using several discount factors. Columns (2) and (3) report Generalized Public Market Equivalents (GPMEs) following Korteweg and Nagel (2016) who consider discount factors affine in the public equity returns for the general case $(K N)$, and the special case $(K S)$ where market risk premium is restricted to the log-Utility CAPM as per PME of Kaplan and Schoar (2005). Columns (4), (7), and (10) report conceptually same NPV estimates as in column (3) obtained with the discount factor implied by CAPM but using a different procedure to estimate parameters and adjust for the sampling errors. The remaining columns report either $N P V$ or $\triangle N P V$ estimates against consumption-based discount factors implied by the Long-run Risk model of Bansal and Yaron (2004), and the Habit formation model of Campbell and Cochrane (1999). $\triangle N P V$ is the differences between the venture funds' NPV and that of the hypothetical funds (constructed as in Korteweg and Nagel (2016)) invested in CRSP value-weighted index or Fama-French small value portfolio. The estimates statistically significant at 5\%(10\%) are superscripted with ${ }^{a}\left({ }^{b}\right)$. Fund cash flows are normalized to $\$ 1$ commitment and equally weighted. Panel A reports results for all funds in the respective vintage year group. Panel B reports results for funds with inflation-adjusted distributions being at least three times the latest residual NAV reported by the fund. 


\begin{tabular}{|c|c|c|c|c|c|c|c|c|c|c|c|c|}
\hline \multirow[b]{2}{*}{ Vintage } & \multirow[b]{2}{*}{$\begin{array}{c}\text { Funds \# } \\
\text { (1) }\end{array}$} & \multicolumn{2}{|c|}{ GPME } & \multicolumn{3}{|c|}{ NPV } & \multicolumn{3}{|c|}{$\triangle \mathrm{NPV}(\mathrm{crsp})$} & \multicolumn{3}{|c|}{$\Delta \mathrm{NPV}(\mathrm{ff} 6)$} \\
\hline & & $\begin{array}{l}\mathrm{KS} \\
(2)\end{array}$ & $\begin{array}{c}\mathrm{KN} \\
(3)\end{array}$ & $\begin{array}{c}\text { CAPM } \\
(4)\end{array}$ & $\begin{array}{c}\text { LRR } \\
(5)\end{array}$ & $\begin{array}{c}\text { Habit } \\
(6)\end{array}$ & $\begin{array}{c}\text { CAPM } \\
(7)\end{array}$ & $\begin{array}{c}\text { LRR } \\
(8)\end{array}$ & $\begin{array}{l}\text { Habit } \\
(9)\end{array}$ & $\begin{array}{c}\text { CAPM } \\
(10)\end{array}$ & $\begin{array}{c}\text { LRR } \\
(11)\end{array}$ & $\begin{array}{c}\text { Habit } \\
(12)\end{array}$ \\
\hline \multicolumn{13}{|c|}{ Panel A: All buyout funds } \\
\hline$\leq 1985$ & 14 & 1.10 & 0.57 & 0.45 & $-0.32^{a}$ & $-0.38^{a}$ & 0.72 & 0.06 & 0.02 & 0.59 & 0.04 & -0.01 \\
\hline $1986-87$ & 18 & 0.15 & -0.11 & -0.17 & $-0.37^{a}$ & $-0.33^{b}$ & 0.05 & 0.00 & 0.00 & -0.08 & -0.01 & 0.00 \\
\hline $1988-89$ & 25 & 0.06 & -0.16 & $-0.25^{b}$ & $-0.40^{b}$ & -0.37 & 0.00 & -0.05 & -0.04 & -0.14 & -0.08 & -0.06 \\
\hline $1990-91$ & 17 & 0.16 & -0.10 & $-0.19^{b}$ & $-0.41^{a}$ & $-0.38^{b}$ & 0.07 & 0.00 & 0.00 & -0.07 & -0.03 & -0.03 \\
\hline $1992-93$ & 10 & $0.11^{b}$ & -0.17 & $-0.28^{b}$ & $-0.31^{a}$ & -0.34 & 0.04 & 0.00 & 0.00 & -0.06 & -0.01 & -0.01 \\
\hline 1994 & 29 & $0.09^{b}$ & -0.08 & -0.14 & $-0.30^{a}$ & -0.33 & 0.04 & -0.01 & -0.01 & -0.11 & -0.01 & -0.01 \\
\hline 1995 & 33 & $0.08^{b}$ & 0.01 & -0.02 & $-0.29^{a}$ & -0.31 & 0.07 & 0.01 & 0.02 & -0.22 & 0.01 & 0.01 \\
\hline 1996 & 28 & 0.15 & 0.12 & 0.11 & $-0.32^{a}$ & -0.33 & 0.13 & 0.00 & 0.01 & -0.33 & 0.00 & 0.00 \\
\hline 1997 & 44 & $0.17^{a}$ & $0.30^{a}$ & $0.40^{a}$ & -0.27 & -0.25 & $0.26^{a}$ & -0.01 & 0.00 & -0.62 & -0.02 & -0.01 \\
\hline 1998 & 75 & $0.43^{a}$ & $0.67^{a}$ & $0.89^{a}$ & $-0.30^{b}$ & -0.28 & $0.64^{a}$ & 0.01 & 0.00 & $-0.75^{b}$ & -0.04 & -0.02 \\
\hline 1999 & 57 & $0.32^{a}$ & $0.57^{a}$ & $0.84^{a}$ & -0.28 & -0.24 & $0.51^{a}$ & 0.02 & 0.01 & $-1.50^{a}$ & -0.07 & -0.03 \\
\hline 2000 & 78 & $0.84^{a}$ & $7.26^{a}$ & $1.76^{a}$ & $-0.24^{b}$ & $-0.28^{b}$ & $1.56^{a}$ & 0.12 & 0.08 & -0.06 & -0.06 & -0.05 \\
\hline 2001 & 46 & 0.59 & $1.36^{a}$ & $0.60^{a}$ & -0.12 & -0.16 & $0.61^{a}$ & $0.14^{b}$ & 0.12 & 0.17 & 0.01 & 0.01 \\
\hline 2002 & 38 & $0.68^{a}$ & 0.80 & $0.56^{a}$ & $0.07^{b}$ & 0.05 & $0.60^{a}$ & $0.17^{b}$ & 0.16 & $0.39^{a}$ & 0.06 & 0.07 \\
\hline 2003 & 33 & 0.55 & 0.77 & $0.47^{a}$ & $0.36^{a}$ & 0.38 & $0.46^{a}$ & $0.26^{a}$ & $0.27^{a}$ & $0.32^{a}$ & $0.15^{a}$ & $0.18^{a}$ \\
\hline 2004 & 75 & $0.43^{a}$ & $1.05^{a}$ & $0.48^{a}$ & $0.98^{a}$ & $1.54^{b}$ & $0.45^{a}$ & $0.36^{a}$ & $0.49^{a}$ & $0.33^{a}$ & $0.17^{a}$ & $0.24^{a}$ \\
\hline 2005 & 104 & $0.20^{a}$ & 0.40 & 0.12 & $1.67^{a}$ & $3.17^{a}$ & 0.14 & $0.22^{a}$ & $0.43^{a}$ & 0.06 & -0.06 & -0.01 \\
\hline 2006 & 136 & 0.11 & -0.03 & -0.08 & $2.04^{a}$ & $4.28^{a}$ & $0.06^{b}$ & $-0.13^{a}$ & $-0.09^{a}$ & -0.01 & $-0.58^{a}$ & $-0.88^{a}$ \\
\hline 2007 & 144 & $-0.03^{b}$ & $-1.30^{a}$ & $-0.53^{a}$ & $1.45^{a}$ & $3.32^{a}$ & $-0.12^{a}$ & $-1.01^{a}$ & $-1.52^{a}$ & -0.23 & $-1.67^{a}$ & $-2.52^{a}$ \\
\hline 2008 & 128 & $-0.03^{a}$ & $-0.71^{a}$ & $-0.38^{a}$ & 0.09 & $1.11^{a}$ & -0.04 & $-0.63^{a}$ & $-1.29^{a}$ & -0.08 & $-0.90^{a}$ & $-1.80^{a}$ \\
\hline$\leq 2000$ & 438 & 0.36 & $0.44^{a}$ & $0.59^{a}$ & $-0.30^{a}$ & $-0.30^{a}$ & $0.52^{a}$ & 0.02 & 0.01 & $-0.44^{a}$ & -0.03 & -0.02 \\
\hline$\overline{1996-00}$ & 282 & $0.45^{a}$ & $0.70^{a}$ & $0.97^{a}$ & $-0.28^{a}$ & -0.27 & $0.76^{a}$ & 0.04 & 0.02 & $-0.65^{a}$ & -0.05 & -0.02 \\
\hline 2001-05 & 296 & $0.42^{a}$ & $0.80^{a}$ & $0.38^{a}$ & $0.86^{a}$ & $1.53^{b}$ & $0.39^{a}$ & $0.24^{a}$ & $0.34^{a}$ & $0.22^{a}$ & $0.05^{b}$ & $0.09^{b}$ \\
\hline$>2000$ & 704 & $0.19^{a}$ & -0.06 & -0.03 & $1.07^{a}$ & $2.35^{b}$ & 0.14 & $-0.25^{a}$ & $-0.42^{a}$ & 0.03 & $-0.60^{a}$ & $-0.98^{a}$ \\
\hline All & 1,142 & $0.25^{a}$ & $0.45^{b}$ & $0.21^{a}$ & $0.55^{a}$ & 1.34 & $0.29^{a}$ & $-0.14^{a}$ & $-0.25^{b}$ & -0.15 & $-0.38^{a}$ & $-0.61^{b}$ \\
\hline \multicolumn{13}{|c|}{ Panel B: Nearly resolved buyout funds } \\
\hline$\leq 2000$ & 331 & $0.43^{a}$ & 0.50 & $0.68^{a}$ & $-0.30^{a}$ & $-0.30^{a}$ & $0.61^{a}$ & 0.03 & 0.02 & $-0.38^{b}$ & -0.03 & -0.02 \\
\hline 2001 & 39 & $0.64^{a}$ & $0.82^{a}$ & $0.66^{a}$ & -0.13 & -0.18 & $0.70^{a}$ & $0.13^{b}$ & 0.11 & $0.25^{b}$ & 0.00 & 0.00 \\
\hline 2002 & 27 & $0.88^{a}$ & $0.70^{a}$ & $0.74^{a}$ & 0.06 & 0.01 & $0.80^{a}$ & $0.20^{b}$ & 0.17 & $0.55^{a}$ & 0.08 & 0.07 \\
\hline 2003 & 23 & $0.69^{a}$ & $0.68^{a}$ & $0.63^{a}$ & $0.39^{a}$ & 0.38 & $0.62^{a}$ & $0.30^{a}$ & $0.28^{b}$ & $0.47^{a}$ & $0.19^{a}$ & $0.19^{b}$ \\
\hline 2004 & 52 & 0.48 & $0.70^{a}$ & $0.54^{a}$ & $1.03^{a}$ & $1.61^{b}$ & $0.50^{a}$ & $0.42^{a}$ & $0.59^{a}$ & $0.37^{a}$ & $0.24^{a}$ & $0.36^{a}$ \\
\hline 2005 & 52 & 0.31 & $0.55^{a}$ & $0.35^{a}$ & $1.74^{a}$ & $3.01^{a}$ & $0.35^{a}$ & $0.30^{a}$ & $0.33^{b}$ & $0.27^{a}$ & 0.01 & $-0.13^{b}$ \\
\hline 2006 & 59 & $0.17^{a}$ & 0.12 & 0.06 & $2.07^{a}$ & $4.04^{a}$ & 0.21 & $-0.11^{a}$ & $-0.25^{a}$ & 0.13 & $-0.55^{a}$ & $-1.01^{a}$ \\
\hline 2007 & 39 & $-0.19^{b}$ & $-1.02^{a}$ & $-0.60^{a}$ & $1.31^{a}$ & $2.77^{a}$ & $-0.19^{a}$ & $-1.46^{a}$ & $-2.54^{a}$ & -0.31 & $-2.29^{a}$ & $-3.82^{a}$ \\
\hline 2008 & 27 & $-0.15^{b}$ & $-0.78^{b}$ & $-0.49^{a}$ & 0.00 & $0.82^{b}$ & $-0.09^{a}$ & $-0.79^{a}$ & $-1.56^{a}$ & -0.15 & $-1.15^{a}$ & $-2.18^{a}$ \\
\hline $1996-00$ & 216 & $0.50^{a}$ & $0.74^{a}$ & $1.08^{a}$ & $-0.28^{a}$ & $-0.27^{b}$ & $0.85^{a}$ & 0.04 & 0.03 & $-0.58^{b}$ & -0.04 & -0.02 \\
\hline $2001-05$ & 193 & $0.55^{a}$ & $0.68^{a}$ & $0.55^{a}$ & $0.77^{a}$ & $1.26^{b}$ & $0.55^{a}$ & $0.28^{a}$ & $0.33^{b}$ & $0.36^{a}$ & $0.10^{a}$ & 0.09 \\
\hline$>2000$ & 318 & $0.33^{a}$ & 0.24 & 0.23 & $1.01^{a}$ & $1.92^{b}$ & $0.34^{a}$ & $-0.09^{a}$ & $-0.29^{a}$ & $0.19^{b}$ & $-0.42^{a}$ & $-0.79^{a}$ \\
\hline All & 649 & $0.38^{a}$ & $0.52^{a}$ & $0.46^{a}$ & $0.35^{b}$ & 0.79 & $0.48^{a}$ & $-0.03^{b}$ & $-0.13^{b}$ & -0.10 & $-0.22^{a}$ & -0.39 \\
\hline
\end{tabular}




\section{Table V \\ Generalist fund performance: CAPM versus CBAPMs}

This table reports the Net Present Values and excess Net Present Values ( $\triangle N P V)$ of PE funds that are classified as 'generalists' and 'expansion capital' (rather than 'buyout' and 'venture'). Columns (2) and (3) report Generalized Public Market Equivalents (GPMEs) following Korteweg and Nagel (2016) who consider discount factors affine in the public equity returns for the general case $(K N)$, and the special case $(K S)$ where market risk premium is restricted to the log-Utility CAPM as per PME of Kaplan and Schoar (2005). Columns (4), (7), and (10) report conceptually same NPV estimates as in column (3) obtained with the discount factor implied by CAPM but using a different procedure to estimate parameters and adjust for the sampling errors. The remaining columns report either $N P V$ or $\triangle N P V$ estimates against consumption-based discount factors implied by the Long-run Risk model of Bansal and Yaron (2004), and the Habit formation model of Campbell and Cochrane (1999). $\triangle N P V$ is the differences between the venture funds' NPV and that of the hypothetical funds (constructed as in Korteweg and Nagel (2016)) invested in CRSP value-weighted index or Fama-French small value portfolio. The estimates statistically significant at 5\%(10\%) are superscripted with ${ }^{a}\left({ }^{b}\right)$. Fund cash flows are normalized to $\$ 1$ commitment and equally weighted. Panel A reports results for all funds in the respective vintage year group. Panel B reports results for sufficiently resolved funds only.

\begin{tabular}{|c|c|c|c|c|c|c|c|c|c|c|c|c|}
\hline \multirow[b]{2}{*}{ Vintage } & \multirow[b]{2}{*}{$\begin{array}{c}\text { Funds \# } \\
\text { (1) }\end{array}$} & \multicolumn{2}{|c|}{ GPME } & \multicolumn{3}{|c|}{ NPV } & \multicolumn{3}{|c|}{$\Delta \mathrm{NPV}(\mathrm{crsp})$} & \multicolumn{3}{|c|}{$\Delta \mathrm{NPV}(\mathrm{ff6})$} \\
\hline & & $\begin{array}{l}\text { KS } \\
(2)\end{array}$ & $\begin{array}{c}\mathrm{KN} \\
(3)\end{array}$ & $\begin{array}{c}\text { CAPM } \\
(4)\end{array}$ & $\begin{array}{c}\text { LRR } \\
(5)\end{array}$ & $\begin{array}{l}\text { Habit } \\
(6)\end{array}$ & $\begin{array}{c}\text { CAPM } \\
(7)\end{array}$ & $\begin{array}{c}\text { LRR } \\
(8)\end{array}$ & $\begin{array}{l}\text { Habit } \\
(9)\end{array}$ & $\begin{array}{c}\text { CAPM } \\
(10)\end{array}$ & $\begin{array}{c}\text { LRR } \\
(11)\end{array}$ & $\begin{array}{c}\text { Habit } \\
(12)\end{array}$ \\
\hline \multicolumn{13}{|c|}{ Panel A: All funds } \\
\hline$\leq 1989$ & 16 & 0.02 & -0.33 & $-0.35^{a}$ & $-0.49^{a}$ & $-0.45^{a}$ & $-0.09^{a}$ & -0.02 & -0.01 & -0.27 & -0.04 & -0.03 \\
\hline$\overline{1990-95}$ & 44 & $0.34^{a}$ & -0.11 & $-0.15^{a}$ & $-0.41^{a}$ & $-0.42^{a}$ & 0.12 & -0.01 & -0.01 & -0.03 & -0.02 & -0.02 \\
\hline 1996-00 & 99 & $0.29^{a}$ & $0.67^{a}$ & $0.70^{a}$ & $-0.31^{a}$ & $-0.30^{b}$ & $0.47^{a}$ & $0.03^{b}$ & 0.02 & $-1.06^{a}$ & -0.06 & -0.03 \\
\hline $2001-03$ & 31 & $0.27^{a}$ & 0.74 & $0.23^{a}$ & -0.03 & -0.06 & $0.27^{a}$ & $0.12^{a}$ & $0.09^{b}$ & -0.07 & -0.03 & -0.03 \\
\hline 2004-05 & 38 & $0.29^{a}$ & $0.99^{b}$ & $0.33^{b}$ & $1.44^{a}$ & $2.48^{a}$ & $0.26^{b}$ & $0.32^{a}$ & $0.50^{a}$ & $0.16^{b}$ & $0.10^{a}$ & $0.16^{b}$ \\
\hline 2006 & 41 & 0.17 & 0.28 & 0.04 & $2.57^{a}$ & $5.09^{a}$ & 0.14 & $0.11^{b}$ & $0.30^{a}$ & 0.06 & $-0.37^{a}$ & $-0.50^{a}$ \\
\hline 2007 & 54 & $-0.15^{a}$ & $-1.57^{a}$ & $-0.66^{a}$ & $1.34^{a}$ & $3.25^{a}$ & $-0.23^{a}$ & $-1.34^{a}$ & $-1.99^{a}$ & -0.35 & $-2.11^{a}$ & $-3.15^{a}$ \\
\hline 2008 & 43 & $-0.10^{a}$ & $-0.85^{a}$ & $-0.45^{a}$ & $0.36^{b}$ & $1.61^{a}$ & $-0.08^{b}$ & $-0.71^{a}$ & $-1.21^{a}$ & -0.12 & $-1.06^{a}$ & $-1.81^{a}$ \\
\hline$\leq 2000$ & 159 & $0.27^{a}$ & $0.35^{a}$ & $0.36^{a}$ & $-0.36^{a}$ & $-0.35^{a}$ & $0.32^{a}$ & 0.02 & 0.01 & $-0.70^{a}$ & -0.04 & -0.03 \\
\hline $2001-05$ & 69 & $0.28^{a}$ & $0.88^{b}$ & $0.28^{a}$ & $0.78^{a}$ & $1.34^{b}$ & $0.27^{a}$ & $0.23^{a}$ & $0.31^{a}$ & 0.06 & $0.04^{b}$ & $0.07^{b}$ \\
\hline$>2000$ & 207 & 0.06 & -0.24 & $-0.17^{a}$ & $1.19^{a}$ & $2.64^{b}$ & 0.04 & $-0.40^{a}$ & $-0.60^{a}$ & -0.09 & $-0.83^{a}$ & $-1.27^{a}$ \\
\hline All & 366 & $0.16^{a}$ & 0.33 & 0.06 & $0.52^{b}$ & $1.34^{b}$ & $0.16^{a}$ & $-0.22^{a}$ & $-0.34^{b}$ & $-0.35^{a}$ & $-0.49^{a}$ & $-0.73^{b}$ \\
\hline \multicolumn{13}{|c|}{ Panel B: Nearly resolved funds } \\
\hline$\leq 2000$ & 127 & $0.33^{a}$ & $0.42^{a}$ & $0.40^{a}$ & $-0.36^{a}$ & $-0.35^{a}$ & $0.37^{a}$ & 0.02 & 0.01 & $0.27^{a}$ & 0.02 & 0.01 \\
\hline$\overline{2} 001-03$ & 22 & $0.39^{a}$ & $0.44^{b}$ & $0.33^{a}$ & -0.04 & -0.07 & $0.39^{a}$ & $0.18^{a}$ & $0.14^{b}$ & $0.24^{b}$ & $0.11^{a}$ & 0.08 \\
\hline 2004-05 & 26 & $0.31^{a}$ & $0.55^{a}$ & 0.34 & $1.48^{a}$ & $2.54^{b}$ & 0.30 & $0.33^{a}$ & $0.45^{b}$ & 0.18 & 0.11 & 0.11 \\
\hline 2006 & 22 & -0.02 & 0.05 & -0.06 & $1.85^{a}$ & $3.63^{a}$ & 0.04 & $-0.49^{a}$ & $-0.79^{a}$ & -0.10 & $-1.02^{a}$ & $-1.70^{a}$ \\
\hline 2007 & 19 & $-0.34^{b}$ & $-1.18^{a}$ & $-0.79^{a}$ & $0.97^{b}$ & $2.57^{a}$ & $-0.36^{a}$ & $-2.26^{a}$ & $-3.49^{a}$ & $-0.53^{a}$ & $-3.17^{a}$ & $-4.87^{a}$ \\
\hline 2008 & 13 & $-0.27^{b}$ & $-0.77^{b}$ & $-0.56^{a}$ & $-0.51^{a}$ & -0.19 & $-0.16^{a}$ & $-0.96^{a}$ & $-1.68^{a}$ & $-0.22^{a}$ & $-1.22^{a}$ & $-2.14^{a}$ \\
\hline 2001-05 & 48 & $0.35^{a}$ & $0.50^{a}$ & $0.34^{a}$ & $0.79^{a}$ & $1.34^{b}$ & $0.34^{a}$ & $0.26^{a}$ & $0.31^{b}$ & 0.21 & $0.11^{b}$ & 0.10 \\
\hline$>2000$ & 102 & 0.06 & -0.07 & -0.07 & $0.89^{a}$ & $1.87^{b}$ & 0.08 & $-0.53^{a}$ & $-0.89^{a}$ & $-0.05^{a}$ & $-0.91^{a}$ & $-1.50^{a}$ \\
\hline All & 229 & $0.21^{a}$ & $0.30^{a}$ & $0.19^{a}$ & 0.20 & 0.64 & $0.24^{a}$ & $-0.22^{a}$ & $-0.39^{a}$ & 0.13 & $-0.40^{a}$ & $-0.66^{b}$ \\
\hline
\end{tabular}


Figure 1. Key findings

This figure graphs the main findings of this study. The bars are the estimates of expected NPV per dollar invested in, respectively, venture, generalist and buyout funds according to two types of asset pricing models: CAPM and consumption-based ones. Log Utility CAPM corresponds to the assumption implied in the computation of PME of Kaplan and Schoar (2005), whereas Unrestricted CAPM builds on the method of Korteweg and Nagel (2016). Long-run Risk and External Habit formation models are of Campbell and Cochrane (1999) and Bansal and Yaron (2004) respectively. See panel A of tables $\mathrm{V}, \mathrm{IV}$, and $\mathrm{V}$ for detail. The estimates reported in this figure correspond to those in columns (2) and (7) through (9).
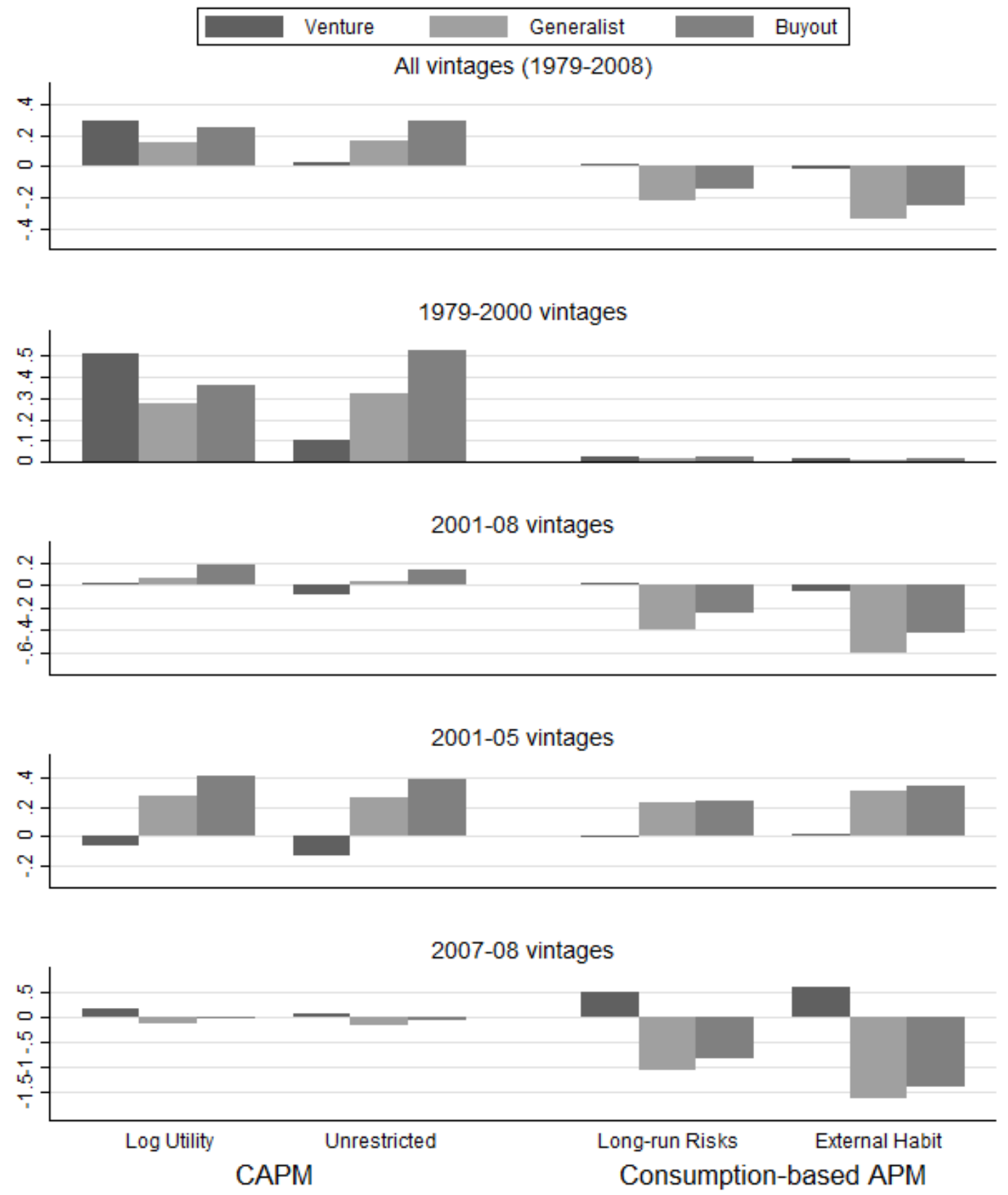
Figure 2. Private equity cash flows and SDF changes: 2005-16

This figure compares cash flows and residual NAVs of venture funds incepted during 2005-06 (2007-08) with in Panel A (B) with those of respective buyout funds. In both panels, the fund-level values are normalized by the fund's commitment size and then averaged over the respective quarter. Panel $\mathrm{C}$ plots the cumulative change since to the discount factors implied by CAPM, Long Run Risk model (Bansal and Yaron (2004)) and Habit formation model (Campbell and Cochrane (1999)) during 2005-2016.

Panel A: 2005-06 vintage funds

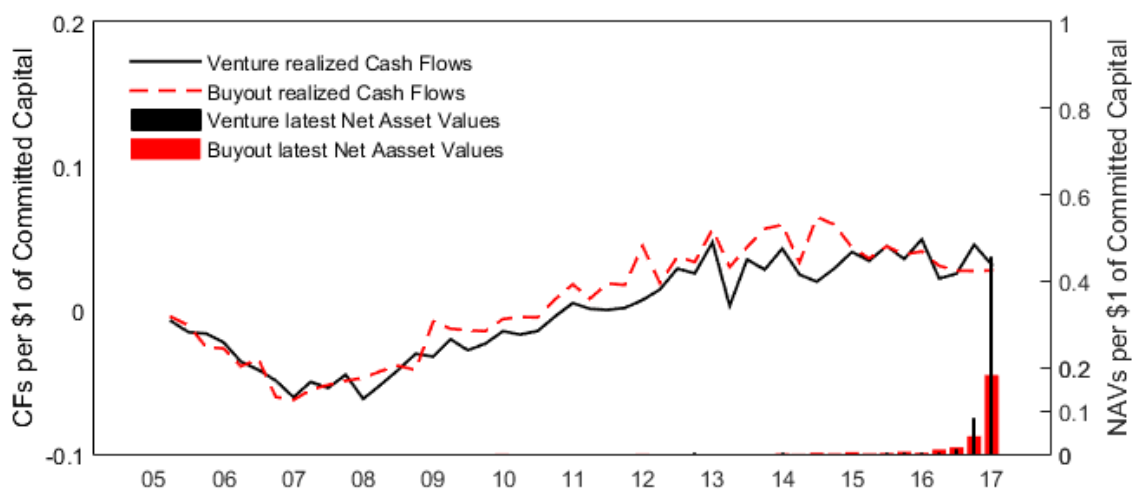

Panel B: 2007-08 vintage funds

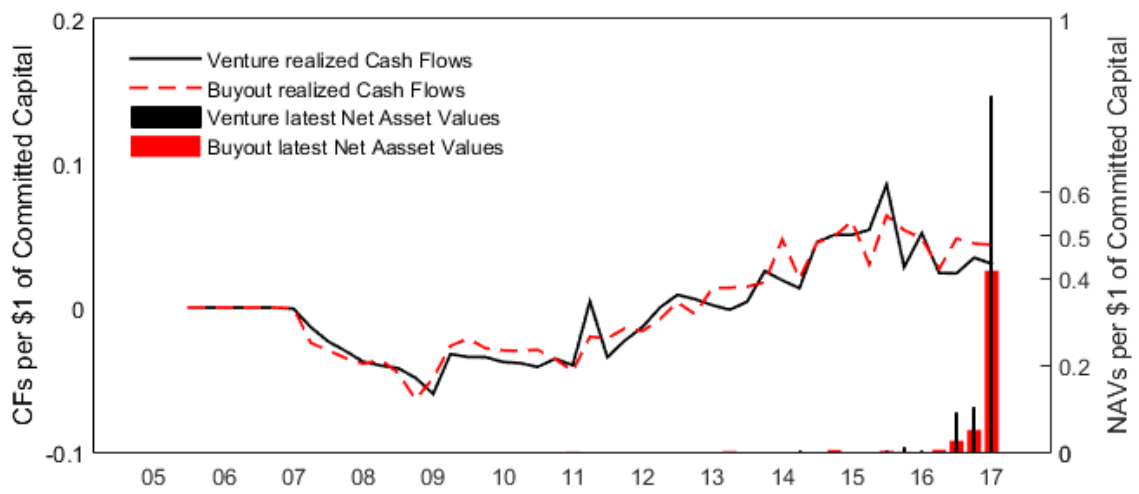

Panel C: Cumulative SDF change

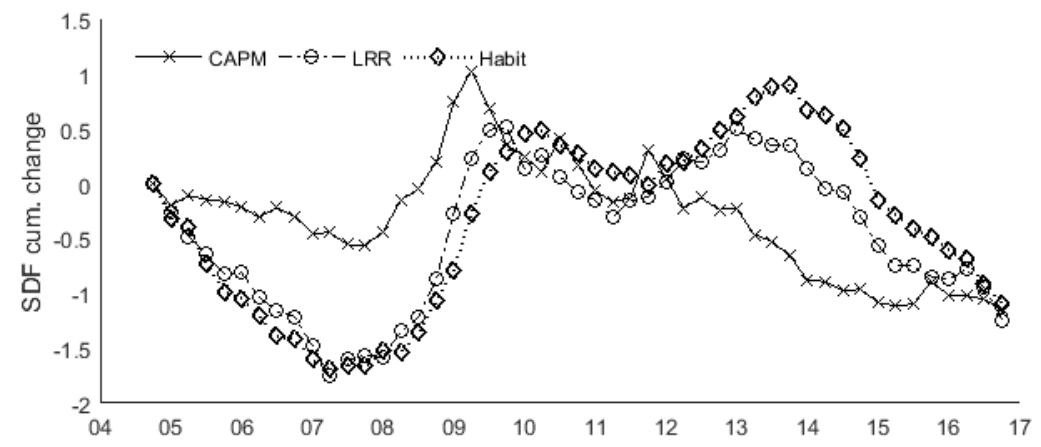


Figure 3. Consumption-based Discount Factors and the Marginal Utility of Core PE sponsors

This figure plots the annual changes in log-SDF implied by Bansal and Yaron (2004) Long Run Risk model and estimated following Colacito and Croce (2011) and Campbell and Cochrane (1999) as estimated in Ghosh, Julliard, and Taylor (2016). Those changes (negated and standardized for convenience) are plotted against the growth in aggregate contributions to pension funds and university endowments, also demeaned and normalized by standard deviations. $\triangle$.UEdw (Agg. Gifts) is the real growth rate of gifts to US institutional endowment funds obtained from the Council for Financial Aid to Education. $\triangle . S P P$ (Ave. Cont. is the growth rate of contributions to state pension plans, equally weighted by assets, obtained from the Center for Retirement Research at Boston College. All variables are adjusted for inflation.

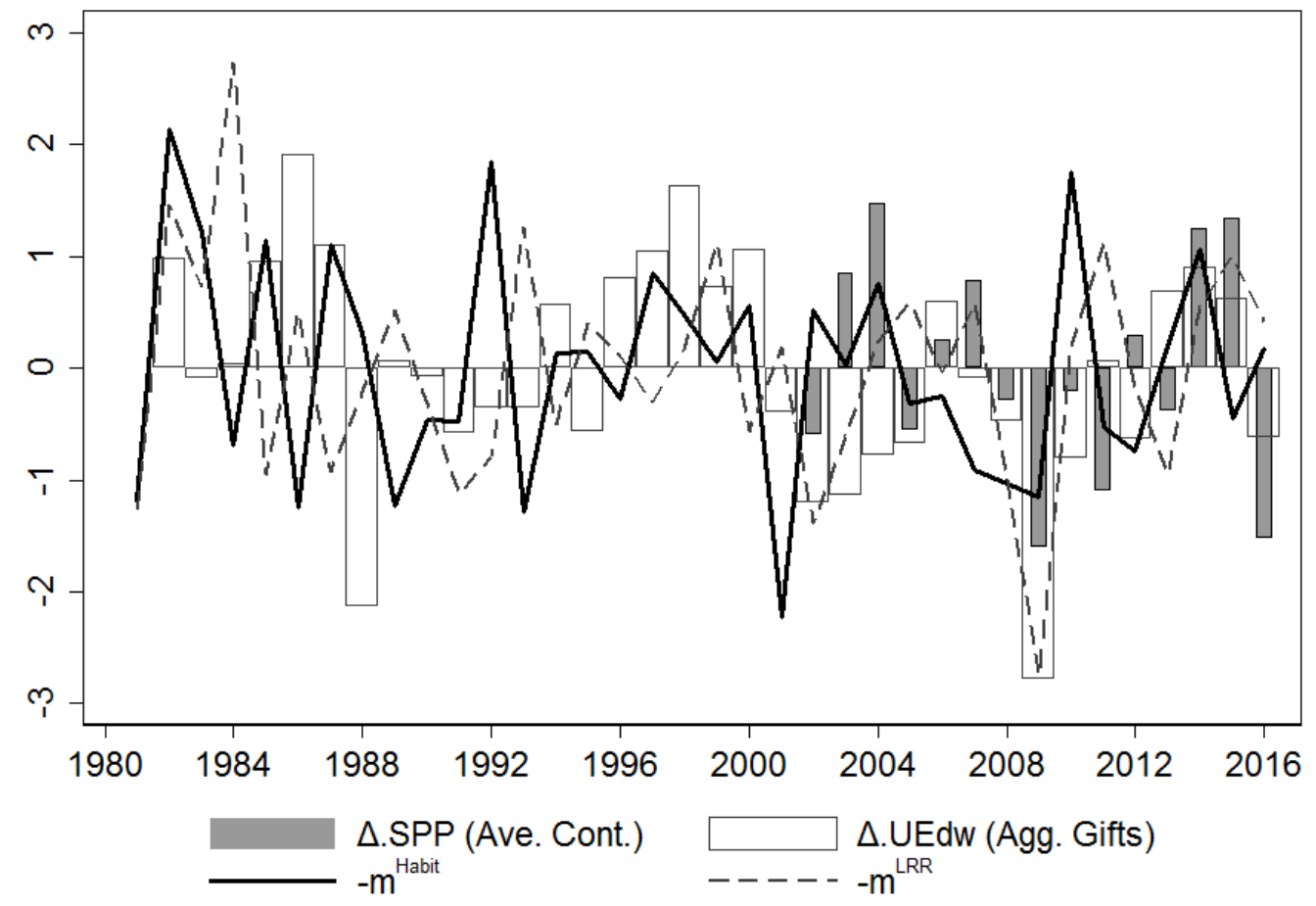


Figure 4. Macro drivers for the CAPM changes during 2005-2016

This figure plots cumulative quarterly changes in log-SDF implied by CAPM, Long Run Risk, and Habit formation models between 2005 and 2016.

Panel A. Cumulative SDF Changes: 2005--16

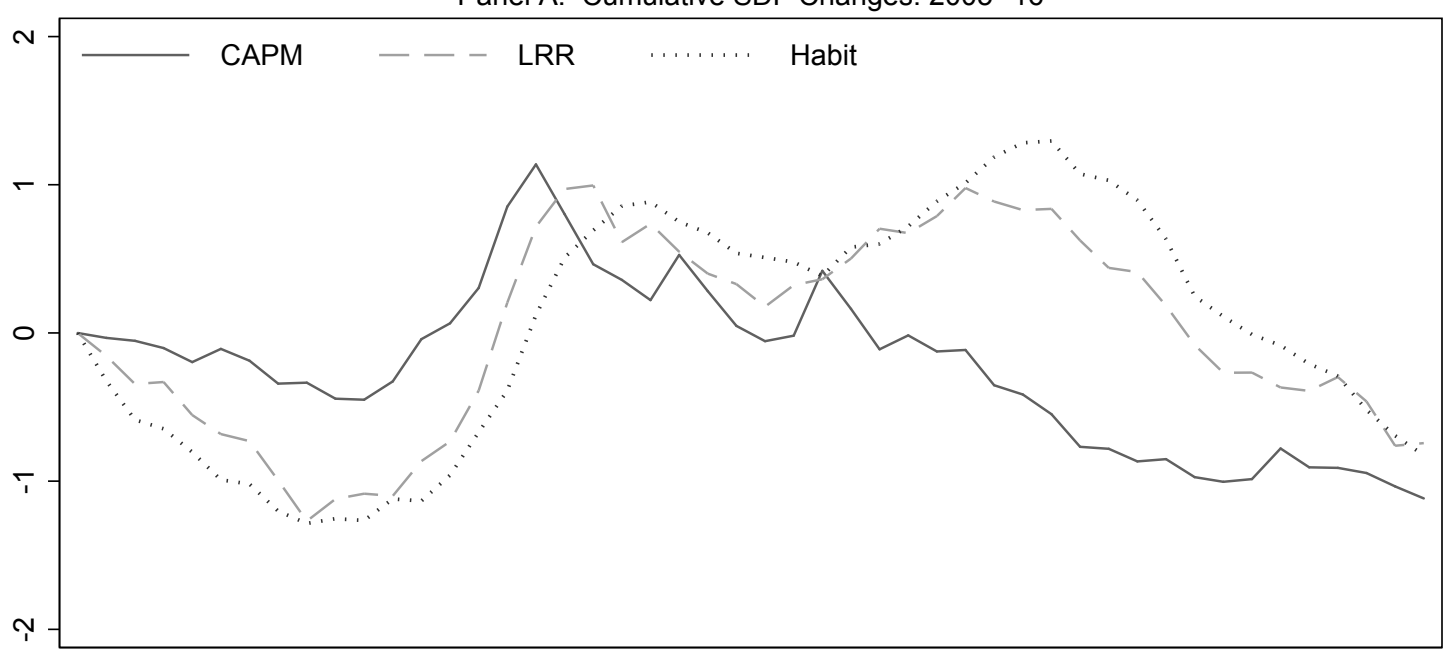

Panel B. Contribution to LRR SDF changes

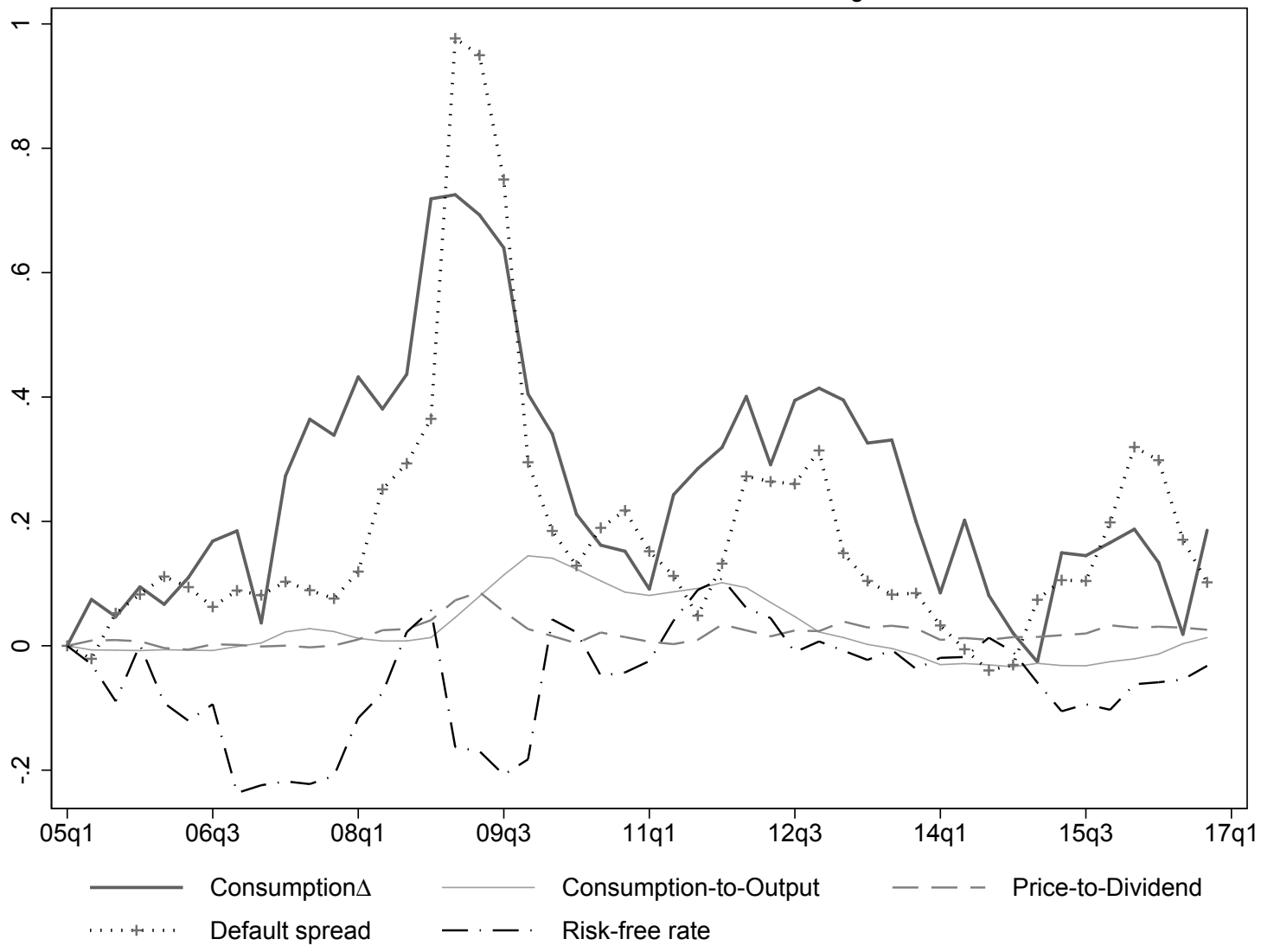


Figure 5. Pseudo funds' NAVs

This figure plots pseudo funds NAVs of PE funds (value-weighted by fund size) computed as of the end-of-month values of capital calls if those were invested in a value-weighted CRSP index net of hypothetical distributions. The hypothetical distributions are non-zero if the actual funds had non-zero distribution with the magnitude determined following Korteweg and Nagel (2016): $\min \left(\frac{t_{j}-t_{p}}{40-t_{p}}, 1\right)$, where $t_{j}$ and $t_{p}$ are, respectively, the current quarter and the previous quarter with non-zero distribution. The solid line reflect series based on $\$$-values adjusted for inflation. The dashed line reflect series normalized by the market capitalization of the CRSP index.

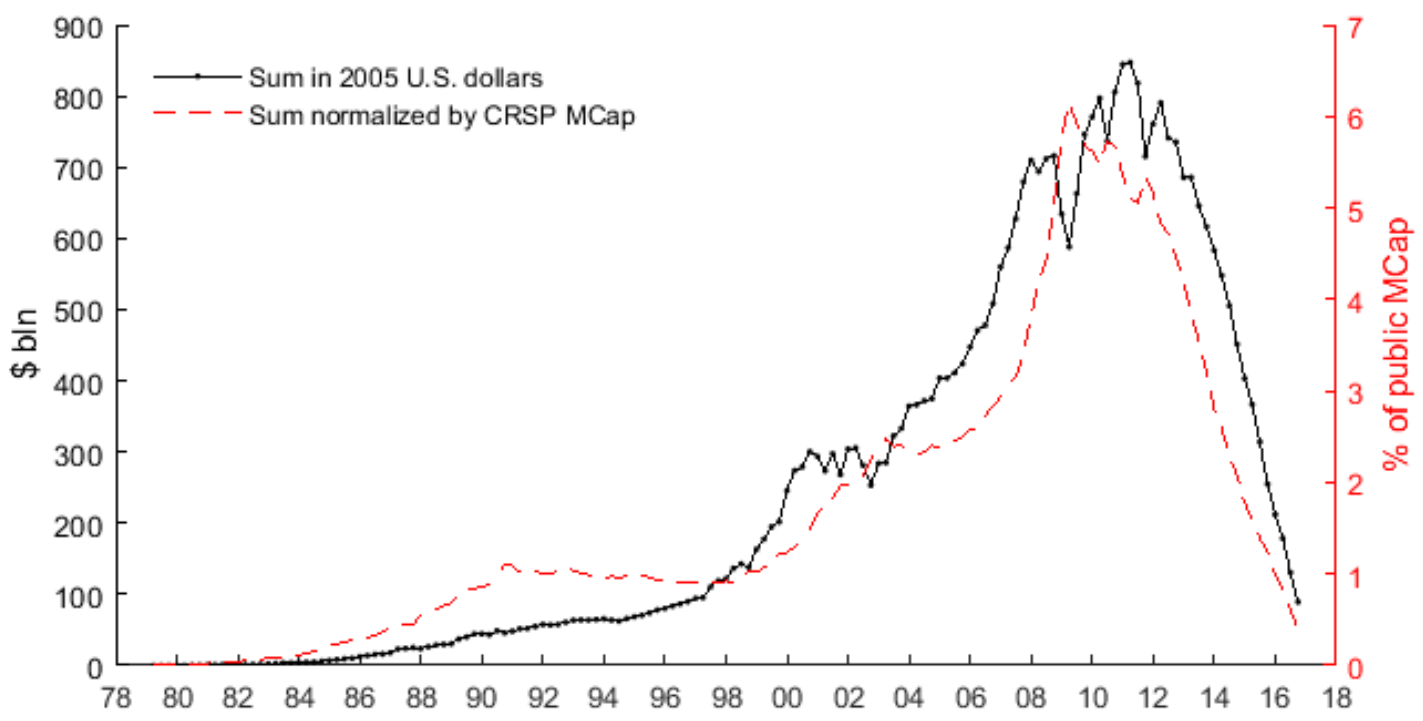


Figure 6. Venture fund performance in excess of public equities

This figure plots venture fund performance by vintage year against the log-utility CAPM (KS.GPME), the discount factors implied by unrestricted CAPM, the Long-run Risk model of Bansal and Yaron (2004), and the Habit formation model of Campbell and Cochrane (1999) adjusted for the NPV of similarly timed public investments. Panel A reports results net of value-weighted CRSP index, Panel B - Fama-French Small Value stocks. Fund cash flows are normalized to $\$ 1$ commitment and equally weighted.

Panel A: $\triangle \mathrm{NPV}$ versus CRSP market index

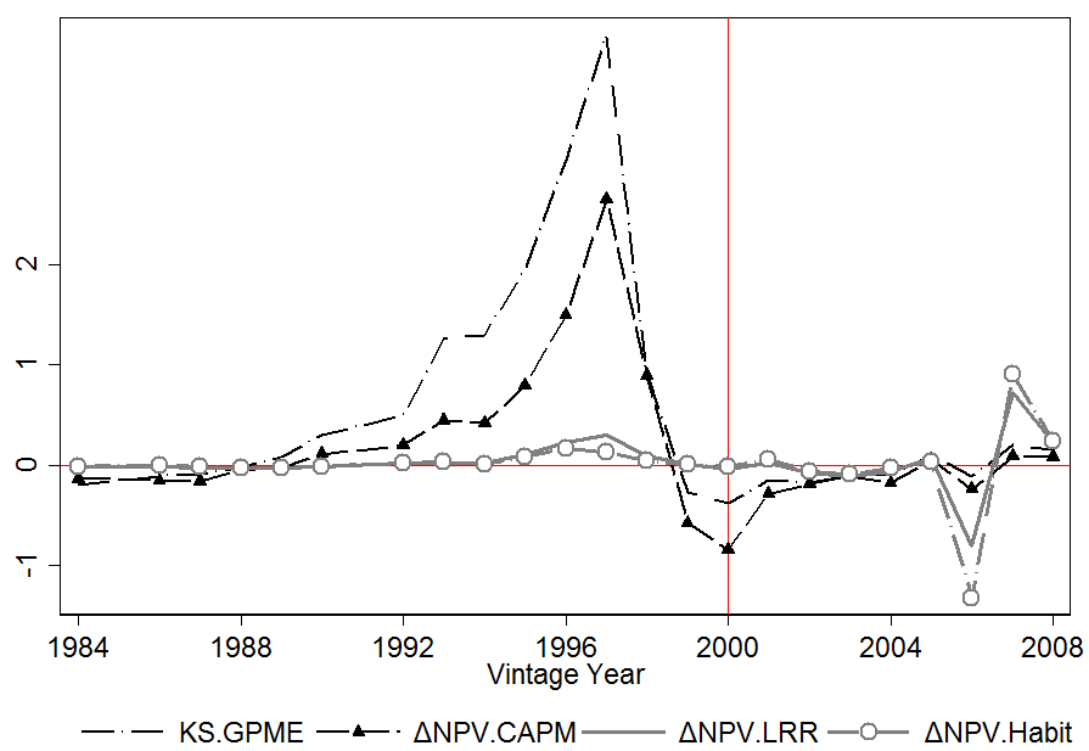

Panel B: $\triangle \mathrm{NPV}$ versus Small Growth

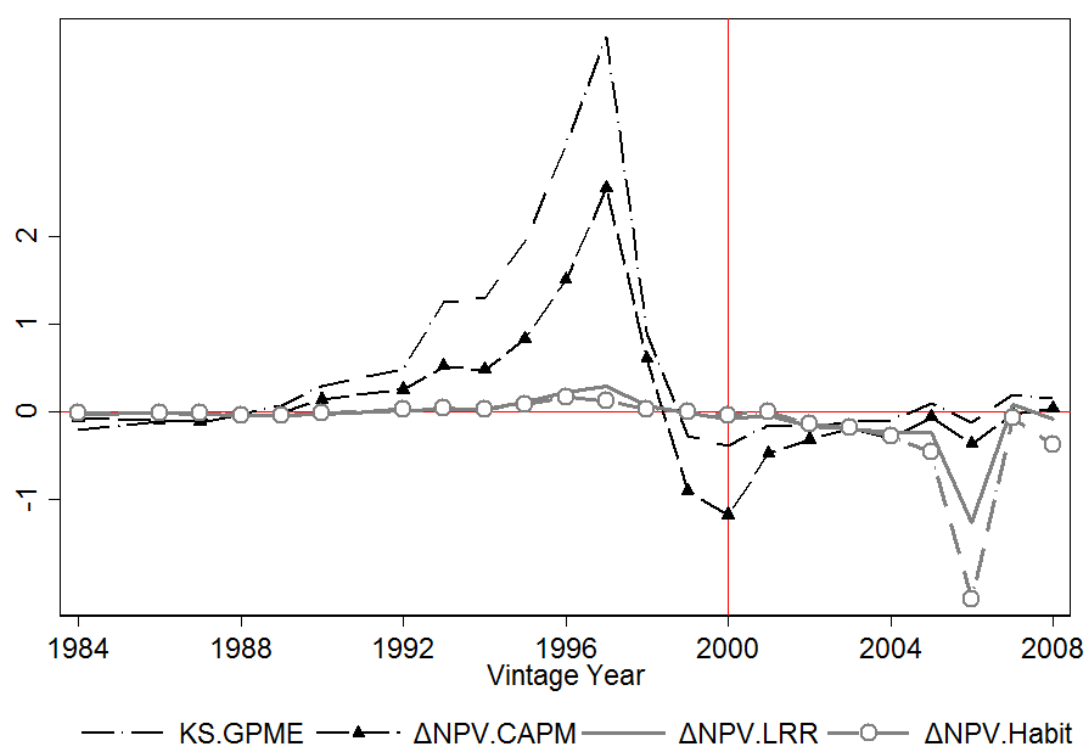


Figure 7. Buyout fund performance in excess of public equities

This figure plots venture fund performance by vintage year against the log-utility CAPM (KS.GPME), and the discount factors implied by unrestricted CAPM, the Long-run Risk model of Bansal and Yaron (2004), and the Habit formation model of Campbell and Cochrane (1999) adjusted for the NPV of similarly timed public investments. Panel A reports results net of valueweighted CRSP index, Panel B - Fama-French Small Value stocks. Fund cash flows are normalized to $\$ 1$ commitment and equally weighted.

Panel A: $\triangle \mathrm{NPV}$ versus CRSP market index

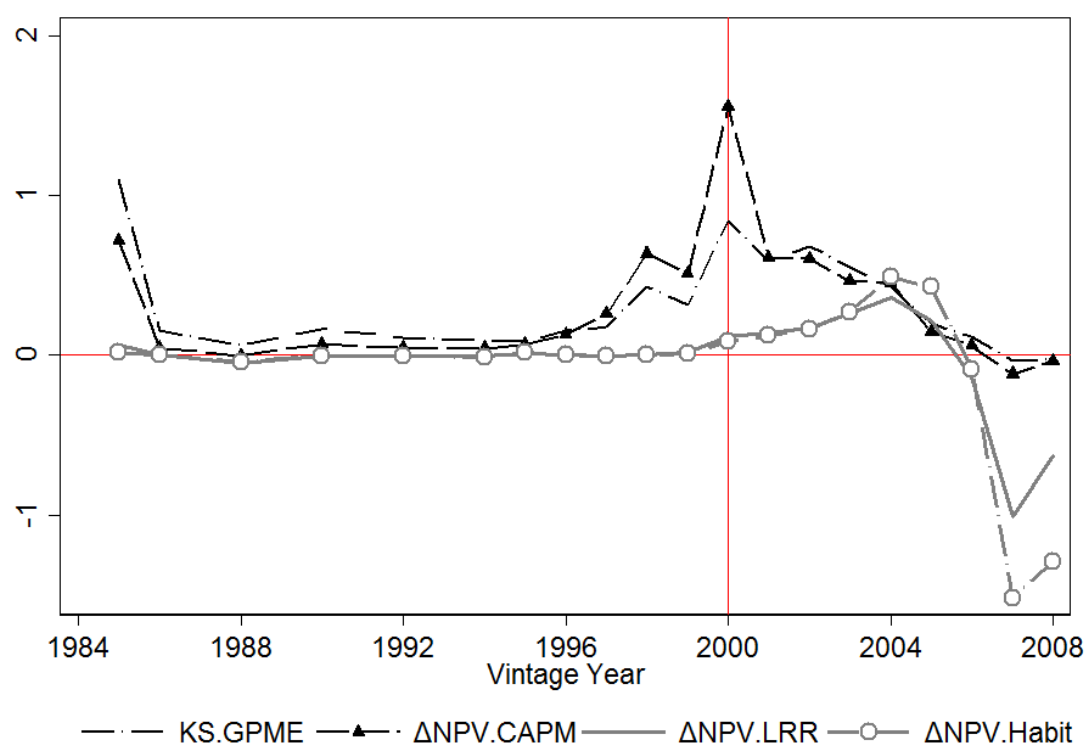

Panel B: $\triangle$ NPV versus Small Value

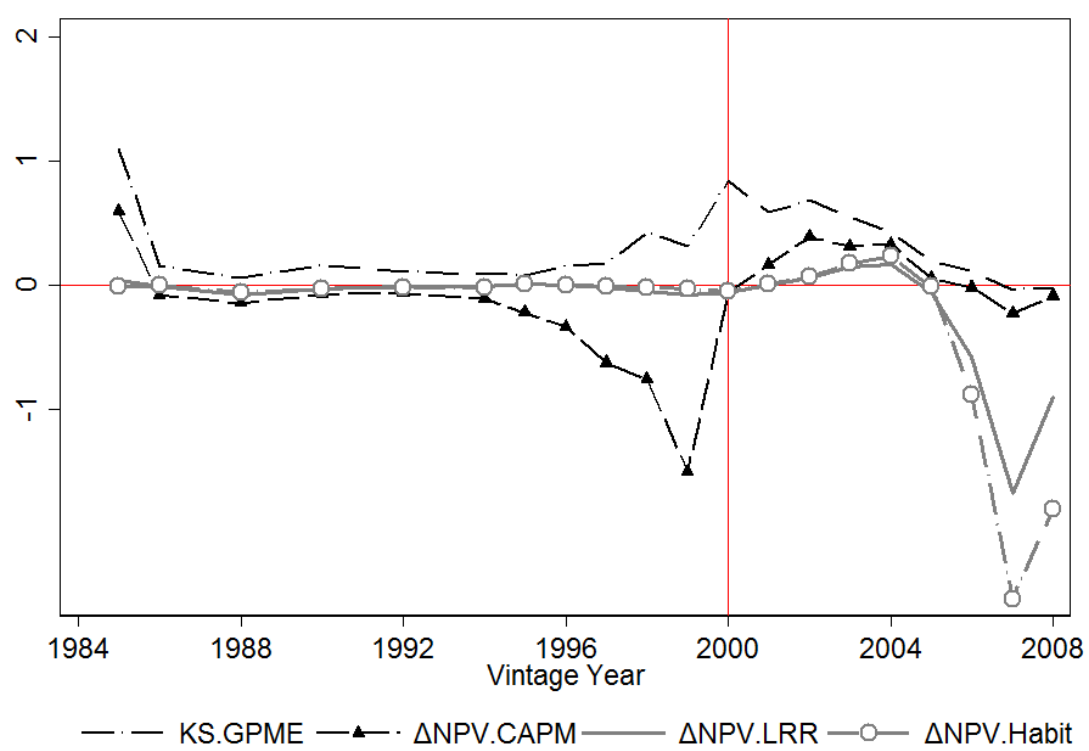


Figure 8. Model calibration effects and the performance against style\&size benchmarks

This figure compares excess Net Present Value ( $\Delta . \mathrm{NPV})$ estimates for all and nearly resolved funds across different fund types for two Long-run Risk SDF parameter values. $\gamma=10.5 \mid \rho=0.95$ refers to the baseline calibration and estimates from Table [I], while $\gamma=7 \mid \rho=0.9383$, besides imposing a lower coefficient of relative risk aversion, assumes lower persistence in the Long-run risk factor, following the calibration in Ghosh, Julliard, and Taylor (2016). $\Delta$.NPV is the average per dollar of capital committed against the respective style\&size public benchmarks - small growth for venture, and small value for generalists and buyout funds. Panel A plots results for the full sample (1979-2008 vintage years), whereas Panel B plot the results for 2007-2008 vintage years only.

Panel A: All vintages

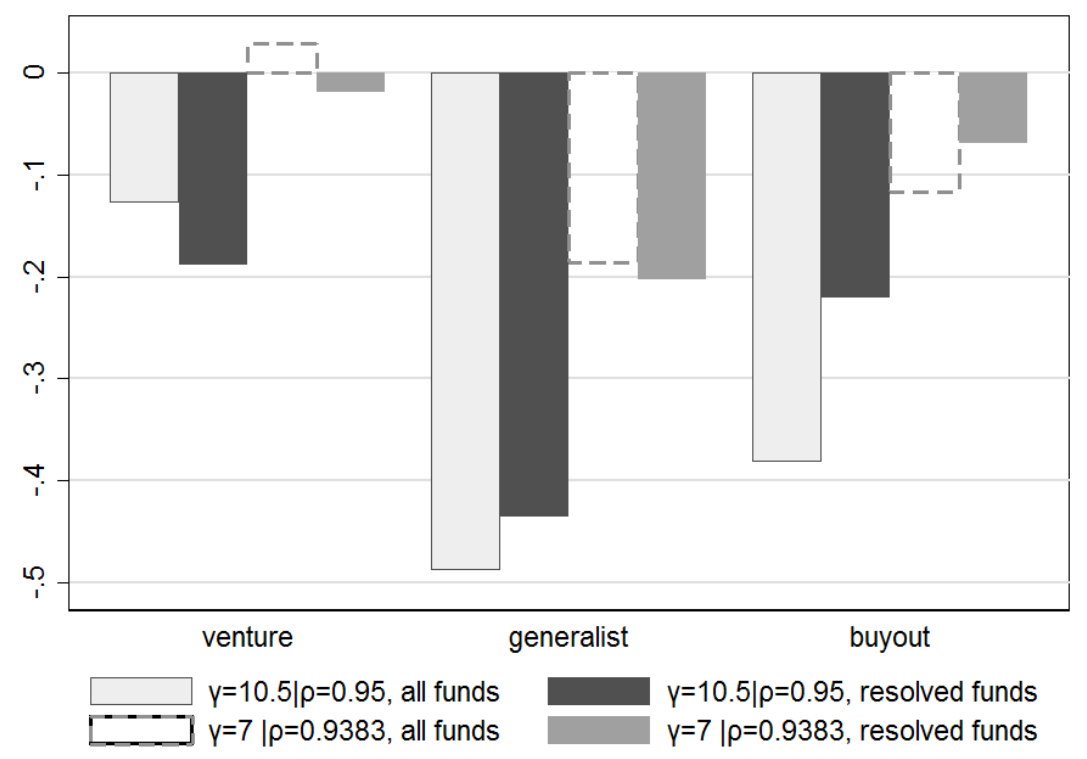

Panel B: 2007-2008 vintages

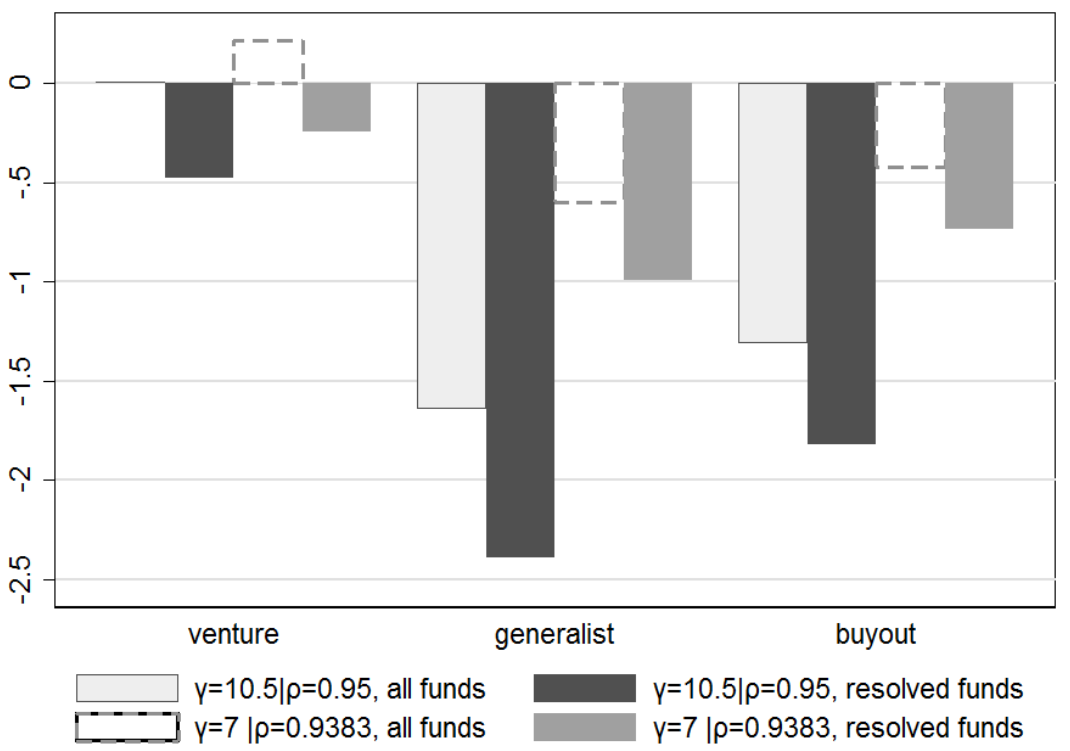




\section{Appendix A. Additional details on methodology}

\section{Appendix A.1. Proofs}

PROPOSITION 1 (Compounding Error bias): The NPV-based test per 4 is biased relatively to the returns-based test 3 even if the SDF is exponentially affine. The magnitude and direction of the bias are not explained by the duration of the funds alone but also depend on the compounding of pricing errors.

Proof. Consider a population of 3-period funds with perfectly overlapping lives that make a single capital call of $\$ 1$ in the beginning of the first period, earn $R_{i 1}, R_{i 2}$, and $R_{i 3}$ gross return on their assets during the first, second, and third, and distribute all capital in the end of the third period . The SDF realization are, respectively, $M_{1}, M_{2}$, and $M_{3}$.

Plugging $z_{0}=z_{1}=z_{2}=1, \delta_{i 0}=-1, \delta_{i 1}=0, \delta_{i 2}=0, \delta_{i 3}=1$ in equations (3) 4 ) and dropping $i$ superscript to reduce notation clatter, we get the following difference between the statistics of the tests (4) and (3):

$$
\begin{aligned}
N \operatorname{Vbias}_{T=3} & :=\mathbb{E}\left[R_{1} R_{2} R_{3} M_{1} M_{2} M_{3}-1\right]-\frac{1}{3}\left(\mathbb{E}\left[R_{1} M_{1}-1\right]+\mathbb{E}\left[R_{2} M_{2}-1\right]+\mathbb{E}\left[R_{3} M_{3}-1\right]\right) \\
& =\mathbb{E}\left[R_{1} M_{1} \cdot R_{2} M_{2} \cdot R_{3} M_{3}\right]-\frac{1}{3} \sum_{k=1}^{3} \mathbb{E}\left[R_{k} M_{k}\right] \\
& =\mathbb{E}\left[\left(e_{1}+1\right)\left(e_{2}+1\right)\left(e_{3}+1\right)\right]-\frac{\sum_{k=1}^{3} \mathbb{E}\left[e_{k}\right]}{3}-\frac{3}{3} \\
& =\mathbb{E}\left[e_{1} e_{2} e_{3}+e_{1} e_{2}+e_{1} e_{3}+e_{1}+e_{2} e_{3}+e_{2}+e_{3}+1\right]-\frac{\sum_{k=1}^{3} \mathbb{E}\left[e_{k}\right]}{3}-1 \\
& =\frac{2}{3} \sum_{k=1}^{3} \mathbb{E}\left[e_{k}\right]+\mathbb{E}\left[e_{1} e_{2} e_{3}\right]+\mathbb{E}\left[e_{1} e_{2}\right]+\mathbb{E}\left[e_{1} e_{3}\right]+\mathbb{E}\left[e_{2} e_{3}\right] .
\end{aligned}
$$

Similarly, for a 4-period funds, the inference bias is:

$$
\begin{aligned}
& N P \text { Vias }_{T=4}:=\frac{3}{4} \sum_{k=1}^{4} \mathbb{E}\left[e_{k}\right]+ \\
& +\mathbb{E}\left[e_{1} e_{2} e_{3} e_{4}\right]+\mathbb{E}\left[e_{1} e_{2}\right]+\mathbb{E}\left[e_{1} e_{3}\right]+\mathbb{E}\left[e_{1} e_{4}\right]+\mathbb{E}\left[e_{2} e_{3}\right]+\mathbb{E}\left[e_{2} e_{4}\right]+\mathbb{E}\left[e_{2} e_{5}\right]+ \\
& +\mathbb{E}\left[e_{1} e_{2} e_{3}\right]+\mathbb{E}\left[e_{1} e_{2} e_{4}\right]+\mathbb{E}\left[e_{2} e_{3} e_{4}\right]+\mathbb{E}\left[e_{2} e_{3} e_{5}\right]
\end{aligned}
$$

and for a more general case of $T$-periods funds,

$$
\begin{array}{rlr}
\operatorname{NPVbias}_{T}:= & \frac{(T-1)}{T} \sum_{k=1}^{4} \mathbb{E}\left[e_{k}\right]+ & \text {-duration difference } \\
& +\mathbb{E}\left[\prod_{k=1}^{T} e_{k}\right]+\frac{1}{2} \mathbb{E}\left[\sum_{k=1}^{T} \sum_{j \neq k}^{T} e_{k} e_{j}\right]+\mathbb{E}\left[\sum_{n=3}^{T-2} C^{e}(T-1, n)\right] . & \text {-compounding error }
\end{array}
$$

, where $C^{e}(T, t)$ demotes a permutation term, e.g., $C^{e}(5,4)=e_{1} e_{2} e_{3} e_{4}+e_{1} e_{2} e_{3} e_{5}+e_{1} e_{2} e_{4} e_{5}+$ $e_{1} e_{3} e_{4} e_{5}+e_{2} e_{3} e_{4} e_{5}$. 
With not fully overlapping fund lives and interim distributions, $e_{k}$-terms simply get scaled by the cross-sectional expectation of $\delta_{i t}$, which can also be autocorrelated and cross-autocorrelated with $e_{k}$.

PROPOSITION 2 (Cash flow-based moments equivalence): The benchmark NPV restriction per 7 is equivalent to the benchmark return restriction 1, in which the instrument, $z_{t}$, is either less efficient or correlated with the pricing error, $e_{t+1}^{B}$.

Proof. Using the mapping definition per 7, rewrite the expectation of $N P V\left(\theta_{C B}\right)_{i}^{b}$ as follows:

$$
\begin{aligned}
\mathbb{E}\left[N P V_{i}^{B}\left(\theta_{C B}\right)\right]= & E\left[\sum_{t=s(i)}^{T(i)} C_{i t}^{b} \prod_{\tau=s(i)}^{t} M_{\tau}\left(\theta_{C B}\right)\right] \\
= & \mathbb{E}\left[z_{t-1}^{\prime}\left(R_{t}^{b} \cdot M_{t}\left(\theta_{C B}\right)-1\right) \cdot c M_{t-1}^{-}\left(\theta_{C B}\right) \cdot \tilde{\delta}_{t}\right] \\
= & \mathbb{E}\left[z_{t-1}^{\prime} e_{t}^{b}\left(\theta_{C B}\right)\right] \cdot \mathbb{E}\left[\tilde{\delta}_{t}\right] \cdot \mathbb{E}\left[c M_{t}^{-}\left(\theta_{C B}\right)\right]+ \\
& +\operatorname{cov}\left(z_{t-1}^{\prime} e_{t}^{b}\left(\theta_{C B}\right), \tilde{\delta}_{t}\right) \cdot E\left[c M_{t-1}^{-}\left(\theta_{C B}\right)\right]+\operatorname{cov}\left(z_{t-1}^{\prime} \tilde{\delta}_{t} \cdot e_{t}^{b}\left(\theta_{C B}\right), c M_{t-1}^{-}\left(\theta_{C B}\right)\right) .
\end{aligned}
$$

, where $z_{t}^{\prime}$ is the average NAVs of pseudo funds which life spans over period $t(\equiv I(t))$ :

$$
z_{t}^{\prime}=\sum_{i}^{i \in I(t)}\left(-C_{i 0}^{b} \prod_{\tau(i)=1}^{t} R_{\tau(i)}^{b}\left(1-\tilde{\delta}_{\tau(i)}\right)\right) /|I|,
$$

and $c M_{t}^{-}\left(\theta_{C B}\right)$ is the cumulative SDF innovation through period $t$ since the average sample fund inception:

$$
c M_{t}^{-}\left(\theta_{C B}\right)=\sum_{i}^{i \in I(t)}\left(\prod_{\tau=s(i)}^{t} M_{\tau}\left(\theta_{C B}\right)\right) /|I| .
$$

From expression A.2 it follows that, given a valid instrument $z_{t}^{\prime}$ (i.e., which does not condition on the information set when pricing errors are realized), the 'pseudo funds'-based identification scheme exhibits a loss of efficiency relatively to expression (1) because it features the covariance terms of the pricing error of the pseudo funds with their distribution intensity and the SDF history. The identification of $\theta$ via expression (1) is equivalent to that via 77 for $z_{t}=z_{t}^{\prime} \cdot m\left(\theta_{C B}\right)_{t}^{-} \cdot \tilde{\delta}_{t+1}$ which potentially fails the orthogonality condition, $\mathbb{E}\left[z_{t}, e\left(\theta_{C B}\right)_{t}\right]=0$, and exhibits additional variation that is theoretically uninformative of $\theta$. Therefore, $\theta_{C B}$ is not equal to $\theta_{B}$ due to either noise or bias, whereby the latter can be present even asymptotically for some $\tilde{\delta}_{t}$ or $m\left(\theta_{C B}\right)_{t}^{-}$that result in non-zero covariance with the pricing error. In other words, for a given $z_{t}^{\prime}$, one cannot improve upon the sample counterpart of expression (1) in estimating SDF parameters, so $\theta_{C B}$ is at most as good an estimate of true $\theta$ as $\theta_{B}$ but strictly worse at least for some choice of $M_{t}(\theta)$ and $\tilde{\delta}_{t}$.

PROPOSITION 3 (Benchmark choice conflict): Given a mapping function $\tilde{\delta}_{i t}$, the excess NPV test (9) performed at $\theta_{B}$ is less biased and more efficient than the NPV-test (4) or the excess NPV test (9) at $\theta_{C B}$.

Proof. PROOF. The intuition is that Korteweg and Nagel (2016) GPME is a weighted average excess NPV over the selected pseudo fund NPVs. To see this, consider an overidentified system 
whereby number of benchmark exceeds the dimension of SDF parameter vector $\theta$, and one of the pseudo funds invests in risk-free rate, $r f$ :

$$
\begin{gathered}
G P M E(\theta)=N P V(\theta)-\left(w_{r f} \cdot N P V(\theta)^{r f}+\sum_{b \neq r f} w_{b} \cdot N P V(\theta)^{b}\right) \\
\text {, where } \sum_{b \neq r f} w_{b}+w_{r f}=1
\end{gathered}
$$

and parameters $\theta$ are chosen so that the squared NPVs of pseudo funds are jointly minimized, while each being affected by the compounding error as discussed in PROPOSITION 1. This implies that the bias correction through GPME puts non-zero weight $w_{r f}$ on $N P V(\theta)^{r f}$. The latter reflects pricing error series $e(\theta)_{t}^{r f}$ which are the least correlated with those of the actual PE funds, $e(\theta)_{t}$, and, thus, are more likely to exhibit a different compounding error than that in PE funds' NPV estimates (provided that SDF innovations, returns of risky assets and PE funds, indeed have a significant common factor). Meanwhile, the fact that $\theta_{C B}$ is further away from true parameter values than $\theta_{B}$ (see PROPOSITION 1) adds additional noise to inference about excess NPV.

\section{Appendix A.2. Simulations}

The estimations utilize either 2 , or 4 , or 8 benchmarks, one of which is risk free rate $\left(r_{f, t}=\right.$ $(1-\rho) r_{f}+\rho f_{t-1}, r_{f}=0.02$ p.a. $)$, and the other ones are functions of contemporaneous factor realization: $r_{b t}=f_{t}+u_{b t}$, where $u_{b t} \sim \mathcal{N}\left(0, \sigma^{2}\right)$ and

$$
\begin{aligned}
f_{t} & =(1-\rho)\left(r_{f}+\frac{\gamma \sigma^{2}}{1-\rho}-\frac{\sigma^{2}}{2(1-\rho)}\right)+\rho f_{t-1}+\sigma \varepsilon_{t} \\
& =r_{f, t}+\gamma \sigma^{2}-\frac{\sigma^{2}}{2}+\sigma \varepsilon_{t}, \text { and } \\
\varepsilon_{t} & \sim \mathcal{N}\left(0,0.15^{2} \text { p.a. }\right)
\end{aligned}
$$

Assuming that log-SDF, $m_{t}=a+b f_{t}$, perfectly prices $f_{t}$ and $r_{f, t}$, such that $\mathbb{E}_{t-1}\left[\exp \left(r_{f, t}\right) \exp \left(m_{t}\right)\right]=$ 1 and $\mathbb{E}_{t-1}\left[\exp \left(f_{t}\right) \exp \left(m_{t}\right)\right]=1$, one can solve for SDF parameters $a$ and $b$ (collectively refereed to as $\theta)$ :

$$
\begin{aligned}
b & =\gamma \\
a & =(\gamma-1) r_{f, t}+\frac{\gamma \sigma^{2}}{2}(\gamma-1) \\
\mathbb{E}[a] & =(\gamma-1)\left(r_{f}+\frac{\rho \gamma \sigma^{2}}{1-\rho}-\frac{\rho \sigma^{2}}{2(1-\rho)}\right)+\frac{\gamma \sigma^{2}}{2}(\gamma-1)
\end{aligned}
$$

from where it follows that the DGP simplifies to that considered in Korteweg and Nagel (2016) when $\rho=0$. However, unlike in their simulations' setup, we not do not use $f_{t}$ directly as one of the "investible" benchmarks to construct "pseudo-fund" cash flows (following Equation 5 of the main text).

We assume that the first non-risk free benchmark has $\sigma$ of 0.1 per year which can be interpreted as the idiosyncratic return relatively to the factor. If two [six] more benchmarks are used, their $\sigma$ are equal to, respectively, 0.15 and $0.20(0.15,0.20,0.20,0.25,0.25$, and 0.25$)$. The PE funds return process is defined similarly to that the benchmark's with $\sigma=0.25$ per year and is 0.1 - 


\section{Table AI}

\section{Simulation Evidence - cash flow mapping and factor types}

This tables reports .

\begin{tabular}{|c|c|c|c|c|c|c|c|c|c|c|c|c|}
\hline \multirow{2}{*}{$\begin{array}{l}\text { Identifying } \\
\text { moments }\end{array}$} & \multicolumn{4}{|c|}{$\gamma=2.0$} & \multicolumn{4}{|c|}{$\Delta . \mathrm{NPV}=0$} & \multicolumn{4}{|c|}{$\mathrm{NPV}=0$} \\
\hline & mean & $\mathrm{p} 5 \overline{0}$ & RMSE & MAE & mean & $\overline{\mathrm{p} 50}$ & RMSE & MAE & mean & $\mathrm{p} 50$ & RMSE & MAE \\
\hline & (1) & (2) & (3) & (4) & (5) & (6) & (7) & (8) & (9) & (10) & (11) & (12) \\
\hline & \multicolumn{12}{|c|}{ Panel A: Just-identified $\theta$, treadeable factor } \\
\hline (i) Exact $\delta_{i t}$ & & & & & & & & & & & & \\
\hline$g^{N}$ & 3.372 & 2.778 & 3.388 & 2.327 & 0.002 & -0.006 & 0.091 & 0.072 & 0.002 & -0.006 & 0.091 & 0.072 \\
\hline$g^{R}$ & 2.049 & 2.017 & 1.082 & 0.858 & 0.000 & -0.006 & 0.092 & 0.070 & -0.027 & -0.035 & 0.184 & 0.132 \\
\hline \multicolumn{13}{|c|}{ (ii)Approx. $\delta_{i t}$} \\
\hline$g^{N}$ & 2.572 & 2.414 & 1.963 & 1.478 & 0.034 & 0.026 & 0.113 & 0.087 & 0.034 & 0.026 & 0.113 & 0.087 \\
\hline$g^{R}$ & 2.043 & 1.999 & 1.085 & 0.862 & 0.006 & -0.002 & 0.099 & 0.075 & -0.025 & -0.036 & 0.190 & 0.134 \\
\hline \multicolumn{13}{|c|}{ Panel B: Just-identified $\theta$, nontradeable factor } \\
\hline (i) Exact $\delta_{i t}$ & & & & & & & & & & & & \\
\hline$g^{N}$ & 3.536 & 2.699 & 4.441 & 2.908 & 0.016 & 0.005 & 0.150 & 0.116 & 0.016 & 0.005 & 0.150 & 0.116 \\
\hline$g^{R}$ & 2.010 & 1.963 & 1.297 & 1.025 & 0.013 & 0.006 & 0.158 & 0.116 & -0.014 & -0.022 & 0.232 & 0.163 \\
\hline \multicolumn{13}{|c|}{ (ii)Approx. $\delta_{i t}$} \\
\hline$g^{N}$ & 2.702 & 2.436 & 2.687 & 1.891 & 0.038 & 0.034 & 0.126 & 0.098 & 0.038 & 0.034 & 0.126 & 0.098 \\
\hline$g^{R}$ & 2.026 & 1.996 & 1.286 & 1.012 & 0.014 & 0.012 & 0.119 & 0.091 & -0.023 & -0.015 & 0.202 & 0.142 \\
\hline \multicolumn{13}{|c|}{ Panel C: Over-identified $\theta$, nontradeable factor } \\
\hline (i) Exact $\delta_{i t}$ & & & & & & & & & & & & \\
\hline$g^{N}$ & 3.169 & 2.555 & 34.252 & 3.430 & 0.009 & 0.004 & 0.138 & 0.108 & 0.002 & -0.009 & 0.113 & 0.088 \\
\hline$g^{R}$ & 2.024 & 2.013 & 1.151 & 0.912 & 0.004 & 0.004 & 0.148 & 0.112 & -0.022 & -0.032 & 0.191 & 0.140 \\
\hline \multicolumn{13}{|c|}{ (ii)Approx. $\delta_{i t}$} \\
\hline$g^{N}$ & 2.226 & 2.076 & 1.910 & 1.474 & 0.030 & 0.031 & 0.121 & 0.096 & 0.032 & 0.028 & 0.084 & 0.065 \\
\hline$g^{R}$ & 2.010 & 1.995 & 1.148 & 0.910 & 0.005 & 0.008 & 0.121 & 0.091 & -0.024 & -0.019 & 0.178 & 0.119 \\
\hline
\end{tabular}

correlated across funds. The number of simulated funds per sample, their inception years and life-spans correspond to those of actual funds in the venture sample (see Table I of the main text). The simulated funds make on average 20 distributions of (future values of) the equal fraction of capital invested in quarter 0 . The distributions are uniformly distributed over a maximum of 44 quarters.

We compute the excess NPV of PE funds (as per equation ?? in the main text) relatively to the non-risk free benchmark with the smallest idiosyncratic return relatively to the factor, and, thus by construction, also exhibits smallest noise relatively to the PE funds returns. The intuition here is that one can ex-ante determine a publicly traded asset that is most related to the PE group of funds of interest (e.g., 'small growth' equities for venture, 'small value' for buyouts). At the same time, we seek to mimic the reality where other publicly traded assets are also observable and informative of the SDF process, even though being less related to the return generating process of PE funds. 


\section{Table AII}

\section{Simulation Evidence - sources of NPV bias}

This tables reports .

\begin{tabular}{|c|c|c|c|c|c|c|c|c|c|c|c|c|}
\hline \multirow{2}{*}{$\begin{array}{l}\text { Identifying } \\
\text { moments }\end{array}$} & \multicolumn{4}{|c|}{$\gamma=2.0$} & \multicolumn{4}{|c|}{$\Delta . \mathrm{NPV}=0$} & \multicolumn{4}{|c|}{$\mathrm{NPV}=0$} \\
\hline & mean & $\mathrm{p} 5 \overline{0}$ & RMSE & MAE & mean & $\overline{\mathrm{p} 50}$ & $\overline{\mathrm{RMSE}}$ & MAE & mean & $\mathrm{p} 5 \overline{0}$ & $\overline{\mathrm{RMSE}}$ & MAE \\
\hline & (1) & (2) & (3) & (4) & (5) & (6) & (7) & (8) & (9) & (10) & (11) & $(12)$ \\
\hline & \multicolumn{12}{|c|}{ Panel A: Reference specifications } \\
\hline \multicolumn{13}{|c|}{ (i) Two-quarter funds } \\
\hline$g^{N}$ & 2.125 & 1.924 & 6.138 & 3.407 & 0.000 & 0.000 & 0.015 & 0.012 & 0.000 & 0.000 & 0.014 & 0.011 \\
\hline$g^{R}$ & 2.028 & 2.020 & 1.482 & 1.174 & 0.001 & 0.001 & 0.015 & 0.012 & 0.001 & 0.001 & 0.029 & 0.021 \\
\hline \multicolumn{13}{|c|}{ (ii) 44-quarter funds } \\
\hline$g^{N}$ & 1.926 & 1.770 & 2.100 & 1.589 & 0.023 & 0.020 & 0.151 & 0.120 & 0.029 & 0.016 & 0.141 & 0.109 \\
\hline$g^{R}$ & 2.019 & 1.995 & 1.261 & 0.998 & 0.006 & 0.006 & 0.154 & 0.117 & -0.024 & -0.030 & 0.217 & 0.154 \\
\hline \multicolumn{13}{|c|}{ Panel B: Longer duration funds } \\
\hline (i) 44-quart & r funds & distrib & tions aft & r 30th & & & & & & & & \\
\hline$g^{N}$ & 3.575 & 2.075 & 24.281 & 4.250 & 0.068 & 0.010 & 0.520 & 0.254 & 0.076 & 0.011 & 0.520 & 0.250 \\
\hline$g^{R}$ & 2.024 & 2.008 & 1.255 & 1.001 & 0.003 & -0.013 & 0.258 & 0.187 & -0.040 & -0.062 & 0.378 & 0.263 \\
\hline \multicolumn{13}{|c|}{ (ii) 88-quarter funds } \\
\hline$g^{N}$ & 1.795 & 1.678 & 2.341 & 1.751 & 0.068 & 0.032 & 0.314 & 0.230 & 0.079 & 0.030 & 0.305 & 0.218 \\
\hline$g^{R}$ & 2.047 & 2.022 & 1.116 & 0.890 & 0.019 & 0.001 & 0.276 & 0.202 & -0.048 & -0.083 & 0.355 & 0.262 \\
\hline \multicolumn{13}{|c|}{ Panel C: Non-iid discount factors } \\
\hline (i) 44-quart & r funds & $0.2 \mathrm{AR}$ & & & & & & & & & & \\
\hline$g^{N}$ & 1.524 & 1.451 & 2.058 & 1.574 & 0.025 & 0.025 & 0.127 & 0.098 & 0.037 & 0.030 & 0.128 & 0.096 \\
\hline$g^{R}$ & 2.011 & 2.009 & 1.289 & 1.016 & 0.009 & 0.014 & 0.184 & 0.109 & 0.034 & 0.009 & 0.295 & 0.169 \\
\hline \multicolumn{13}{|c|}{ (ii) 44-quarter fund, $0.2 \mathrm{AR}(1)+\mathrm{MA}(2)$ measurement error } \\
\hline$g^{N}$ & 1.367 & 1.232 & 2.112 & 1.636 & 0.023 & 0.017 & 0.140 & 0.106 & 0.041 & 0.030 & 0.138 & 0.101 \\
\hline$g^{R}$ & 2.007 & 1.994 & 1.298 & 1.027 & 0.012 & 0.018 & 0.248 & 0.138 & 0.149 & 0.053 & 0.590 & 0.275 \\
\hline
\end{tabular}


Figure AI. Simulation Evidence - Parameters vs NPV inference, iid SDF, exact $\delta_{i t}$, Justid $\theta$

This figure plots estimates across 5,000 simulations correspondent to the summary reported in Panel B(ii) or Table AI Blue dotted lines are true values.

Panel A: SDF parameter estimates

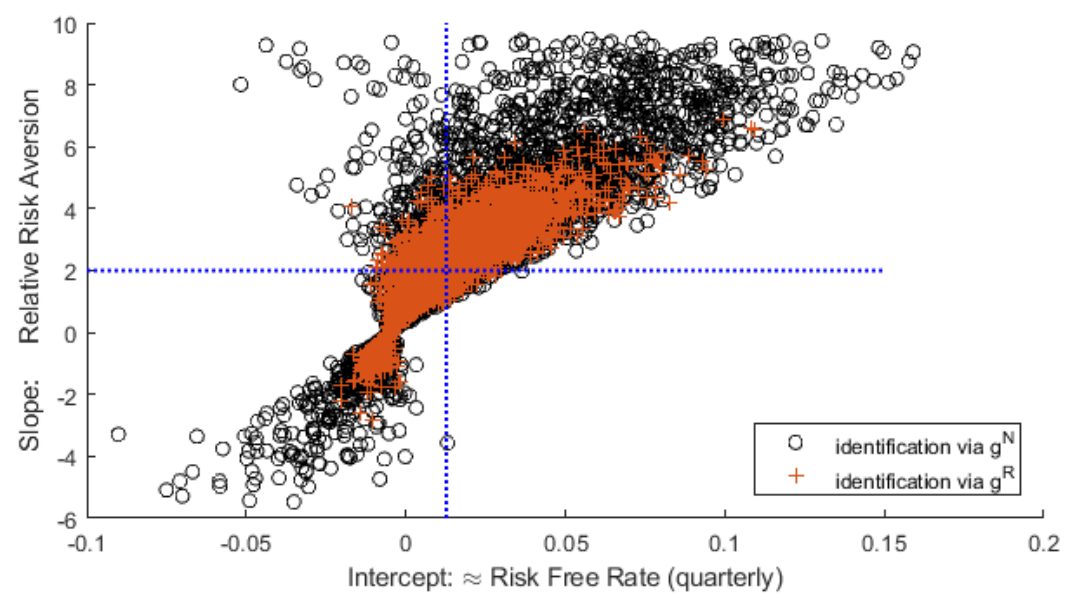

Panel B: SDF drift Versus NPV estimates

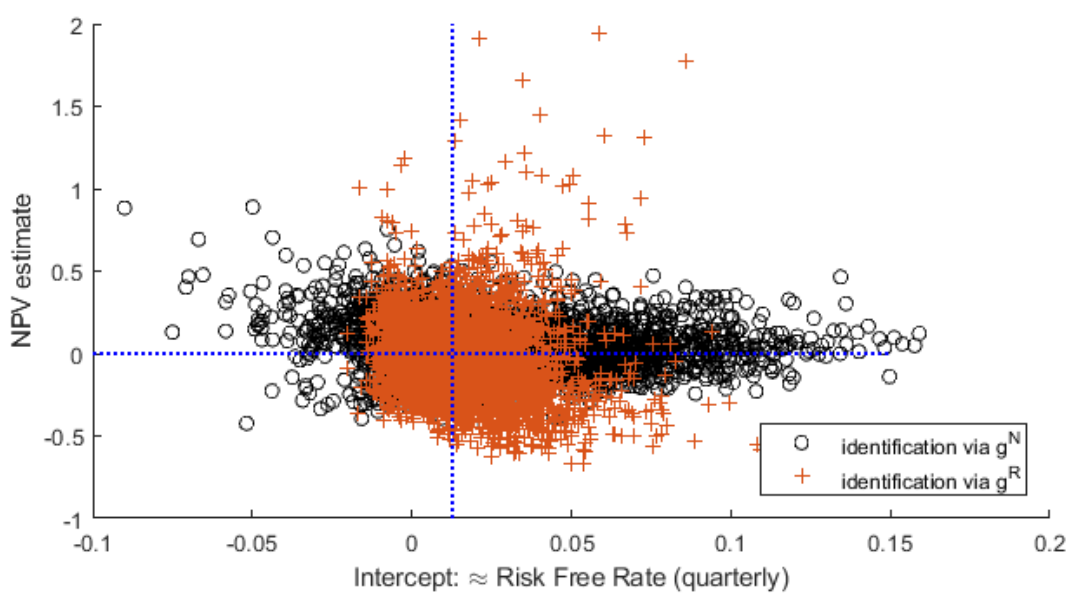

Panel C: SDF drift Versus Excess NPV estimates

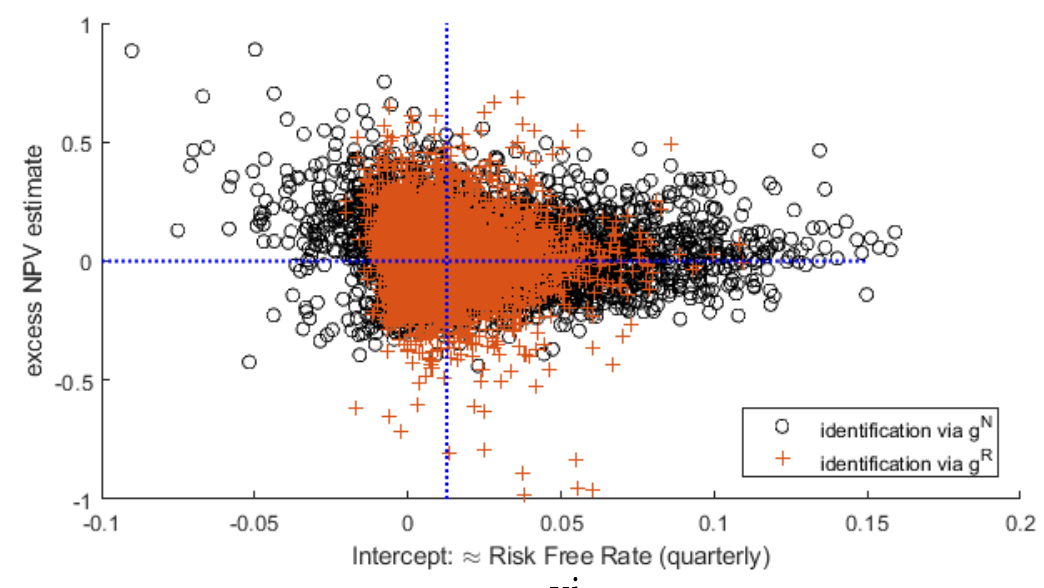

vi 
Figure AII. Simulation Evidence $-\theta$ vs NPV inference, AR(1) SDF with MA(2) ME

This figure plots estimates across 5,000 simulations correspondent to the summary reported in Panel C(ii) or Table AIT Blue dotted lines are true values.

Panel A: SDF parameter estimates

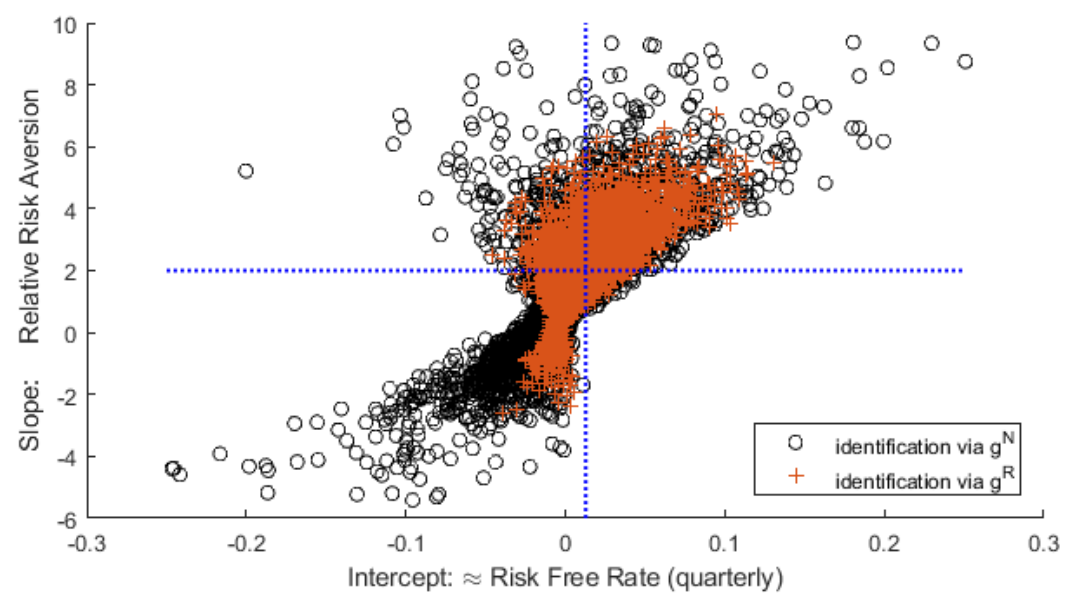

Panel B: SDF drift Versus NPV estimates

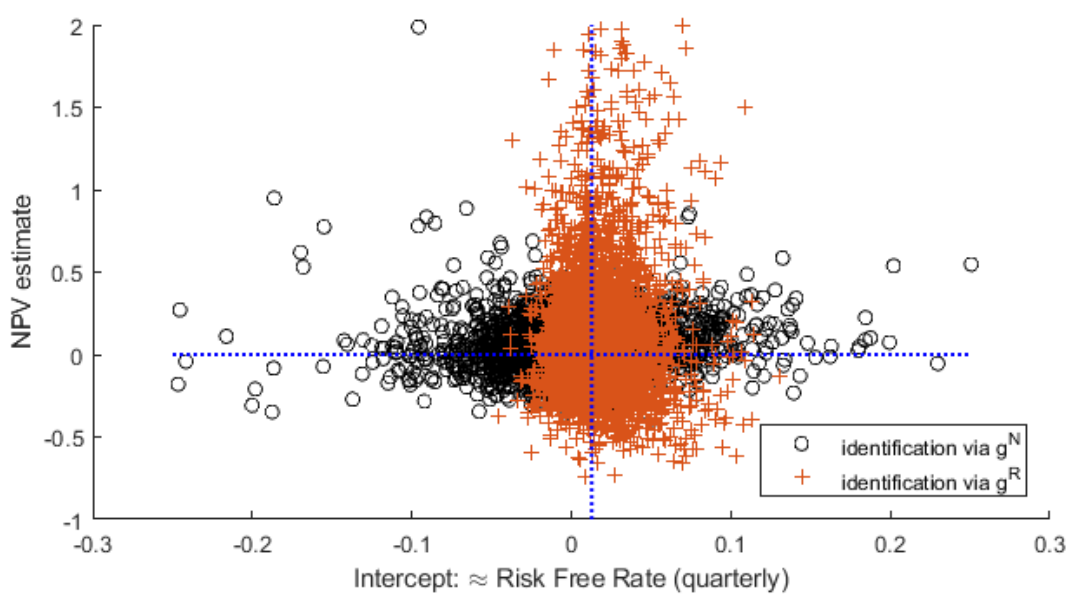

Panel C: SDF drift Versus Excess NPV estimates

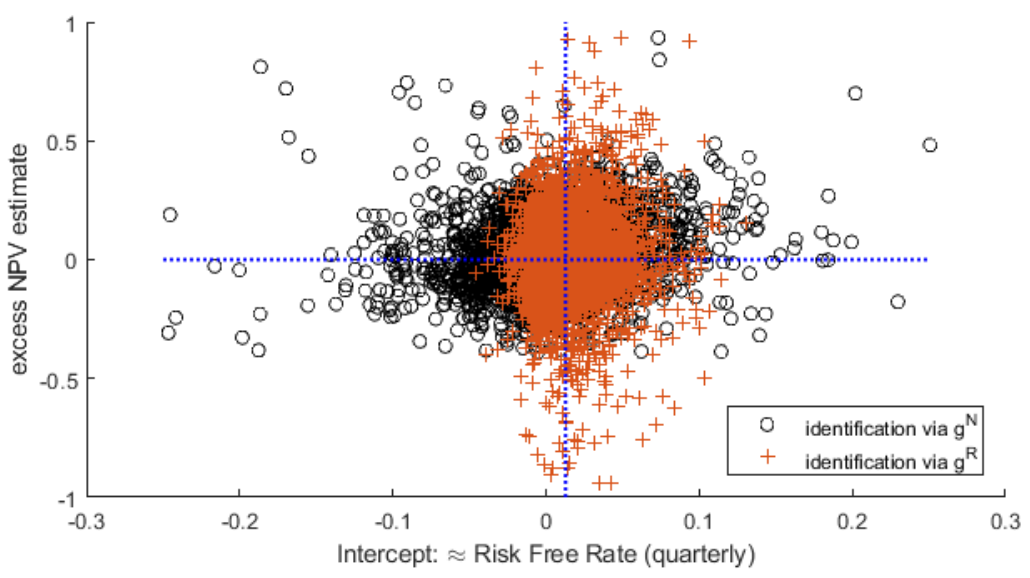

vii 


\section{Table AIII}

\section{Size across Estimation Types}

This table reports size statistics for the high-frequency return augmented estimations with bootstrapped standard errors versus the pseudo cash flow estimation with asymptotic standard errors. The bootstrapped standard errors are computed as described in Section ??. The asymptotic standard errors are adjusted for overlapping cash flows as in Korteweg and Nagel (2016). Simulations are conducted 1000 times with 1000 bootstrap draws each. The three estimation strategies, "EW TS", "Pseudo NAV", and "Pseudo CF", are as described in the main text. We consider the exactly identified ( 2 bmarks) case as well as overidentified (4 bmarks and 8 bmarks) cases. The factor is observed with i.i.d. measurement error as described in Section A.2 with the exception of the baseline "Pseudo CF, no ME" case. Panels present results with varying autocorrelation in the factor series, denoted by $\rho_{f} .10 \%-\alpha, 5 \%-\alpha$, and $1 \%-\alpha$ denote the actual size at a nominal size of $\alpha=10 \%, 5 \%$, and $1 \%$, respectively. AUC equals the area between the actual size curve and the curve where actual size equals nominal size. $A U C^{*}$ equals this area when nominal size is less than or equal to $10 \%$.

\begin{tabular}{|c|c|c|c|c|c|c|c|c|c|c|c|c|c|c|c|}
\hline & \multicolumn{5}{|c|}{2 bmarks } & \multicolumn{5}{|c|}{4 bmarks } & \multicolumn{5}{|c|}{8 bmarks } \\
\hline & $10 \%-\alpha$ & $5 \%-\alpha$ & $1 \%-\alpha$ & $\mathrm{AUC}$ & $\mathrm{AUC}^{*}$ & $10 \%-\alpha$ & $5 \%-\alpha$ & $1 \%-\alpha$ & $\mathrm{AUC}$ & $\mathrm{AUC}^{*}$ & $10 \%-\alpha$ & $5 \%-\alpha$ & $1 \%-\alpha$ & $\mathrm{AUC}$ & $\mathrm{AUC}^{*}$ \\
\hline \multicolumn{16}{|l|}{ Panel A: $\rho_{f}=0.0$} \\
\hline Pseudo CF, no $\mathrm{ME}$ & 0.161 & 0.111 & 0.056 & 0.021 & 0.005 & & & & & & & & & & \\
\hline Pseudo CF & 0.221 & 0.163 & 0.089 & 0.071 & 0.010 & 0.296 & 0.227 & 0.133 & 0.127 & 0.016 & 0.295 & 0.219 & 0.134 & 0.120 & 0.015 \\
\hline EW TS & 0.237 & 0.127 & 0.042 & 0.152 & 0.008 & 0.228 & 0.157 & 0.077 & 0.138 & 0.010 & 0.233 & 0.153 & 0.078 & 0.148 & 0.009 \\
\hline Pseudo NAV & 0.246 & 0.140 & 0.023 & 0.164 & 0.008 & 0.234 & 0.145 & 0.054 & 0.143 & 0.009 & 0.232 & 0.142 & 0.052 & 0.143 & 0.008 \\
\hline \multicolumn{16}{|l|}{ Panel B: $\rho_{f}=0.2$} \\
\hline Pseudo CF & 0.216 & 0.155 & 0.081 & 0.071 & 0.009 & 0.291 & 0.218 & 0.135 & 0.125 & 0.015 & 0.284 & 0.219 & 0.131 & 0.116 & 0.015 \\
\hline EW TS & 0.183 & 0.108 & 0.029 & 0.131 & 0.005 & 0.210 & 0.131 & 0.059 & 0.122 & 0.007 & 0.206 & 0.141 & 0.064 & 0.134 & 0.008 \\
\hline Pseudo NAV & 0.219 & 0.099 & 0.021 & 0.156 & 0.005 & 0.211 & 0.119 & 0.029 & 0.141 & 0.007 & 0.195 & 0.121 & 0.043 & 0.138 & 0.006 \\
\hline \multicolumn{16}{|l|}{ Panel C: $\rho_{f}=0.4$} \\
\hline Pseudo CF & 0.189 & 0.134 & 0.075 & 0.055 & 0.008 & 0.264 & 0.196 & 0.118 & 0.110 & 0.013 & 0.247 & 0.184 & 0.106 & 0.090 & 0.012 \\
\hline EW TS & 0.148 & 0.067 & 0.017 & 0.114 & 0.002 & 0.169 & 0.101 & 0.028 & 0.109 & 0.005 & 0.172 & 0.115 & 0.033 & 0.117 & 0.006 \\
\hline Pseudo NAV & 0.215 & 0.114 & 0.024 & 0.190 & 0.006 & 0.219 & 0.130 & 0.024 & 0.179 & 0.007 & 0.236 & 0.150 & 0.035 & 0.172 & 0.008 \\
\hline
\end{tabular}




\section{Figure AIII. Size and Power}

This figure plots size and power for the bootstrapped versus asymptotic standard errors. The bootstrapped standard errors are computed as described in Section ??. The asymptotic standard errors are adjusted for overlapping cash flows as in Korteweg and Nagel (2016). Simulations are conducted 1000 times with 1000 bootstrap draws each. The "no ME" case is the case considered in Korteweg and Nagel (2016) adjusted for the number of funds, the time series length, and the quarterly nature of our dataset. In the "ME" case, the econometrician observes the factor with i.i.d. measurement error with $\sigma$ of 0.1 per year. When investigating power, we follow Korteweg and Nagel (2016) and set the pricing error to $\$ 0.30$ (for a total investment of $\$ 1)$.

Panel A: Size Plot

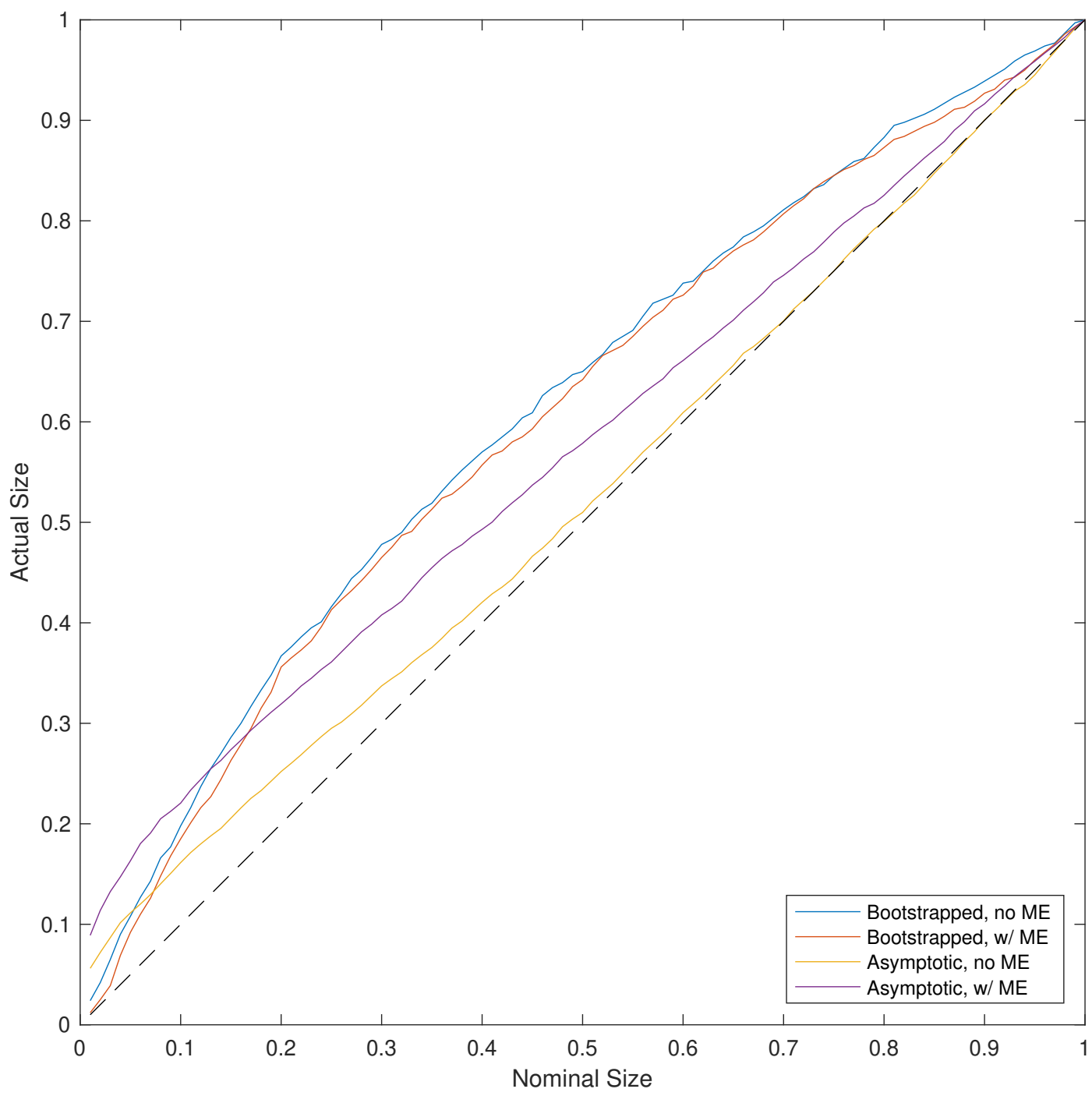


Figure AIII. Size and Power (cont.)

Panel B: Power Plot

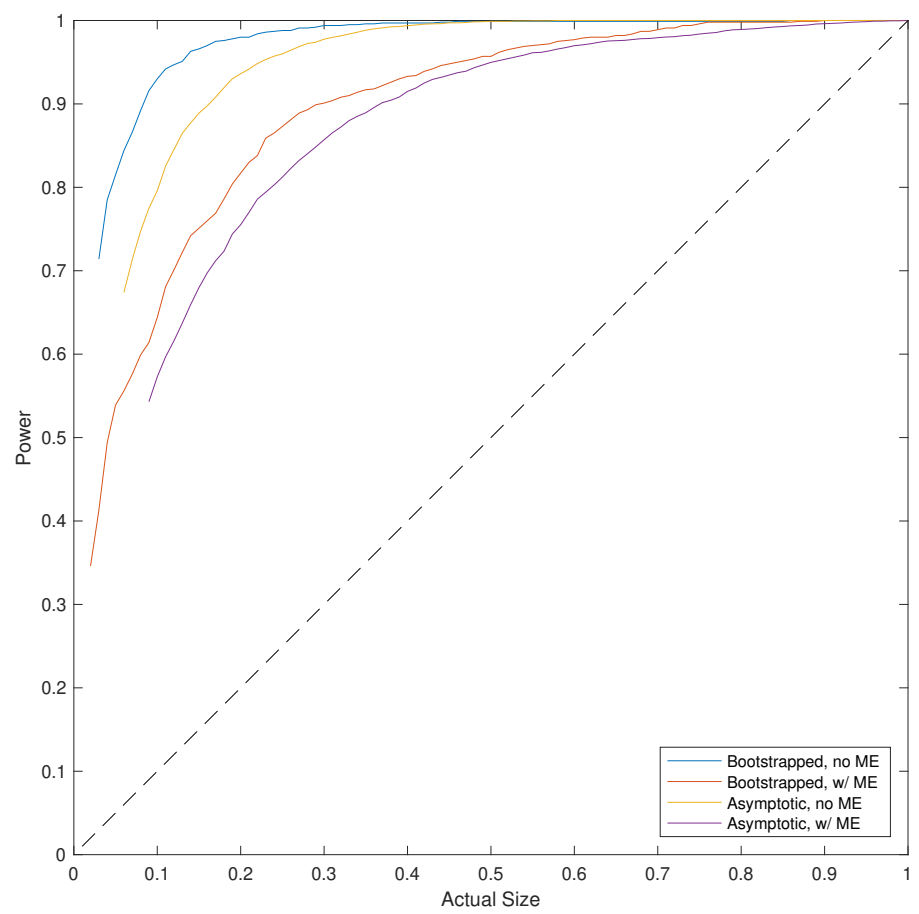

Panel C: Size-adjusted Power Plot

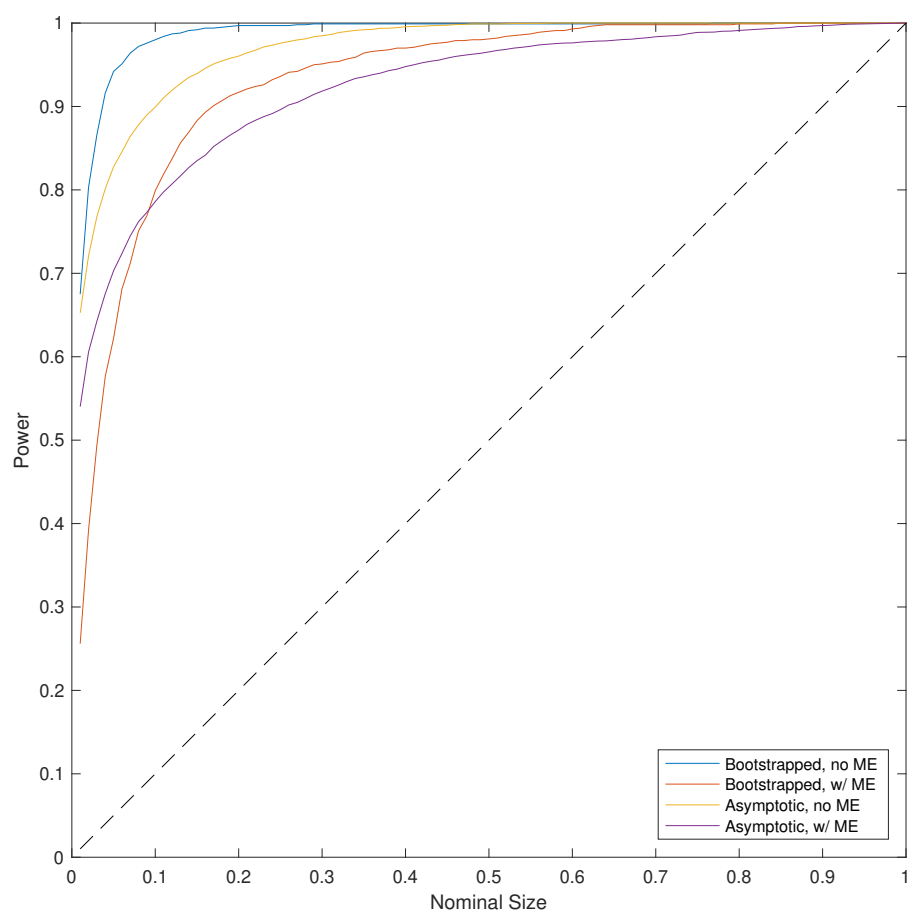




\section{Figure AIV. Size across Estimation Types}

This figure plots size for the equal-weighted time series estimation with bootstrapped standard errors versus the pseudo cash flow estimation with asymptotic standard errors. The bootstrapped standard errors are computed as described in Section ??. The asymptotic standard errors are adjusted for overlapping cash flows as in Korteweg and Nagel (2016). Simulations are conducted 1000 times with 1000 bootstrap draws each. The "EW TS" and "Pseudo CF" estimation are as described in the main text. We consider both an exactly identified ( 2 bmarks) case and an overidentified ( 4 bmarks) case. In all case, the factor is observed with i.i.d. measurement error as described in Section .A.2.

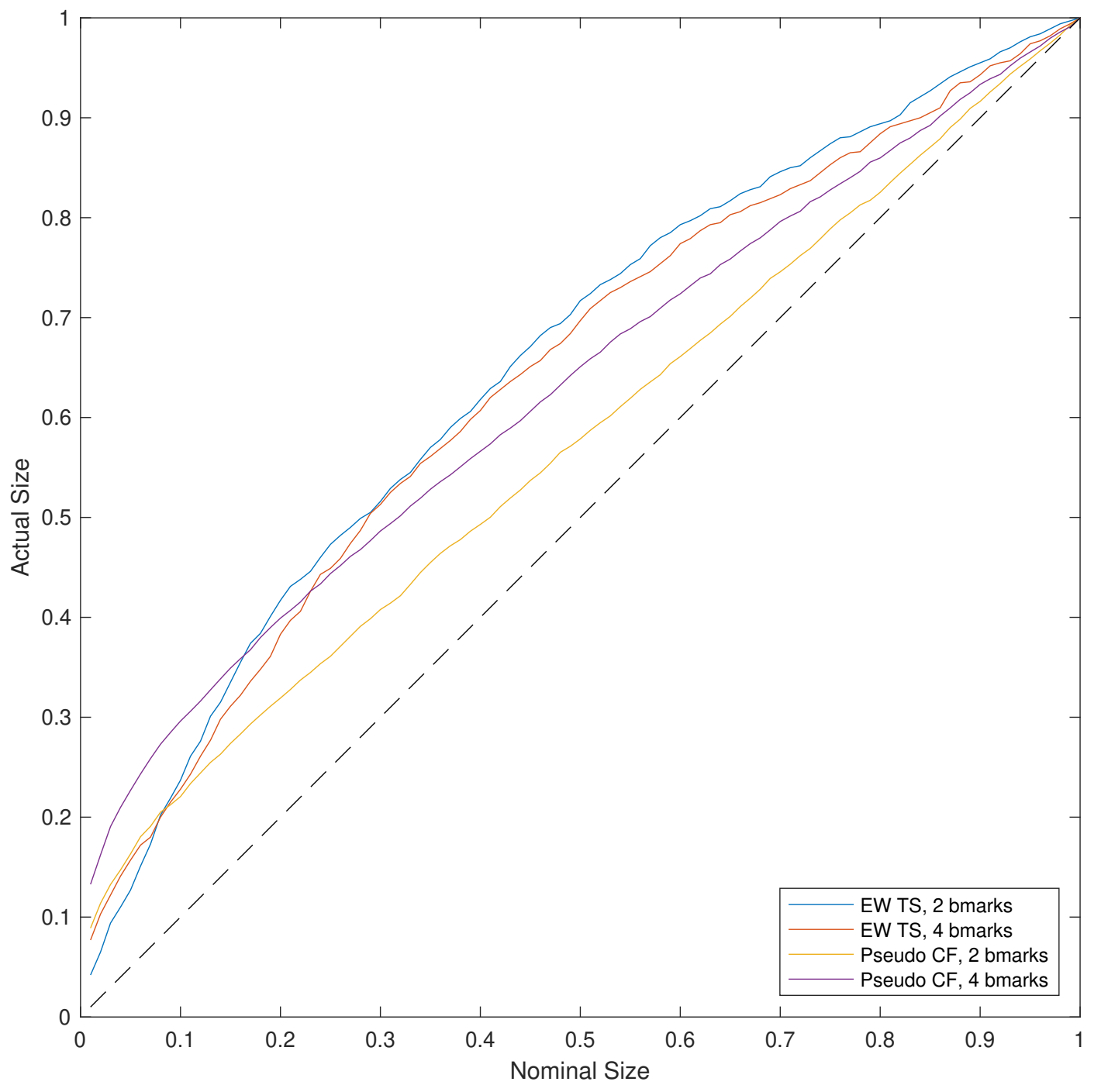




\section{Appendix B. Additional Data and Results}

\section{Table AIV \\ "Off-the-shelf" SDFs: pricing errors for public benchmarks}

This table reports the SDF pricing error at a quarterly frequency for discount factors $(M)$ implied by Kaplan and Schoar (2005) PME - Panel A, Korteweg and Nagel (2016) - Panel B1-B2, the Long-run Risk model of Bansal and Yaron (2004) - Panel C, and the External Habit model of Campbell and Cochrane (1999) - Panel D. The gross returns $R$ are for the 8 assets as stated in the column name, nominal in Panels A and $\mathrm{B}$, adjusted for inflation in Panels $\mathrm{C}$ and $\mathrm{D}$. The rows indicate the annual period of the estimations, independently across assets and periods. The pricing errors (in basis points) are defined as $\sum_{t=1}^{T}\left[M_{t} \cdot r_{t}\right] / T$ for SMB and HML factors (since these are long-short portfolio returns), and $\sum_{t=1}^{T}[M \cdot(1+r)] / T-1$ for all other assets: risk free rate - $r f r$; market portfolio - $m k t$; and six size and style portfolios with (smlo smme - smhi) and (bilo - bime - bihi) denoting growth - medium book-to-market - value for small and large capitalization stocks, respectively.

Panel A: Log-Utility CAPM

\begin{tabular}{ccccccccc} 
& rfr & mkt & smb & hml & smlo & bilo & bihi & smhi \\
\hline $1951-2015$ & -115 & 0 & 28 & 107 & -25 & -7 & 57 & 125 \\
$1980-2015$ & -121 & 0 & 15 & 97 & -68 & 7 & 32 & 106 \\
$1980-1991$ & -84 & 0 & -55 & 133 & -150 & 1 & 59 & 52 \\
$1992-2003$ & -185 & 0 & 36 & 183 & -80 & 10 & 87 & 214 \\
$2004-2015$ & -98 & 0 & 53 & -3 & 8 & 10 & -34 & 60
\end{tabular}

Panel B1: CAPM, $\theta=(0.022 / \mathrm{q}, 2.650)$

\begin{tabular}{ccccccccc} 
& rfr & mkt & smb & hml & smlo & bilo & bihi & smhi \\
\hline $1951-2015$ & -99 & -107 & -1 & 128 & -178 & -116 & -47 & 5 \\
$1980-2015$ & -115 & -123 & -14 & 119 & -239 & -115 & -85 & -26 \\
$1980-1991$ & -152 & -219 & -96 & 178 & -428 & -229 & -131 & -177 \\
$1992-2003$ & -316 & -237 & 9 & 235 & -368 & -230 & -116 & -6 \\
$2004-2015$ & 80 & 46 & 34 & -23 & 17 & 70 & -23 & 78
\end{tabular}

Panel B2: CAPM w/ small growth, $\theta=(0.023 / \mathrm{q}, 2.680,-0.154)$

\begin{tabular}{ccccccccc} 
& rfr & mkt & smb & hml & smlo & bilo & bihi & smhi \\
\hline $1951-2015$ & -88 & -86 & 1 & 125 & -154 & -94 & -27 & 26 \\
$1980-2015$ & -101 & -99 & -12 & 116 & -211 & -91 & -62 & -2 \\
$1980-1991$ & -138 & -191 & -93 & 173 & -396 & -200 & -106 & -149 \\
$1992-2003$ & -291 & -204 & 10 & 230 & -331 & -196 & -85 & 26 \\
$2004-2015$ & 85 & 60 & 35 & -23 & 34 & 83 & -7 & 93
\end{tabular}

Panel C: Long-run Risk

\begin{tabular}{ccccccccc} 
& rfr & mkt & smb & hml & smlo & bilo & bihi & smhi \\
\hline $1951-2015$ & -219 & 4 & 84 & 26 & 71 & 16 & 14 & 120 \\
$1980-2015$ & -64 & 111 & 97 & -10 & 171 & 142 & 74 & 214 \\
$1980-1991$ & -564 & -310 & 102 & -63 & -199 & -270 & -367 & -260 \\
$1992-2003$ & -1451 & -1173 & 126 & 93 & -1103 & -1151 & -1141 & -939 \\
$2004-2015$ & 1471 & 1497 & 70 & -52 & 1510 & 1531 & 1421 & 1538
\end{tabular}

Panel D: External Habit

\begin{tabular}{ccccccccc} 
& rfr & mkt & smb & hml & smlo & bilo & bihi & smhi \\
\hline $1951-2015$ & -163 & -4 & 33 & 106 & -20 & -14 & 54 & 122 \\
$1980-2015$ & -208 & -35 & 13 & 95 & -99 & -28 & -1 & 64 \\
$1980-1991$ & 60 & 204 & -57 & 153 & 41 & 199 & 274 & 264 \\
$1992-2003$ & -326 & -90 & 27 & 156 & -162 & -74 & -18 & 94 \\
$2004-2015$ & -325 & -180 & 58 & -3 & -159 & -173 & -208 & -120
\end{tabular}


Figure AV. Venture performance by vintage year and model calibration

This figure compares vintage-level performance between all and nearly resolved funds for different Long-run Risk SDF parameter values. $\gamma=10.5 \mid \rho=0.95$ refers to the baseline calibration and estimates from Table II], while $\gamma=7 \mid \rho=0.9383$ besides imposing a lower coefficient of relative risk aversion, assumes lower persistence in the Long-run risk factor, following the calibration in Ghosh, Julliard, and Taylor (2016). Panel A (B) plots $\Delta$ NPVs as the differences between the venture funds' NPV and that of the hypothetical funds invested in CRSP value-weighted index (Fama-French small value portfolio).

Panel A: $\triangle \mathrm{NPV}$ versus CRSP market index

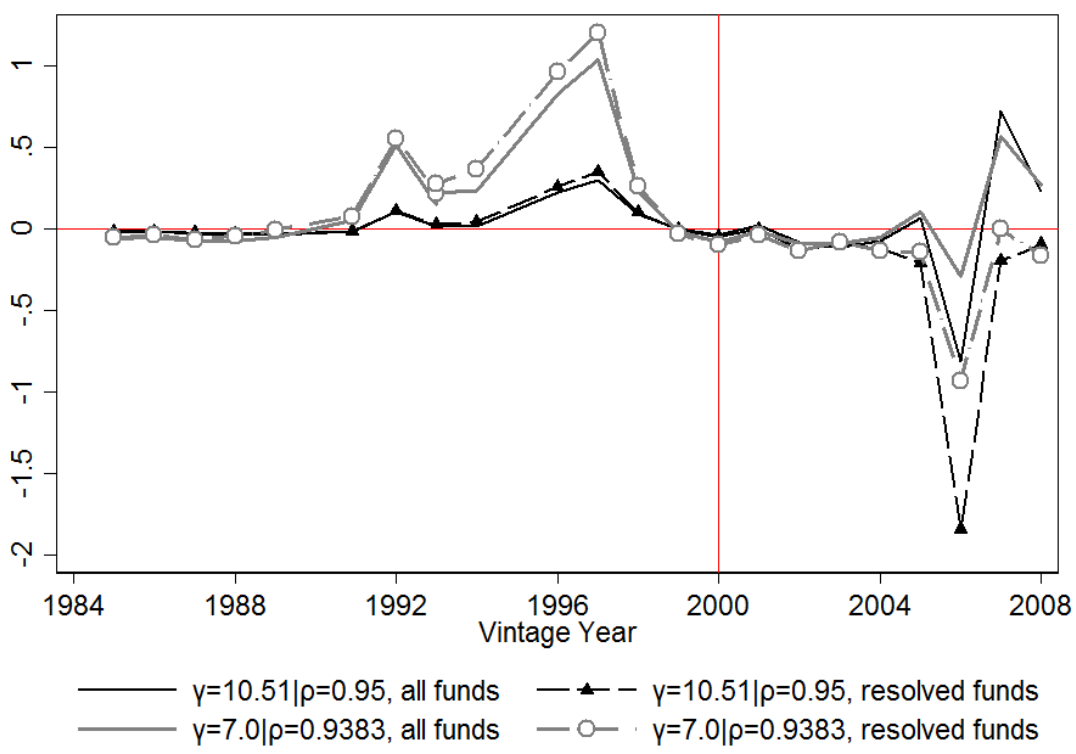

Panel B: $\triangle$ NPV versus Small Growth

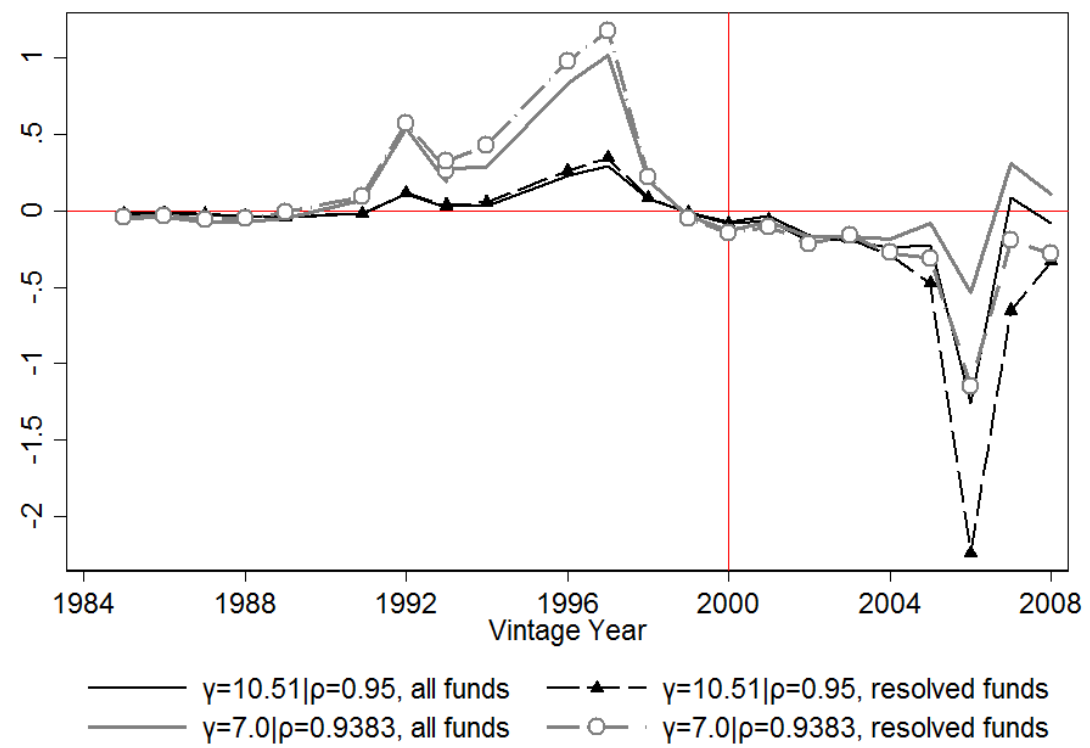


Figure AVI. Model calibration effects: buyout performance by vintage year

This figure compares vintage-level performance between all and nearly resolved funds for different Long-run Risk SDF parameter values. $\gamma=10.5 \mid \rho=0.95$ refers to the baseline calibration and estimates from Table $\mathrm{II}$, while $\gamma=7 \mid \rho=0.9383$, besides imposing a lower coefficient of relative risk aversion, assumes lower persistence in the Long-run risk factor, following the calibration in Ghosh, Julliard, and Taylor (2016). Panel A (B) plots $\triangle$ NPVs as the differences between the buyout funds' NPV and that of the hypothetical funds invested in CRSP value-weighted index (Fama-French small value portfolio).

Panel A: $\triangle \mathrm{NPV}$ versus CRSP market index

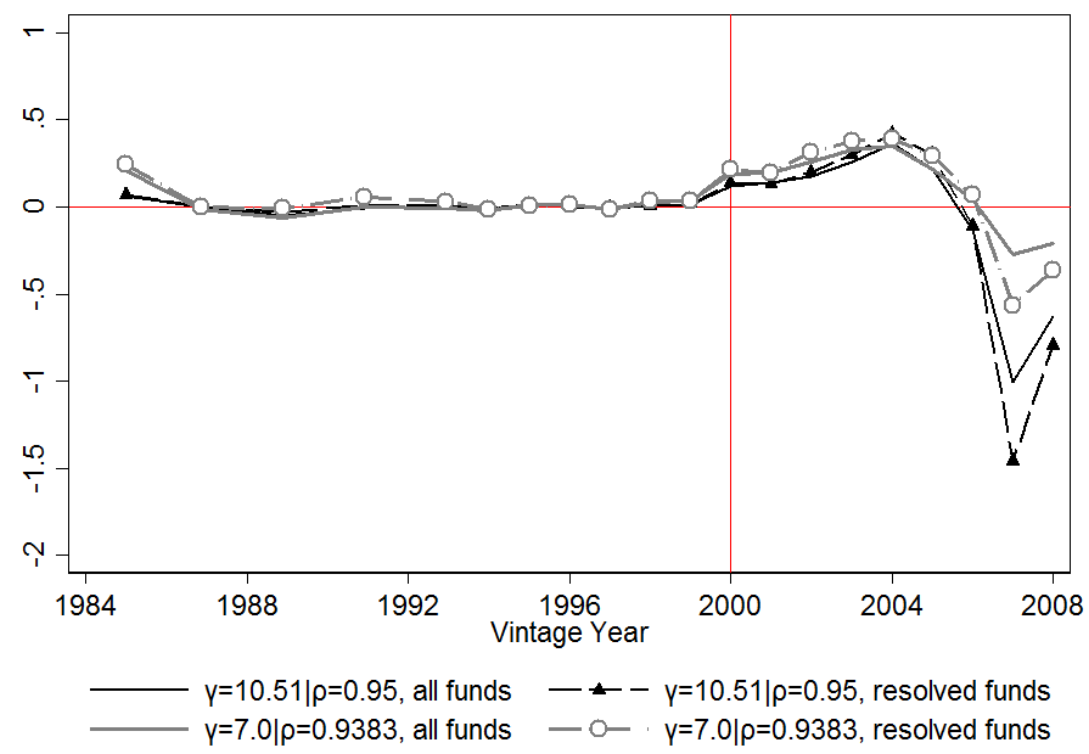

Panel B: $\triangle \mathrm{NPV}$ versus Small Value

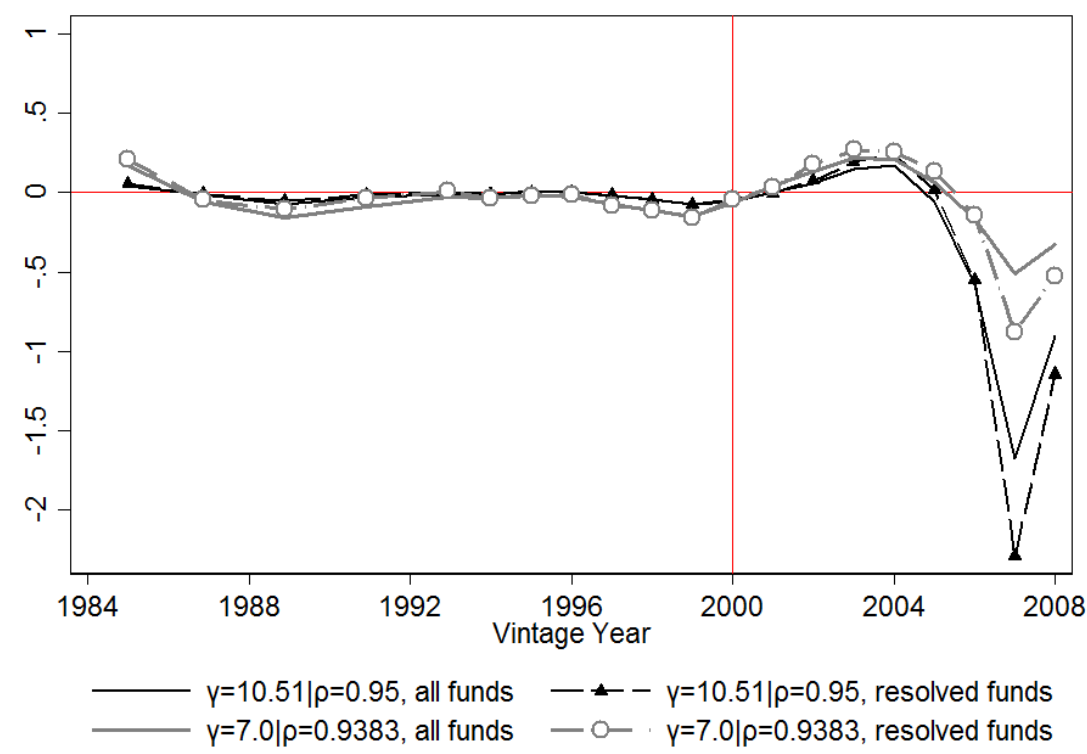

